Canadian

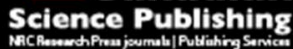

Canadian Geotechnical Journal Revue canadienne de géotechnique

\title{
Correlations for undrained shear strength of Finnish soft clays
}

\begin{tabular}{|r|l|}
\hline Journal: & Canadian Geotechnical Journal \\
\hline Manuscript ID & cgj-2016-0037.R2 \\
\hline Manuscript Type: & Article \\
\hline Date Submitted by the Author: & 10 -Jun-2016 \\
\hline Complete List of Authors: & $\begin{array}{l}\text { D'Ignazio, Marco; Tampere University of Technology, Civil Engineering } \\
\text { Phoon, Kok-Kwang; National University of Singapore, Department of Civil \& } \\
\text { Environmental Engineering } \\
\text { Tan, Siew Ann; National University of Singapore, Department of Civil and } \\
\text { Environmental Engineering } \\
\text { Lansivaara, T; Tampere University of Technology, Department of Civil } \\
\text { Engineering }\end{array}$ \\
\hline Keyword: & $\begin{array}{l}\text { soft clays, undrained shear strength, multivariate database, global } \\
\text { transformation models }\end{array}$ \\
\hline \multicolumn{2}{|c}{} \\
\hline
\end{tabular}


Title:

\section{Correlations for undrained shear strength of Finnish soft clays}

\section{Authors:}

Marco D’Ignazio ${ }^{1}$

Kok-Kwang Phoon ${ }^{2}$

Siew Ann $\operatorname{Tan}^{3}$

Tim Tapani Länsivaara ${ }^{4}$

${ }^{1}$ Tampere University of Technology, Department of Civil Engineering, Tampere, Finland. Address: Korkeakoulunkatu 5, 33720, Tampere, Finland (email: marco.dignazio@tut.fi)

${ }^{2}$ National University of Singapore, Department of Civil and environmental Engineering, Singapore. Address: No. 1 Engineering Drive 2, 117576, Singapore (email: kkphoon@nus.edu.sg)

${ }^{3}$ National University of Singapore, Department of Civil and environmental Engineering, Singapore. Address: No. 1 Engineering Drive 2, 117576, Singapore (email: ceetansa@nus.edu.sg)

${ }^{4}$ Tampere University of Technology, Department of Civil Engineering, Tampere, Finland. Address: Korkeakoulunkatu 5, 33720, Tampere, Finland (email: tim.lansivaara@tut.fi)

\section{Corresponding author:}

Marco D'Ignazio

Tampere University of Technology, Department of Civil Engineering Korkeakoulunkatu 5, 33720, Tampere, Finland

Mob: +358407058557 


\section{ABSTRACT}

The study focuses on the derivation of transformation models for undrained shear strength $\left(\mathrm{s}_{\mathrm{u}}\right)$ of Finnish soft sensitive clays. Specific correlation equations for $s_{u}$ of Finnish clays are presented in this work for the first time. Field and laboratory measurements from 24 test sites in Finland are exploited for this purpose and a multivariate database is constructed. The multivariate data consists of $s_{u}$ from field vane, preconsolidation stress, vertical effective stress, liquid limit, plastic limit, natural water content and sensitivity. The main objective is to evaluate the interdependence of $s_{u}$, consolidation stresses and index parameters and provide a consistent framework for practical use. The new correlations are established through regression analyses. The constructed framework is further validated by another independent multivariate database of clays from Sweden and Norway as well as by empirical equations for Swedish and Norwegian clays. Existing correlations are evaluated for Finnish and Scandinavian clays. Finally, bias and uncertainties of the new correlations are presented.

Key words: global transformation models; soft clays; multivariate database; undrained shear strength. 


\section{INTRODUCTION}

Soft sensitive clays are widespread in Scandinavia, especially on coastal areas. The high compressibility of these soils, along with their low undrained shear strength $\left(\mathrm{s}_{\mathrm{u}}\right)$ (even lower than $10 \mathrm{kPa}$ near the ground surface), makes geotechnical design often rather challenging. Therefore, $s_{u}$ needs to be carefully evaluated for a reliable assessment of the safety level.

Scandinavian soft clays are typically slightly over consolidated. The over-consolidation is normally the result of the aging process (Bjerrum 1973). For quick clays, the remolded undrained shear strength $\left(\mathrm{s}_{\mathrm{u}}{ }^{\mathrm{re}}\right)$ can be even less than $0.5 \mathrm{kPa}$ and 50-100 times lower than the initially “intact” $\mathrm{s}_{\mathrm{u}}$ (e.g. Rankka et al. 2004; Karlsrud and Hernandez-Martinez 2013).

$\mathrm{s}_{\mathrm{u}}$ can be evaluated from in-situ as well as laboratory tests. In Scandinavia, field vane (FV) test and CPTU are the most commonly used in-situ tests. Laboratory tests include undrained triaxial compression (TXC) and direct simple shear (DSS) tests. For some special cases where $\mathrm{S}_{\mathrm{u}}$ anisotropy needs to be assessed, triaxial extension (TXE) tests are also performed.

In situations where $s_{u}$ is not directly measured or measurements are considered to be unreliable, $s_{u}$ is commonly evaluated from transformation models based on clay properties, such as vertical preconsolidation pressure $\left(\sigma_{\mathrm{p}}^{\prime}\right)$ (e.g. Mesri 1975; Jamiolkowski et al. 1985) or plasticity (e.g. Hansbo 1957; Chandler 1988). Such transformation models are typically empirical or semi-empirical, obtained by data fitting through regression analyses (e.g. Kulhawy and Mayne 1990). However, such models must be carefully applied and their limitations be recognized, as soil properties, soil behavior and site geology may differ from the data source from where the transformation models are calibrated. As a direct consequence, predictions from these models may result biased with respect to the actual property $\left(\mathrm{s}_{\mathrm{u}}\right)$ values.

According to Phoon and Kulhawy (1999), uncertainty coming from transformation models can be customarily categorized as epistemic, meaning that it can be reduced by collecting a greater number of data or improving the available models. Therefore, "global" models, calibrated from data sets covering several sites and soil types, are preferred to "site-specific" 
models, which are restricted to a specific soil type or a specific site. Ching and Phoon (2012a; 2012b; 2014a; 2014b) presented global models based on soil data covering a large number of test sites from several countries. Ching and Phoon (2012b) pointed out how site-specific models are more accurate (or less uncertain) than global models, although bias can be significant when applied to another site. Instead, global models are less biased, although less precise (or more uncertain).

Global transformation models for $s_{u}$ of Swedish and Norwegian clays are available in the literature (Larsson and Mulabdic 1991; Larsson et al. 2007; Karlsrud and HernandezMartinez 2013). However, a comparable model calibrated using a sufficiently large soil database containing Finnish soft clay data is still missing. Therefore, the main objectives of the present paper are i) to test existing transformation models for $s_{u}$ for Finnish soft clays and ii) to derive, for the first time, transformation models for $s_{u}$ specific to Finnish soft clays using a large multivariate database consisting of FV data points from Finland. Another independent multivariate database of FV data points from Sweden and Norway is compiled and used for comparison and validation.

The value of multivariate soil databases has been demonstrated by Ching and Phoon (2012a, 2012b, 2013, 2014a, 2014b) and Ching et al. (2014). Müller (2013), Müller et al. (2014), Müller et al. (2016), Prästing et al. (2016) have demonstrated how uncertainties related to $s_{u}$ can be reduced when multivariate soil data is available, showing the benefits of using multivariate analyses (e.g. Ching et al. 2010) in geotechnical engineering applications. Multivariate soil databases are however limited in the literature. A summary is given in Table 1. Ching and Phoon (2014a) proposed labeling a multivariate database as: (soil type)/(number of parameters of interest)/(number of data points). Based on this nomenclature, the two databases presented in this paper are i) F-CLAY/7/216 for Finnish clays (where "F" stands for Finland) and ii) S-CLAY/7/168 for Scandinavian clays (where "S" stands for Scandinavia). The 7 parameters in these databases consisted of $s_{u}$ from FV test $\left(s_{u}{ }^{F V}\right)$, effective vertical 
stress $\left(\sigma_{v}^{\prime}\right)$, vertical preconsolidation pressure $\left(\sigma_{p}^{\prime}\right)$, natural water content $(w)$, liquid limit (LL), plastic limit (PL) and sensitivity $\left(\mathrm{S}_{\mathrm{t}}=\mathrm{S}_{\mathrm{u}} / \mathrm{S}_{\mathrm{u}}{ }^{\mathrm{re}}\right)$.

The paper is organized as follows. Firstly, after a brief overview on existing transformation models for $\mathrm{s}_{\mathrm{u}}$, the compilation of F-CLAY/7/216 and S-CLAY/7/168 databases is presented. Secondly, 10 dimensionless parameters are derived from the 7 basic parameters, resulting in two dimensionless databases. These dimensionless databases (labelled as F-CLAY/10/216 and S-CLAY/10/168) are compared to existing correlations in the literature. To develop more refined correlations for Finnish clays, outliers are removed from F-CLAY/10/216 according to systematic criteria based on soil nature, mechanical characteristics and statistical considerations. New transformation models for $s_{u}$ specific to Finnish clays are derived through regression analyses from the resulting F-CLAY/10/173 database. These new transformation models are compared with existing correlations for Scandinavian clays from the literature. Finally, the performance of the new models derived from F-CLAY/10/173 is evaluated by calculating the biases and uncertainties associated with S-CLAY/10/168.

\section{OVERVIEW ON EXISTING TRANSFORMATION MODELS FOR UNDRAINED}

\section{SHEAR STRENGTH}

The dependency of $s_{u}$ on $\sigma_{p}$ and plasticity has been object of research over the last decades, because of its practical usefulness. Skempton (1954) suggested a linear correlation between the normalized $s_{u}$ determined from FV test $\left(\mathrm{s}_{\mathrm{u}}{ }^{\mathrm{FV}} / \sigma_{\mathrm{v}}\right)$ and plasticity index (PI) for normally consolidated clays. Subsequently, Chandler (1988) indicated that the same correlation could be valid also for OC clays as shown in eq. (1), although attention must be paid when dealing with fissured, organic, sensitive, or other special clays.

$$
\frac{s_{u}{ }^{F V}}{\sigma_{p}^{\prime}} \approx 0.11+0.0037 \cdot P I
$$


Hansbo (1957) suggested, for Scandinavian clays, that $\mathrm{s}_{\mathrm{u}}^{\mathrm{FV}} / \sigma_{\mathrm{p}}{ }_{\mathrm{p}}$ is directly proportional to LL. Larsson (1980), collected strength data points from FV test in Scandinavian clays and proposed a transformation model similar to eq. (1), as described by eq. (2):

$$
\frac{s_{u}^{F V}}{\sigma_{p}^{\prime}}=0.08+0.0055 \cdot P I
$$

According to Bjerrum (1972), $\mathrm{s}_{\mathrm{u}}^{\mathrm{FV}}$ needs to be converted into mobilized $\mathrm{s}_{\mathrm{u}}\left[\mathrm{s}_{\mathrm{u}}(\mathrm{mob})=\mathrm{s}_{\mathrm{u}}^{\mathrm{FV}} \cdot \lambda\right]$.

The parameter $\lambda$ is a correction multiplier that accounts for rate effects as well as anisotropy, and it is thought to be dependent on the plasticity of the clay.

Mesri (1975, 1989) suggested a unique relationship for $s_{u}(m o b)$ of clays and silts, corresponding approximately to direct simple shear (DSS) condition [eq. (3)], regardless of the plasticity of the clay.

$$
\frac{s_{u}(m o b)}{\sigma_{p}^{\prime}}=0.22
$$

However, according to Larsson (1980), eq. (3) tends to overestimate $s_{\mathrm{u}}$ in very low-plastic clays, while it underestimates $s_{u}$ in high-plastic clays. For low OC clays with low to moderate PI, Jamiolkowski et al. (1985) recommended [eq. (4)]:

$$
\frac{s_{u}(m o b)}{\sigma_{v}^{\prime}}=(0.23 \pm 0.04) \cdot O C R^{0.8}
$$

The transformation model suggested by Jamiolkowski et al. (1985) is based on the SHANSEP framework [eq. (5)] proposed by Ladd and Foott (1974). The SHANSEP framework is normally adopted to describe the variation of $s_{u}$ with the over-consolidation ratio, OCR (OCR $=\sigma_{\mathrm{p}}^{\prime} / \sigma_{\mathrm{v}}{ }^{\prime}$.

$$
\frac{s_{u}}{\sigma_{v}^{\prime}}=S \cdot O C R^{m}
$$

where $S$ and $m$ are constants dependent on material and test type. $S$ represents the normalized $\mathrm{s}_{\mathrm{u}}$ for normally consolidated state. The exponent $m$ varies between 0.75 and 0.95 (Jamiolkowski et al. 1985). A value of $m$ equal to 0.8 is often assumed in practice. Note that $m=1$ would reduce eq. (5) to eq. (3) with $S=0.22$. 
Larsson et al. (2007) studied the SHANSEP relation between $\mathrm{s}_{\mathrm{u}} / \sigma_{\mathrm{v}}$ and OCR for inorganic Scandinavian clays. Data from undrained triaxial compression (TXC), direct simple shear (DSS) and triaxial extension (TXE) tests were collected to assess $\mathrm{s}_{\mathrm{u}}$ anisotropy. By assuming an average $m$ value equal to 0.8 , it was shown how the normally consolidated undrained shear strength ratio $(S)$ is material dependent for DSS [eq. (6)] and TXE, as it increases with increasing liquid limit; while it seems fairly constant for TXC.

Karlsrud and Hernandez-Martinez (2013) studied the $\mathrm{s}_{\mathrm{u}} / \sigma_{\mathrm{v}}{ }_{\mathrm{v}}-$ OCR relation for Norwegian soft clays from laboratory tests on high-quality block samples. Outcomes from this study indicate that $\mathrm{s}_{\mathrm{u}}$ strongly correlates with natural water content $(w)$ combined with OCR [eq. (7) for DSS strength]. More specifically, peak strengths from TXC, DSS and TXE test were observed to increase with increasing $w$. Possible reasons to explain this might be e.g. i) the open structure typical of Norwegian clays (Rosenqvist 1953, 1966), which allows the soil to retain a quantity of pore water, typically above the liquid limit of the soil or ii) the increasing rate effects with plasticity.

$$
\begin{gathered}
\frac{s_{u}{ }^{D S S}}{\sigma^{\prime}{ }_{v}}=(0.125+0.205 \cdot L L / 1.17) \cdot O C R^{0.8} \\
\frac{s_{u}{ }^{D S S}}{\sigma^{\prime}{ }_{v}}=(0.14+0.18 \cdot w) \cdot O C R^{(0.35+0.77 \cdot w)}
\end{gathered}
$$

Ching and Phoon (2012a) proposed a global transformation model for $\mathrm{s}_{\mathrm{u}}(\mathrm{mob})$ from FV and unconfined compression (UC) tests as a function of OCR and $\mathrm{S}_{\mathrm{t}}$. The model was built based on a large database of structured clays (CLAY/5/345) consisting of 345 clay data points from several locations all over the world [eq. (8)].

$$
\frac{s_{u}(\mathrm{mob})}{\sigma_{v}^{\prime}}=0.229 \cdot O C R^{0.823} \cdot S_{t}^{0.121}
$$


ANALYSIS OF MULTIVARIATE CLAY DATABASES

\section{F-CLAY/7/216 and S-CLAY/7/168}

The first clay database compiled in this study consists of $216 \mathrm{FV}$ data points from 24 different test sites from Finland. Each data "point" contains multivariate information, i.e. information from different tests conducted in close proximity is available. The collected data points contain information on 7 basic parameters measured at comparable depths and sampling locations: $\mathrm{s}_{\mathrm{u}}^{\mathrm{FV}}, \sigma^{\prime}{ }_{\mathrm{v}}, \sigma_{\mathrm{p}}{ }_{\mathrm{p}}, w, \mathrm{LL}, \mathrm{PL}$ and $\mathrm{S}_{\mathrm{t}}$.

Standard FV test is normally carried out at high speed of rotation, inducing strain rates in the soil that are much higher than in conventional laboratory tests (e.g. triaxial tests, direct simple shear tests). The main consequence is that $\mathrm{s}_{\mathrm{u}}{ }^{\mathrm{FV}}$ is overestimated and, therefore, a correction is needed to convert $\mathrm{s}_{\mathrm{u}}{ }^{\mathrm{FV}}$ into $\mathrm{s}_{\mathrm{u}}(\mathrm{mob})$ (e.g. Bjerrum 1972). The parameter $\mathrm{s}_{\mathrm{u}}(\mathrm{mob})$ is defined as the undrained shear strength that is mobilized in a full-scale failure of an embankment or slope in the field (Bjerrum 1972; Mesri and Huvaj 2007). $\mathrm{s}_{\mathrm{u}}$ (mob) cannot be uniquely defined, as it is a function of failure mode, stress state and strain rate, among others. In this study, the $\mathrm{s}_{\mathrm{u}}^{\mathrm{FV}}$ values are converted into $\mathrm{s}_{\mathrm{u}}(\mathrm{mob})$ values through a correction factor $\lambda$, as reported in the Finnish Guidelines for stability analysis (Ratahallintokeskus 2005). In this way, rate effects and anisotropy are implicitly accounted for. The strength correction factor used is expressed by eq. (9):

$$
\lambda=\frac{1.5}{1+L L}
$$

According to Jamiolkowski et al. (1985) and Chandler (1988), $\mathrm{s}_{\mathrm{u}}$ obtained from FV is somewhat comparable to $s_{u}$ from DSS test results. It is common practice in Sweden to consider $\mathrm{s}_{\mathrm{u}}$ from DSS tests as a reference value (e.g. Westerberg et al. 2015). DSS tests may be however affected by some disturbance effects resulting from sampling as well as specimen preparation. In Finland, DSS tests are not in use and FV test is normally assumed to provide reliable $s_{u}$ values, despite some issues related to test equipment. As suggested by Mansikkamäki (2015), when casing is used to protect the vane during penetration into the 
ground, rod friction is minimized and, therefore, measured torque values are assumed to be less biased than when slip-coupling is used. FV data points from Finland collected in this study are mostly obtained using FV test equipment which includes casing. As a consequence, the results presented later will be likely representative of the best possible estimate of $s_{u}{ }^{F V}$ in Finnish current practice.

The database is compiled from data given in Gardemeister (1973), Lehtonen et al. (2015), together with data from recent soil investigations performed by Tampere University of Technology, Finland (Selänpää 2015). Gardemeister (1973) collected FV and oedometer tests performed at different construction sites in Finland. For the purpose of the present study, sites characterized by organic (organic content higher than $2 \%$ ) and/or silty soils have been discarded, because the focus of this study is on the strength of inorganic clays. Some low organic clays may be however present in the database.

This database is labeled as F-CLAY/7/216 following the nomenclature proposed by Ching and Phoon (2014a). F-CLAY/7/216 is a new database that would contribute to the list of multivariate soil databases shown in Table 1. The basic statistics of the 7 clay parameters in F-CLAY/7/216 are listed in Table 2. The parameters $\sigma^{\prime}{ }_{\mathrm{v}}$ and $\sigma_{\mathrm{p}}$ are normalized to the atmospheric pressure, $\mathrm{P}_{\mathrm{a}}\left(\mathrm{P}_{\mathrm{a}}=101.3 \mathrm{kPa}\right)$. The numbers of available data points $(\mathrm{n})$ are reported in the second column. The statistics shown are the mean value, coefficient of variation (COV), minimum value (Min) and maximum value (Max). Clay properties cover a wide range of $S_{t}$ values varying from 2 (insensitive clays) to 64 (quick clays), and a wide range of PI values (2 95) and $w$ values (25 150).

A second independent database consisting of $168 \mathrm{FV}$ data points from Sweden and Norway is extracted from the existing global CLAY/10/7490 database (Ching and Phoon 2014a). This database is labelled as S-CLAY/7/168 and it contains multivariate information on the same soil parameters as in F-CLAY/7/216. The purpose of S-CLAY/7/168 is to act as an independent set of data to be used for comparison with F-CLAY/7/216 in subsequent analyses. The geographical coverage of S-CLAY/7/168 is restricted to Sweden (12 sites) and Norway ( 7 sites). Full information on all 7 parameters is available for only 59 data points. 
Fortunately, for the remaining 109 data points, information on all 6 parameters with the exception of $\mathrm{S}_{\mathrm{t}}$ is known. The practical implication here is that the effect of $\mathrm{S}_{t}$ on $\mathrm{S}_{\mathrm{u}}$ correlations is more difficult to discern in the case of S-CLAY/7/168. Basic statistics of the 7 clay parameters in S-CLAY/7/168 are reported in Table 3. The multivariate clay data contained in F-CLAY/7/216 and S-CLAY/7/168 are listed in Appendix A.

Fig. 1 shows how the data points are positioned in the plasticity chart to provide a broad physical overview of the databases. Fig. 2 suggests that $w$ tends to increase for increasing LL, and that $w$ is higher than LL for the majority of the data points.

\section{Dimensionless databases: F-CLAY/10/216 and S-CLAY/10/168}

Ten (10) dimensionless soil parameters are of primary interest in this study. They are derived from the 7 basic clay parameters appearing in F-CLAY/7/216 and S-CLAY/7/168 and they can be categorized into two groups.

1. Index properties, including natural water content (w), liquid limit (LL), plasticity index (PI) and liquidity index (LI).

2. Stresses and strengths, including OCR, normalized $\mathrm{s}_{\mathrm{u}}(\mathrm{mob})$ against vertical effective stress $\left[\mathrm{s}_{\mathrm{u}}(\mathrm{mob}) / \sigma_{\mathrm{v}}\right]$ and preconsolidation pressure $\left[\mathrm{s}_{\mathrm{u}}(\mathrm{mob}) / \sigma_{\mathrm{p}}\right]$, normalized $\mathrm{s}_{\mathrm{u}}{ }^{\mathrm{FV}}$ against vertical effective stress $\left(\mathrm{s}_{\mathrm{u}}^{\mathrm{FV}} / \sigma_{\mathrm{v}}^{\prime}\right)$ and preconsolidation pressure $\left(\mathrm{s}_{\mathrm{u}}{ }^{\mathrm{FV}} / \sigma_{\mathrm{p}}^{\prime}\right)$, and sensitivity $\left(\mathrm{S}_{\mathrm{t}}=\mathrm{S}_{\mathrm{u}} / \mathrm{S}_{\mathrm{u}}{ }^{\mathrm{re}}\right)$.

Fig. 3a shows the $s_{u}(m o b) / \sigma_{v}$ values plotted against OCR for F-CLAY/10/216 and SCLAY/10/168. The trend described by the $s_{u}(m o b) / \sigma^{\prime}$, points vs. OCR seem on average higher for Finnish clays than for Scandinavian clays. The reason for such a discrepancy could lie in the definition of $\sigma_{p}^{\prime}$ used to estimate OCR. Indeed, $\sigma_{p}^{\prime}$ is normally determined through oedometer test and it is strongly affected by the strain rate used in the test (e.g. Leroueil et al. 1983a, 1985). As suggested by Leroueil et al. (1985), Leroueil (1988) and Leroueil (1996), constant rate of strain (CRS) oedometer tests provide stress-strain curves that normally differs from those provided by conventional $24 \mathrm{~h}$ incrementally loaded (IL) oedometer tests. The 
main reason for such differences can be found in the different rate of loading (or rate of straining) applied during the test. According to Leroueil and Marques (1996), the strain rate in IL test after 24 hours is between $1 \times 10^{-7} \mathrm{~s}^{-1}$ for highly compressible clays and $5 \times 10^{-8} \mathrm{~s}^{-1}$ for low compressible clays. The strain rate in CRS tests is normally between $1 \times 10^{-6}-4 \times 10^{-6} \mathrm{~s}^{-1}$. As a consequence, $\sigma_{\mathrm{p}}{ }_{\mathrm{p}}$ is larger in CRS than in the $24 \mathrm{~h}$ IL test (Leroueil 1996). More specifically, Leroueil (1996) suggests that $\sigma_{\mathrm{p}}$ obtained from CRS oedometer test is typically $25 \%$ larger than that deduced from IL test. For Finnish clays, Kolisoja et al. (1989) reported, for one site in Finland, the ratio $\sigma_{\mathrm{pCRS}}{ }^{\prime} \sigma_{\mathrm{pIL}}$ to be equal to 1.16 . Hoikkala (1991) observed the same ratio to be equal to 1.3 for three different sites in Finland. Länsivaara (1999), based on the data collected by Leroueil (1996) on several types of clays, suggested $\sigma_{\mathrm{pCRS}}^{\prime} / \sigma_{\mathrm{pIL}}^{\prime}=1.27$. Karlsrud and Hernandez-Martinez (2013) observed, for oedometer tests conducted on block samples of Norwegian clays, that $\sigma_{\mathrm{p}}$ values derived from the IL tests were $10-18 \%$ lower than for the CRS tests.

Upon examination of the original sources [listed in Table A1 of Ching and Phoon (2014a)] from where data contained in S-CLAY/7/168 have been collected, it seems that $\sigma_{p}$ p points were mostly measured from CRS oedometer tests. F-CLAY/7/216 contains only $56 \sigma^{\prime}{ }_{\mathrm{pCRS}}$ points, while the remaining 162 points are from $24 \mathrm{~h}$ IL tests $\left(\sigma_{\mathrm{pIL}}^{\prime}\right)$ (Fig. 3a). Therefore, in order to make data suitable for comparison, $\sigma_{\mathrm{pIL}}^{\prime}$ is increased by $27 \%$ for all data points as a first-order correction following the proposal by Länsivaara (1999) (Fig. 3b). By applying $\sigma_{\mathrm{pCRS}}^{\prime} / \sigma_{\mathrm{pIL}}^{\prime}=1.27$ to all $162 \sigma_{\mathrm{pIL}}^{\prime}$ values from Finland, the strength points from FCLAY/10/216 seem to better adapt to the $\mathrm{s}_{\mathrm{u}}(\mathrm{mob}) / \sigma_{{ }_{v}}{ }-$ OCR trend shown by those contained in S-CLAY/10/168 (Fig. 3b). It is plausible that the difference between F-CLAY/10/216 and S-CLAY/10/168 in the $s_{u}(m o b) / \sigma^{\prime}{ }_{v}$ versus OCR plot is primarily caused by the difference between the CRS and IL test, rather than the difference between clay types, as also indicated by Fig. 1 and Fig. 2.

The basic statistics of the 10 dimensionless parameters are listed in Table 4 and Table 5 for the dimensionless databases, labeled as F-CLAY/10/216 and S-CLAY/10/168, respectively. 


\section{Comparison with existing transformation models}

The 384 clay data points constituting F-CLAY/10/216 and S-CLAY/10/168 databases are compared with transformation models proposed in the literature in order to check their consistency. It is worth pointing out that transformation models are generally derived based on certain types of clays and geographical locations. The basis for these models is usually empirical. Very often, for such models we do not know the basic statistics (such as those reported in Table 4 and Table 5).

The 10 transformation models analyzed are labeled using the template: (primary input parameter)-(target parameter)-(secondary input parameter). They are categorized into four types (see e.g. Table 6):

1. Type A. Models for $\mathrm{S}_{\mathrm{t}}$, including two LI- $\left(\mathrm{s}_{\mathrm{u}}{ }^{\mathrm{re}} / \mathrm{P}_{\mathrm{a}}\right)$ models and two LI- $\left(\mathrm{S}_{\mathrm{t}}\right)$ models.

2. Type B. Models for effective stress, including one LI- $\left(\sigma_{\mathrm{p}}^{\prime} / \mathrm{P}_{\mathrm{a}}\right)-\mathrm{S}_{\mathrm{t}}$ model. Basic statistics of $\sigma_{\mathrm{p}}{ }^{\prime} \mathrm{P}_{\mathrm{a}}$ are reported in Table 2 and Table 3 and not included in the dimensionless databases, as $\mathrm{s}_{\mathrm{u}}^{\mathrm{FV}}$ and $\mathrm{s}_{\mathrm{u}}(\mathrm{mob})$ are the parameters of primary interest for this study.

3. Type C. Models for shear strength, including one PI- $\left[\mathrm{s}_{\mathrm{u}}(\mathrm{mob}) / \sigma_{\mathrm{p}}{ }_{\mathrm{p}}\right]$ model, one OCR$\left[\mathrm{s}_{\mathrm{u}}(\mathrm{mob}) / \sigma^{\prime}{ }_{\mathrm{v}}\right]$ model, and one OCR- $\left[\mathrm{s}_{\mathrm{u}}(\mathrm{mob}) / \sigma^{\prime}{ }_{\mathrm{v}}\right]-\mathrm{S}_{\mathrm{t}}$ model.

4. Type D. Models for shear strength, including two PI-( $\left.\mathrm{s}_{\mathrm{u}}^{\mathrm{FV}} / \sigma_{\mathrm{p}}{ }_{\mathrm{p}}\right)$, one LL- $\left(\mathrm{s}_{\mathrm{u}}^{\mathrm{FV}} / \sigma_{\mathrm{p}}{ }^{\prime}\right)$. These three models are compared to uncorrected $\mathrm{s}_{\mathrm{u}}^{\mathrm{FV}}(\lambda$ correction factor is not applied), being originally derived from uncorrected measurements.

Many of the transformation models are derived empirically using regression analyses. Only the LI- $\left(\mathrm{s}_{\mathrm{u}}{ }_{\mathrm{u}}^{\mathrm{r}} / \mathrm{P}_{\mathrm{a}}\right)$ model by Wroth and Wood (1978) represents an exception. It is derived theoretically from the Modified Cam Clay model. The LI- $\left(\sigma^{\prime}{ }_{p} / \mathrm{P}_{\mathrm{a}}\right)-\mathrm{S}_{\mathrm{t}}$ and OCR- $\left[\mathrm{s}_{\mathrm{u}}(\mathrm{mob}) / \sigma_{\mathrm{v}}{ }_{\mathrm{v}}\right]-$ $\mathrm{S}_{\mathrm{t}}$ models proposed by Ching and Phoon (2012a) are derived from sensitive structured clay data. The LI-S model by Bjerrum (1954) is based on Norwegian marine clay data. 
Figs. 4 to 11 show the comparison between databases and transformation models. For the LI$\left(\sigma_{\mathrm{p}}{ }_{\mathrm{p}} / \mathrm{P}_{\mathrm{a}}\right)-\mathrm{S}_{\mathrm{t}}$ and OCR $-\left[\mathrm{s}_{\mathrm{u}}(\mathrm{mob}) / \sigma^{\prime}{ }_{\mathrm{v}}\right]-\mathrm{S}_{\mathrm{t}}$ models by Ching and Phoon (2012a), data points are divided into two groups according to $\mathrm{S}_{\mathrm{t}}$ values. The two groups are based on the distinction between "low to medium sensitive" $\left(S_{t}<15\right)$ and "highly sensitive" $\left(S_{t}>15\right)$ clays suggested by Karlsrud and Hernandez-Martinez (2013) for Norwegian clays.

The OCR- $\left[\mathrm{s}_{\mathrm{u}}(\mathrm{mob}) / \sigma_{\mathrm{v}}\right]$ transformation model by Jamiolkowski et al. (1985) provides a reasonable average fit to the data. For OCR $<8, \mathrm{~s}_{\mathrm{u}}(\mathrm{mob}) / \sigma^{\prime}{ }_{\mathrm{v}}$ seems to be strongly dependent on OCR (Fig. 4). A deviation from the trend line in Fig. 4 is visible at OCR values greater than 5 . However, data points with OCR $>5$ belong to layers located in proximity of the ground surface (above $1.50 \mathrm{~m}$ ) where the clay might be fissured and/or partially saturated. Therefore, the interest for those points is limited, because the focus of this study is on intact clays.

The PI- $\left[\mathrm{s}_{\mathrm{u}}(\mathrm{mob}) / \sigma_{\mathrm{p}}{ }_{\mathrm{p}}\right]$ model by Mesri $(1975,1989)$ takes out the dependency of $\mathrm{s}_{\mathrm{u}}(\mathrm{mob})$ on PI, stating that $\mathrm{s}_{\mathrm{u}}(\mathrm{mob}) / \sigma_{\mathrm{p}}$ is constant and equal to 0.22 . From Fig. $5, \mathrm{~s}_{\mathrm{u}}(\mathrm{mob}) / \sigma_{\mathrm{p}}{ }_{\mathrm{p}}$ seems independent of PI, thus confirming the suggestion given by Mesri.

The dependency of $s_{u}$ on $S_{t}$ predicted by the OCR- $\left[s_{u}(m o b) / \sigma_{v}\right]-S_{t}$ model by Ching and Phoon (2012a), is not visible from the collected data points (Fig. 6). However, the majority of the F-CLAY/10/216 data points for $\mathrm{S}_{\mathrm{t}}<15$ are located between the $\mathrm{s}_{\mathrm{u}}(\mathrm{mob}) / \sigma_{\mathrm{v}}{ }_{\mathrm{v}}$-OCR trend lines for $S_{t}=1$ and $S_{t}=15$ (Fig. 6a).

It is quite difficult to observe a well-defined trend for the data points to the LL- $\left(\mathrm{s}_{\mathrm{u}}^{\mathrm{FV}} / \sigma_{\mathrm{p}}{ }_{\mathrm{p}}\right)$ model by Hansbo (1987) (Fig. 7). Both databases seem to better adapt to the mean trend suggested by the PI-( $\mathrm{s}_{\mathrm{u}}^{\mathrm{FV}} / \sigma_{\mathrm{p}}$ ) models (Fig. 8), although high scatter can be observed along the trend lines suggested by Larsson (1980) and Chandler (1988, after Skempton 1957).

Data points seem to depart from the LI- $\left(\mathrm{s}_{\mathrm{u}}{ }^{\mathrm{re}} / \mathrm{P}_{\mathrm{a}}\right)$ model by Wroth and Wood (1978) for LI values greater than 1 (Fig. 9). However, the transformation model by Locat and Demers (1988) seems able to reproduce the trend observed for LI $<2$ (Fig. 9). For LI $>2$, the data points deviate from the existing transformation models. The authors believe that $\mathrm{S}_{\mathrm{t}}$ was 
determined from the FV test for some of the Finnish data points (from Gardemeister 1973). The FV test is known to produce higher $\mathrm{s}_{\mathrm{u}}^{\mathrm{re}}$ values than the conventional Fall Cone (FC) test. Tanaka et al. (2012) demonstrated how $\mathrm{s}_{\mathrm{u}}{ }^{\text {re }}$ determined from FV and laboratory vane test (LVT) is as much as a tenfold larger than $\mathrm{s}_{\mathrm{u}}{ }^{\text {re }}$ determined using the FC test (Fig. 10b). This was attributed to the different remolding methods, as the turning of the vane is not equivalent to the remolded state for the FC test, which is obtained by kneading by hand. Hence, the actual $\mathrm{s}_{\mathrm{u}}{ }^{\text {re }}$ may be lower than that shown in Fig. 9, which consequently produces a higher $\mathrm{S}_{\mathrm{t}}$. However, there are only 29 points with LI $>2$. The conclusions of this study will be largely unaffected, because 29 points only constitute $13.4 \%$ of the total number of points. Based on the experimental results presented by Tanaka et al. (2012), the authors would like to further suggest that while undisturbed $\mathrm{s}_{\mathrm{u}}$ values from FV and FC can be mixed (as shown in Fig. $10 \mathrm{a}), \mathrm{s}_{\mathrm{u}}{ }^{\text {re }}$ or derived parameters $\left(\mathrm{S}_{\mathrm{t}}\right)$ between FV and FC should be treated separately (as suggested by Fig. 10b).

The LI-( $\left.\mathrm{S}_{\mathrm{t}}\right)$ model by Bjerrum (1954) can reasonably describe the data points for $\mathrm{LI}<2$, despite the high scatter observed (Fig. 11). On the other hand, the global model by Ching and Phoon (2012a) seems to provide an upper bound rather than provide an average fit to the databases (Fig. 11).

The LI- $\left(\sigma_{\mathrm{p}}^{\prime} / \mathrm{P}_{\mathrm{a}}\right)-\mathrm{S}_{\mathrm{t}}$ model by Ching and Phoon (2012a) does not seem to fit the data points in F-CLAY/10/216 for $\mathrm{S}_{\mathrm{t}}<15$ (Fig. 12a). The LI- $\left(\sigma_{\mathrm{p}} / \mathrm{P}_{\mathrm{a}}\right)-\mathrm{S}_{\mathrm{t}}$ transformation model appears to provide a better description of the highly sensitive clays $\left(\mathrm{S}_{\mathrm{t}}>15\right)$ in F-CLAY/10/216, as the majority of the points are contained in the interval between the LI- $\left(\sigma^{\prime}{ }_{p} / P_{a}\right)-S_{t}$ lines for $S_{t}=15$ and $S_{t}=50$ (Fig. 12a). In contrast, for the low to medium sensitive clays $\left(S_{t}<15\right)$ in $S-$ CLAY/10/168, most of the data points are comprised between the LI- $\left(\sigma_{\mathrm{p}}{ }_{\mathrm{p}} / \mathrm{P}_{\mathrm{a}}\right)-\mathrm{S}_{\mathrm{t}}$ boundary lines for $S_{t}=1$ and $S_{t}=15$ (Fig. 12b), while for the highly sensitive clays, the models cannot satisfactorily describe the observed values.

\section{Bias and uncertainties of the existing transformation models}


Bias factor (denoted by $b$ ), and $\mathrm{COV}$ (denoted by $\delta$ ) are evaluated and discussed for the transformation models described in the previous section, based on the F-CLAY/10/216 and SCLAY/10/168 databases. The parameters $b$ and $\delta$ represent the sample mean and the COV, respectively, of the ratio (actual target value)/(predicted target value). If $b=1$, the model prediction is unbiased. For instance, for the OCR- $\left[\mathrm{s}_{\mathrm{u}}(\mathrm{mob}) / \sigma_{\mathrm{v}}\right]$ transformation model by Jamiolkowski et al. (1985), the actual target value is $\mathrm{s}_{\mathrm{u}}(\mathrm{mob}) / \sigma_{\mathrm{v}}$, and the predicted target value is $0.23 \mathrm{OCR}{ }^{0.8}$. For the data points where $\mathrm{s}_{\mathrm{u}}(\mathrm{mob}) / \sigma_{\mathrm{v}}{ }_{\mathrm{v}}$ and $\mathrm{OCR}$ are simultaneously known, (actual target value $) /($ predicted target value $)=\left(\mathrm{s}_{\mathrm{u}}(\mathrm{mob}) / \sigma_{\mathrm{v}}\right) /\left(0.23 \mathrm{OCR}^{0.8}\right)$.

According to Ching and Phoon (2014a):

$\varepsilon=($ actual target value $) /(b \times$ predicted target value $)=($ actual target value $) /($ unbiased prediction)

where $\varepsilon$ is the variability term with mean $=1$ and $\mathrm{COV}=\delta$. If $\delta=0$, there is no data scatter about the transformation model, indicating that the prediction is deterministic, rather than uncertain.

Bias factors and COVs for the different transformation models analyzed are reported in Table 6 for F-CLAY/10/216 and Table 7 for S-CLAY/10/168, respectively. Bias factor, COV of $\varepsilon$, number of data points used for each calibration are denoted, respectively, by $b, \delta, \mathrm{n}$.

The LI- $\left(\mathrm{s}_{\mathrm{u}}^{\mathrm{re}} / \mathrm{P}_{\mathrm{a}}\right)$ model by Locat and Demers (1988) seems quite conservative, as it underpredicts the actual value by a factor of 4.05 for Finnish clays (Table 6) and 1.60 for Scandinavian clays (Table 7). Bjerrum's (1954) transformation model underestimates the actual $S_{t}$ values for both Finnish and Scandinavian clays. Nevertheless, the uncertainty underlying these predictions remains still considerable, as the COV for type A models ranges between 61 and $302 \%$. A similar analysis can be carried out for the LI- $\left(\sigma^{\prime}{ }_{p} / \mathrm{P}_{a}\right)-\mathrm{S}_{\mathrm{t}}$ model by Ching and Phoon (2012a). The deviation of about 50-60\% from the mean trend lines of both F-CLAY/10/216 and S-CLAY/10/168, combined with a COV greater than 1 and equal to 0.61 for Finnish and Scandinavian clays, respectively, would result in predicted values 
characterized by a high degree of uncertainty. Therefore, models of type A and B are "biased" models with respect to both databases.

On the other hand, different outcomes are obtained for the transformation models of type C and $\mathrm{D}$ (models for shear strength). Models of type $\mathrm{C}\left[\mathrm{s}_{\mathrm{u}}(\mathrm{mob}) / \sigma^{\prime}{ }_{\mathrm{v}}\right.$ is the target parameter] show bias factors $(b)$ close to 1 and coefficient of variation $(\delta)$ lower than 0.30 . Exception is found for the OCR- $\left[\mathrm{s}_{\mathrm{u}}(\mathrm{mob}) / \sigma_{\mathrm{v}}\right]-\mathrm{S}_{\mathrm{t}}$ model (Ching and Phoon 2012a), which shows a bias factor of 0.71-0.77 with a COV of 0.32-0.36. These results would though suggest that $\mathrm{s}_{\mathrm{u}}(\mathrm{mob})$ of Scandinavian clays can be described by different well established transformation models with relatively low uncertainty. For instance, the equation by Mesri $(1975,1989)$ can be adapted to Finnish soft clays by including the bias factor $(b)$ calibrated from F-CLAY/10/216 database as $\mathrm{s}_{\mathrm{u}}(\mathrm{mob}) / \sigma_{\mathrm{p}}^{\prime}=b[0.22]=0.95[0.22]=0.209$, with a $\operatorname{COV}\left(\delta^{\prime}\right)=0.28$ (low variability).

Type D models $\left(\mathrm{s}_{\mathrm{u}}^{\mathrm{FV}} / \sigma_{\mathrm{p}}\right.$ is the target parameter, see Table 6-7) show a bias factor $b$ varying between 0.82 and 0.97 with $\mathrm{COV}$ between 0.31 and 0.43 , suggesting reasonably low variability for these models. In particular, the $\mathrm{PI}-\left(\mathrm{s}_{\mathrm{u}}^{\mathrm{FV}} / \sigma_{\mathrm{p}}{ }_{\mathrm{p}}\right)$ model proposed by Chandler (1988) results almost "unbiased" with respect to both F-CLAY/10/216 and S-CLAY/10/168, suggesting $b$ comprised between $0.96-0.97$ and $\delta$ varying between 0.31 and 0.35 .

$s_{u} / \sigma_{v}^{\prime}$ TRANSFORMATION MODELS FOR F-CLAY/10/173

\section{Removal of outliers in F-CLAY/10/216}

As the scope of this study is to derive transformation models for $s_{u}$ of Finnish soft clays that are more refined than the existing models in the literature, the data points collected in FCLAY/10/216 are analyzed with the purpose of improving the quality of the database by removing outliers. The quality of data points is assessed through criteria based on the physical 
nature of the soil, mechanical characteristics and statistical considerations. The adopted criteria are listed below:

i) Points located near the ground surface that may belong to fissured upper layers (dry crust), as the study focuses on intact and saturated clays. Dry crust layers are generally unsaturated and contain cracks and fissures. $s_{u}$ of such soils may be highly overestimated when measured with FV test. (La Rochelle 1974; Lefebvre et al. 1987; D'Ignazio et al. 2015b). Dry crust layers in Finland are normally 1-2 m thick. Therefore, points near the ground surface, at depths lower than $1.50 \mathrm{~m}$, are left out.

ii) Points with $\mathrm{s}_{\mathrm{u}}(\mathrm{mob}) / \sigma_{\mathrm{p}}$ lower than an initial shear stress mobilization $\left(\tau_{0} / \sigma_{\mathrm{p}}^{\prime}\right.$ where $\tau_{0}$ is the initially mobilized shear stress) in the soil $\tau_{0} / \sigma_{\mathrm{p}}=0.5 *\left(1-\mathrm{K}_{0}\right)$ equal to 0.15 for normally consolidated state. $\mathrm{K}_{0}$ is the earth pressure coefficient at rest calculated from Jaky's (1948) formula $\left(\mathrm{K}_{0}=1-\sin \phi\right.$, where $\phi$ ' is the effective friction angle of the soil). $\tau_{0}=0.15$ implies $\phi^{\prime}=18^{\circ}$, which could represent, according to the authors' experience, the lowest boundary value for friction angle of Scandinavian clays.

iii) Outliers identified through the " $2 \sigma$ " $\left[95 \%\right.$ confidence interval of $\left.\mathrm{s}_{\mathrm{u}}(\mathrm{mob}) / \sigma_{\mathrm{v}}\right]$ statistical criteria. " $\sigma$ " is the standard deviation of the variable $s_{u}(m o b) / \sigma$ ' ${ }_{v}$. Data points where, for a given “i” value $\left|\left[\mathrm{s}_{\mathrm{u}}(\mathrm{mob}) / \sigma_{\mathrm{v}}\right]_{\mathrm{i}}-\operatorname{mean}\left[\mathrm{s}_{\mathrm{u}}(\mathrm{mob}) / \sigma_{\mathrm{v}}\right]\right|>2 \sigma$, are removed. Normally, outliers for a given data set are identified using the $3 \sigma$ (three sigma) rule, representing the $99 \%$ confidence interval of the data. The reason why in this study the $95 \%$ confidence interval criteria is used, has to do with the inherent soil variability. $s_{u}$ profiles obtained from FV test are likely to show clear fluctuations against a mean trend. Strength variability with depth may depend not only on the consolidation stresses (initial or mechanically induced), but also on the inherent variability of the soil layers (variation of grain size, index properties). Furthermore, sample disturbance can affect the preconsolidation pressure $\left(\sigma_{\mathrm{p}}^{\prime}\right)$ trend with depth and consequently the ratio $\mathrm{s}_{\mathrm{u}}(\mathrm{mob}) / \sigma_{\mathrm{p}}$. In order to remove these points, a statistical criterion stronger than the " $3 \sigma$ " was preferred to a "visual" one. 
The number of data points left out is 43 out of 216 , corresponding to $20 \%$ of the database. To be more specific, 10, 24, and 9 points are removed based on criteria i), ii) and iii), respectively. The outcomes of this study will be then based on 173 higher quality multivariate clay data points. The updated dimensionless database is hereinafter called F-CLAY/10/173. Updated basic statistics of F-CLAY/10/173 database are listed in Table 8. One major outcome of this procedure is the reduction of the COV for all the analyzed dimensionless variables (see Table 8). Index parameters and sensitivity are not significantly affected by the removal of data points. However, OCR range drops considerably from 1 7.50 to 1 3.70. Such low OCR values are expected to be found in shallow clay deposits in Finland. Therefore, $s_{u}$ of Finnish clays for OCR $>4$ will not be discussed in this study. Moreover, the average $s_{u}(m o b) / \sigma_{p}$ in Table 8 is slightly higher than in Table 4, resulting from the removal of the unreliable data points.

\section{Derivation of new transformation models}

Regression analyses are carried out to derive new transformation models for $\mathrm{s}_{\mathrm{u}}$ of Finnish soft clays. The F-CLAY/10/173 database is used for this purpose. The SHANSEP framework [eq. (5)] proposed by Ladd and Foott (1974) is adopted to describe the variation of $\mathrm{s}_{\mathrm{u}}(\mathrm{mob})$ and $\mathrm{S}_{\mathrm{u}}^{\mathrm{FV}}$ with OCR and index parameters.

Larsson et al. (2007) and Karlsrud and Hernandez-Martinez (2013) studied the anisotropic $s_{u}$ of Scandinavian and Norwegian clays, respectively, from TXC, DSS and TXE tests. Larsson et al. (2007) reported $S$ and $m$ [see eq. (5)] to be dependent on LL [eq.(6) for DSS], while Karlsrud and Hernandez-Martinez (2013) found $w$, combined with the OCR, to be the best index parameter for correlating their test results [eq.(7) for DSS]. A direct comparison between $\mathrm{s}_{\mathrm{u}}$ DSS and $\mathrm{s}_{\mathrm{u}}^{\mathrm{FV}}$ would however be misleading, if rate effects are not accounted for. Nevertheless, equations (6) and (7) will be still used for qualitative comparison.

Linear regression analyses are performed using the "fminsearch" algorithm implemented in the mathematical software Matlab2012. "fminsearch" function (see MATLAB user's manual 1995) finds the minimum of an unconstrained multivariable function through a derivative free 
method (unconstrained linear optimization). The multivariable function $F=\mathrm{f}\left(\mathrm{s}_{\mathrm{u}, \mathrm{i}} / \sigma_{\mathrm{v}},{ }_{\mathrm{v}}, \mathrm{OCR}\right.$, $\mathrm{Y}_{\mathrm{i}}$ ) is defined by eq. (10):

$$
F=\frac{s_{u, i}}{\sigma_{v}^{\prime}}=\alpha \cdot O C R^{\beta} \cdot Y_{i}^{\gamma}
$$

where $\mathrm{s}_{\mathrm{u}}, \mathrm{i}=\left\{\mathrm{s}_{\mathrm{u}, 1}=\mathrm{s}_{\mathrm{u}}(\mathrm{mob}), \mathrm{s}_{\mathrm{u}, 2}=\mathrm{s}_{\mathrm{u}}^{\mathrm{FV}}\right\}, \mathrm{Y}_{\mathrm{i}}=\left\{\mathrm{Y}_{1}=\mathrm{PI}, \mathrm{Y}_{2}=\mathrm{LL}, \mathrm{Y}_{3}=w, \mathrm{Y}_{4}=\mathrm{LI}, \mathrm{Y}_{5}=\mathrm{S}_{\mathrm{t}}\right\}$.

The scalar coefficients $\alpha, \beta$ and $\gamma$ and the coefficient of determination $\left(r^{2}\right)$ for the two newly constructed OCR- $\left(\mathrm{s}_{\mathrm{u}, j} / \sigma^{\prime}{ }_{\mathrm{v}}\right)-\mathrm{Y}_{\mathrm{i}}$ transformation models are given in Table 9. The $r^{2}$ of the new correlations ranges from 0.62 to 0.70 .

The results of the regression analyses suggest that for the OCR $-\left(\mathrm{s}_{\mathrm{u}}^{\mathrm{FV}} / \sigma_{\mathrm{v}}^{\prime}\right)-\mathrm{Y}_{\mathrm{i}}$ transformation model, $\mathrm{s}_{\mathrm{u}}^{\mathrm{FV}} / \sigma_{\mathrm{v}}$ is directly proportional to PI, LL, $w$ and inversely proportional to LI, while it is not markedly dependent on $\mathrm{S}_{\mathrm{t}}$. On the other hand, a similar conclusion cannot be drawn for the OCR- $\left[\mathrm{s}_{\mathrm{u}}(\mathrm{mob}) / \sigma_{\mathrm{v}}\right]-\mathrm{Y}_{\mathrm{i}}$ model, as $\mathrm{s}_{\mathrm{u}}(\mathrm{mob}) / \sigma_{\mathrm{v}}$, seems to be only lightly correlating with index parameters. This concept can be well understood by looking at the scalar coefficient $\gamma$ for the OCR- $\left[\mathrm{s}_{\mathrm{u}}(\mathrm{mob}) / \sigma_{\mathrm{v}}^{\prime}\right]-\mathrm{Y}_{\mathrm{i}}$ models from Table 9. For $\gamma>0, \mathrm{~s}_{\mathrm{u}}(\mathrm{mob}) / \sigma_{\mathrm{v}}{ }_{\mathrm{v}}$ increases with increasing $\mathrm{Y}_{\mathrm{i}}$; on the contrary, for $\gamma<0$ it reduces by increasing $\mathrm{Y}_{\mathrm{i}}$. Although $\gamma$ values indicate that $\mathrm{s}_{\mathrm{u}}(\mathrm{mob}) / \sigma^{\prime}{ }_{\mathrm{v}}$ decreases with increasing PI or LL and, in contrast, increases with increasing $\mathrm{w}, \mathrm{LI}$ or $\mathrm{S}_{\mathrm{t}}$, it should be emphasized how $\gamma$ tends to zero for the OCR$\left[\mathrm{s}_{\mathrm{u}}(\mathrm{mob}) / \sigma_{\mathrm{v}}\right]-\mathrm{Y}_{\mathrm{i}}$ transformation model. As a result, $\mathrm{s}_{\mathrm{u}}(\mathrm{mob}) / \sigma^{\prime}{ }_{\mathrm{v}}$ of Finnish soft clays results i) slightly dependent or nearly independent of the secondary input variable $\mathrm{Y}_{\mathrm{i}}$, and ii) strongly dependent on the consolidation stresses (increasing with increasing OCR). This result agrees with the findings of Mesri $(1975,1989)$ and Jamiolkowski et al. (1985). However, Mesri $(1975,1989)$ suggests $m=1$, which is not consistent with the results presented in Table 9, as for Finnish clays $m$ results lower than 1. To validate such observation, it is worth to mention that the Modified Cam Clay model (Schofield and Wroth 1968) predicts $m=1-\mathrm{C}_{\mathrm{s}} / \mathrm{C}_{\mathrm{c}}$, where $\mathrm{C}_{\mathrm{c}}$ and $\mathrm{C}_{\mathrm{s}}$ are the compression and swelling indices, respectively, of a clay. This result indicates that $m$ is generally less than 1 for normally consolidated to lightly overconsolidated clays, which are typically known to be adequately modeled by Modified Cam Clay. 
Moreover, by averaging $\alpha$ and $\beta$ from the five OCR $\left[\mathrm{s}_{\mathrm{u}}(\mathrm{mob}) / \sigma_{\mathrm{v}}{ }_{\mathrm{v}}\right]-\mathrm{Y}_{\mathrm{i}}$ correlation equations of Table 9, and assuming $\gamma=0$, for Finnish clays [eq. (11)]:

$$
\frac{s_{u}(m o b)}{\sigma_{v}^{\prime}} \approx 0.244 \cdot O C R^{0.763}
$$

which nearly corresponds to the unbiased transformation model presented by Jamiolkowski et al. (1985), as described earlier in this paper. The calibrated bias factor (b) from FCLAY/10/216 database for the OCR- $\left[\mathrm{s}_{\mathrm{u}}(\mathrm{mob}) / \sigma^{\prime}{ }_{\mathrm{v}}\right]$ model by Jamiolkowski et al. (1985) is equal to 1.06 . This means $\mathrm{s}_{\mathrm{u}}(\mathrm{mob}) / \sigma_{\mathrm{v}}{ }_{\mathrm{v}}=b(0.23) \mathrm{OCR}^{0.8}=0.244 \mathrm{OCR}^{0.8}$ with a coefficient of variation $\left(\mathrm{COV}=\delta^{\prime}\right)$ equal to 0.30 .

\section{Validation of the new transformation models}

It is apparent from Table 9 that the OCR $-\left(\mathrm{s}_{\mathrm{u}}^{\mathrm{FV}} / \sigma^{\prime}{ }_{\mathrm{v}}\right)-\mathrm{Y}_{\mathrm{i}}$ transformation model is strongly dependent on index parameters. As earlier explained in this section, $\mathrm{s}_{\mathrm{u}}$ DSS of Scandinavian clays exhibits a marked dependency on LL [eq. (5)] and $w$ [eq. (6)]. These results may be explained by the fact that both tests at laboratory scale and FV test are performed at considerably high strain rate in relatively short time frames, if compared with the time scale needed for causing failure in-situ. It is known that undrained failure of e.g. embankments may take several days (La Rochelle et al. 1974), while DSS and FV test are performed on time scales in the order of hours or minutes, respectively. While TXC, TXE, DSS tests are normally performed at a strain rate of about $1 \% / \mathrm{h}, \mathrm{FV}$ test is executed at strain rates typically 50-60 times larger (i.e. 60\%/h, Ching et al. 2013). This is well reflected in Fig. 13 and Fig. 14 , where the OCR $-\left(\mathrm{s}_{\mathrm{u}}{ }^{\mathrm{FV}} / \sigma^{\prime}{ }_{\mathrm{v}}\right)-\mathrm{Y}_{\mathrm{i}}$ transformation model is compared to eq. (6) and eq. (7). From Fig. 13, it can be noticed how $\mathrm{s}_{\mathrm{u}}{ }^{\mathrm{FV}} / \sigma^{\prime}$, is generally greater than $\mathrm{s}_{\mathrm{u}}{ }^{\mathrm{DSS}} / \sigma^{\prime}{ }_{v}$, except for LL $>100 \%$ at $\mathrm{OCR}=1$. This is possibly due to the limited amount of $\mathrm{LL}>100 \%$ data points used to derive the correlations.

However, more uncertainty comes when $w$ is taken as secondary input parameter. The transformation model given by Karlsrud and Hernandez-Martinez (2013) for DSS strength 
tends to deviate from the mean trend suggested by F-CLAY/10/173 database (Fig. 14), intersecting the regression line and suggesting that for a certain number of combinations of OCR and $w, s_{u}$ DSS of Norwegian clays would result higher than $s_{u}{ }^{F V}$ of Finnish clays. One possible reason which could justify the differences between the two models, could be that eq. (6) is based i) only on a limited number of DSS tests (as reported by Karlsrud and HernandezMartinez 2013) and ii) $w$ of the tested specimens was about $25 \sim 80 \%$, while the new OCR$\left(\mathrm{s}_{\mathrm{u}}^{\mathrm{FV}} / \sigma_{\mathrm{v}}^{\prime}\right)-w$ model is calibrated from a wider range of $w(w=25-150 \%)$. Hence, attention must be paid when using eq. (6), as, based on this study, consistency was found only for $w<$ $60 \%$.

Fig. 15 compares the variation of $\mathrm{s}_{\mathrm{u}}^{\mathrm{FV}} / \sigma^{\prime}{ }_{\mathrm{v}}$ with OCR for various LL ranges. It is noticeable that for Finnish sensitive clays the trend lines (solid lines) for given values of LL move gently upwards for increasing LL. The suggested trends appear to agree with the points from the SCLAY/10/168 database, grouped following the LL ranges adopted.

\section{Bias and uncertainties of the new transformation models}

Bias factor $(b)$ and coefficient of variation of $\varepsilon(\delta)$ are evaluated for the newly derived transformation models for $s_{u}$ of Finnish soft clays, through the independent S-CLAY/10/168 database of Scandinavian clays. $b$ and $\delta$ of the new correlations are summarized in Table 10. Calculated $b$ values range between 0.94 and 0.97 when the effect of PI, LL, $w$ and LI is considered, with COV values lower than 0.30. Exception is only made for the OCR$\left(\mathrm{s}_{\mathrm{u}}{ }^{\mathrm{FV}} / \sigma_{\mathrm{v}}\right)$-LI model which shows $\mathrm{COV}=0.33$. Therefore, the proposed correlations can be considered almost "unbiased" with respect to S-CLAY/10/168 database. The OCR- $\left(\mathrm{s}_{\mathrm{u}}{ }^{\mathrm{FV}} / \sigma{ }_{\mathrm{v}}\right)$ $\mathrm{S}_{\mathrm{t}}$ and OCR- $\left[\mathrm{s}_{\mathrm{u}}(\mathrm{mob}) / \sigma{ }_{\mathrm{v}}\right]-\mathrm{S}_{\mathrm{t}}$ models are characterized by the lowest bias factors $(0.91$ and 0.90 , respectively) and by the highest coefficients of variation $\delta$ ( 0.44 and 0.34 , respectively). One possible reason could be that $b$ and $\delta$ of the models where $\mathrm{S}_{\mathrm{t}}$ is the secondary input parameter are calculated from a lower number of data points $(n=59)$ than for the other models $(n=168)$. 
The new correlation equations appear to be less "biased" than the existing type C and type D transformation models presented in Table 6. In particular, $\mathrm{s}_{\mathrm{u}}^{\mathrm{FV}}$ evaluated using the new equations would result less "biased" $(b \sim 1)$ than from type D models of Table 6 , with $\delta$ values lower than 0.3 (Table 10) versus $\delta=0.35-0.43$ (Table 6). In addition, equations for $\mathrm{s}_{\mathrm{u}}(\mathrm{mob})$ from Table 10 provide an almost unbiased prediction with coefficient of variation $(\delta)$ as low as 0.25 .

\section{DISCUSSION}

Based on the results presented in Table 9, a correct evaluation of $\sigma_{p}^{\prime}$ would be of great importance for assessing $\mathrm{s}_{\mathrm{u}}$ of Finnish soft clays when direct measurements are not available. The transformation models derived in this study can predict $s_{u}$ with relatively low uncertainty, provided that OCR (primary input parameter) and a secondary input parameter (e.g. index parameter) are carefully chosen. The usability of the new models is straightforward, as only little information is required. For instance, simple tests such as oedometer and index tests would provide sufficient information for using the new models specific to Finnish clays. Moreover, the evaluation of a secondary input parameter may not be required, as $\mathrm{s}_{\mathrm{u}}(\mathrm{mob})$ was observed to mainly depend on OCR [eq. (11)].

The transformation models presented in this study may also serve as a practical engineering tool for preliminary short-term analyses and/or as a framework for validation of site-specific measurements which are suspected to be unreliable.

\section{CONCLUSIONS}


In this study, a calibration database of multivariate clay data points from Finland is compiled for the first time, for the scope of providing correlations for undrained shear strength $\left(s_{u}\right)$ of Finnish clays and evaluating the dependency of $s_{u}$ on the over-consolidation ratio (OCR), natural water content $(w)$, liquid limit (LL), plasticity index (PI), liquidity index (LI) and sensitivity $\left(\mathrm{S}_{\mathrm{t}}\right)$. The new transformation models are derived through linear regression analyses.

According to the results presented in this paper, a mutual dependence between the uncorrected $\mathrm{s}_{\mathrm{u}}$ from FV test $\left(\mathrm{s}_{\mathrm{u}}^{\mathrm{FV}}\right), \mathrm{OCR}$ and index parameters (PI, LL, $w$ and LI) exists. The only exception is observed for $\mathrm{S}_{\mathrm{t}}$, which seems to have a negligible influence on $\mathrm{s}_{\mathrm{u}}^{\mathrm{FV}}$. On the contrary, the mobilized undrained shear strength $\left[\mathrm{s}_{\mathrm{u}}(\mathrm{mob})\right]$ seems to be mainly dependent on OCR and not significantly affected by index parameters.

Another independent clay database of Scandinavian clays is compiled to validate the new equations. Consistency of the new transformation models is checked by i) evaluating bias factors and coefficients of variation associated with the validation database and ii) comparison with existing transformation models for undrained shear strength of Swedish and Norwegian clays. Consistency is clearly revealed by the validation process. In particular, the new transformation models result overall less biased than the existing ones, showing coefficients of variation lower than 0.30 .

\section{ACKNOWLEDGMENTS}

The authors acknowledge Dr. Matteo Maggioni, from the Department of Electrical and Electronic Engineering at Imperial College of London, for his support with the regression analyses presented in this work. A special thank is also given to the reviewers for their helpful comments on the manuscript. 


\section{References}

Bjerrum, L. 1954. Geotechnical properties of Norwegian marine clays. Géotechnique, 4(2): 49-69. doi:10.1680/geot.1954.4.2.49.

Bjerrum, L. 1972. Embankments on soft ground. In Proceedings of the ASCE Specialty Conference on Performance of Earth and Earth-Supported Structures, Purdue University, Lafayette, Ind. ASCE. Vol. 2, pp. 1-54.

Chandler, R.J. 1988. The in-situ measurement of the undrained shear strength of clays using the field vane. In Vane shear strength testing in soils: field and laboratory studies. ASTM STP 1014. ASTM, Philadelphia, Pa. pp. 13-44.

Ching J., and Phoon, K. K. 2012a. Modeling parameters of structured clays as a multivariate normal distribution. Canadian Geotechnical Journal 49(5): 522-545.

Ching, J., and Phoon, K. K. 2012b. Establishment of generic transformations for geotechnical design parameters. Structural Safety, 35: 52-62.

Ching, J., and Phoon, K. K. 2013. Multivariate distribution for undrained shear strengths under various test procedures. Canadian Geotechnical Journal, 50(9): 907-923. doi:10.1139/cgj-2013-0002.

Ching, J., and Phoon, K. K. 2014a. Correlations among some clay parameters - the global database. Canadian Geotechnical Journal, 51(6): 663-685.

Ching, J., and Phoon, K. K. 2014b. Correlations among some clay parameters - the multivariate distribution. Canadian Geotechnical Journal, 51(6): 686-704. 
Ching, J., Phoon, K. K., and Chen, Y.-C. 2010. Reducing shear strength uncertainties in clays by multivariate correlations. Canadian Geotechnical Journal, 47(1): 16-33. doi:10.1139/T09074.

Ching, J., Phoon, K.-K., and Lee, W. T. 2013. Second-moment characterization of undrained shear strengths from different test procedures. Proc., Foundation Engineering in the Face of Uncertainty: Honoring Professor F. H. Kulhawy, Geotechnical special publication 229, ASCE, Reston, VA, 308-320.

Ching J, Phoon K.K., and Chen C-H. 2014. Modeling piezocone cone penetration (CPTU) parameters of clays as a multivariate normal distribution. Canadian Geotechnical Journal 51(1): 77-91.

D'Ignazio, M., Di Buò, B., and Länsivaara, T. 2015. A study on the behavior of weathered clay crust in the Perniö failure test. In Proceedings of XVI ECSMGE, 13-17 September 2015, Edinburgh, Scotland. 7: 3639-3644

Gardemeister, R. 1973. Hienorakenteisen maalajien geologisia ja geoteknisiä tutkimustuloksia. Geotekniikan laboratorio, Report n.8. VTT Offsetpaino. Otaniemi, Helsinki, Finland. ISBN 951-38-0046-6.

Hansbo, S. 1957. A new approach to the determination of the shear strength of clay by the fall-cone test. Royal Swedish Geotechnical Institute.

Helenelund, K.V. 1977. Methods for reducing undrained shear strength of soft clay. In Report (3). Swedish Geotechnical Institute. pp. 1-59. 
Hoikkala, S. 1991. Continuous and incremental loading oedometer tests. M. Sc. thesis, Helsinki University of Technology, Espoo, Finland (In Finnish).

Jamiolkowski, M., Ladd, C.C., Germain, J.T., and Lancellotta, R. 1985. New developments in field and laboratory testing of soils. In Proceedings of the 11th International Conference on Soil Mechanics and Foundation Engineering, San Francisco. Vol. 1, pp. 57-153.

Karlsrud, K., and Hernandez-Martinez, F.G. 2013. Strength and deformation properties of Norwegian clays from laboratory tests on high-quality block samples 1. Canadian Geotechnical Journal, 50(12):1273-1293.

Kolisoja, P., Sahi, K., and Hartikainen, J. 1989. An automatic triaxial-oedometer device. In Proc.eedings of the 12th International Conference on Soil Mechanics and Foundation Engineering. 61-64.

Kulhawy, F. H., and Mayne, P. W. 1990. Manual on estimating soil properties for foundation design (No. EPRI-EL-6800). Electric Power Research Inst., Palo Alto, CA (USA); Cornell Univ., Ithaca, NY (USA). Geotechnical Engineering Group.

Ladd, C.C., and Foott, R. 1974. New design procedure for stability of soft clays. Journal of the Geotechnical Engineering Division, ASCE, 100(7): 763-786.

La Rochelle, P., Trak, B., Tavenas, F., and Roy, M. 1974. Failure of a test embankment on a sensitive Champlain clay deposit. Canadian Geotechnical Journal, 11(1): 142-164. doi:10.1139/t74-009. 
Larsson, R. 1980. Undrained shear strength in stability calculation of embankments and foundations on soft clays. Canadian Geotechnical Journal, 17(4):591-602. doi:10.1139/t80066.

Larsson, R., and Mulabdic, M. 1991. Piezocone tests in clay. Swedish Geotechnical Institute, Linkoping, Sweden. Report No.42.

Larsson, R., Sällfors, G., Bengtsson, P.E., Alén, C., Bergdahl, U, and Eriksson, L. 2007. Skjuvhällfasthet: utvärdering I kohesionsjord ( $2^{\text {nd }}$ edition), Information 3 . Swedish Geotechnical Institute (SGI), Linköping.

Lefebvre, G., Paré, J. J., and Dascal, O. 1987. Undrained shear strength in the surficial weathered crust. Canadian Geotechnical Journal, 24(1): 23-34.

Lehtonen, V., Meehan, C., Länsivaara, T., and Mansikkamäki, J. 2015. Full-scale embankment failure test under simulated train loading. Géotechnique, 65(12): 961-974.

Leroueil, S. 1988. Tenth Canadian Geotechnical Colloquium: Recent developments in consolidation of natural clays. Canadian Geotechnical Journal, 25(1): 85-107.

Leroueil, S. 1996. Compressibility of clays: fundamental and practical aspects. Journal of geotechnical engineering, 122(7): 534-543.

Leroueil, S., and Soares Marques, M. E. 1996. Importance of strain rate and temperature effects in geotechnical engineering. In Measuring and modeling time dependent soil behavior (eds T. C. Sheahan and V. N. Kaliakin), Geotechnical Special Publication no. 61: 1-60. New York, NY, USA: American Society of Civil Engineers (ASCE). 
Leroueil, S., Samson, L., and Bozozuk, M. 1983a. Laboratory and field determination of preconsolidation pressures at Gloucester. Canadian Geotechnical Journal, 20(3): 477-490. doi:10.1139/t83-056.

Leroueil, S., Tavenas, F., and Bihan, J.P.L. 1983b. Propriétés caractéristiques des argiles de l'est du Canada. Canadian Geotechnical Journal, 20(4): 681-705.

Leroueil, S., Kabbaj, M., Tavenas, F., and Bouchard, R. 1985. Stress-strain-strain rate relation for the compressibility of sensitive natural clays. Géotechnique, 35(2): 159-180.

Länsivaara, T. 1999. A study of the mechanical behavior of soft clay. PhD thesis, Norwegian University of Science and Technology, Trondheim.

Mansikkamäki, J. 2015 Effective stress finite element stability analysis of an old railway embankment on soft clay. PhD thesis, Tampere University of Technology, Tampere.

MATLAB, user's Manual. 1995. The MathWorks. Inc., Natick, MA.

Mesri, G. 1975. Discussion on "New design procedure for stability of soft clays". Journal of the Geotechnical Engineering Division, ASCE, 101(4): 409-412.

Mesri, G. 1989. A re-evaluation of $\mathrm{s}_{\mathrm{u}}(\mathrm{mob})=0.22 \sigma_{\mathrm{p}}$ ' using laboratory shear tests. Canadian Geotechnical Journal, 26(1): 162-164. doi:10.1139/t89-017.

Mesri, G., and Huvaj, N. 2007. Shear strength mobilized in undrained failure of soft clay and silt deposits. In Advances in measurement and modeling of soil behaviour (GSP 173). Edited by D.J. DeGroot et al. ASCE. pp. 1-22. 
Müller, R. 2013. Probabilistic stability analysis of embankments founded on clay. $\mathrm{PhD}$ Thesis, Royal Institute of Technology (KTH), Stockholm.

Müller, R., Larsson, S., and Spross, J. 2014. Extended multivariate approach for uncertainty reduction in the assessment of undrained shear strength in clays. Canadian Geotechnical Journal, 51(3): 231-245.

Müller, R., Larsson, S., and Spross, J. 2016. Multivariate stability assessment during staged construction. Canadian Geotechnical Journal, 53(4): 603-618.

Phoon, K.K., and Kulhawy, F.H. 1999. Characterization of geotechnical variability. Canadian Geotechnical Journal, 36(4): 612-624. doi:10.1139/t99-038.

Prästings, A., Larsson, S., and Müller, R. 2016. Multivariate approach in reliability-based design of a sheet pile wall. Transportation Geotechnics, 7: 1-12.

Rankka, K., Andersson-Sköld, Y., Hultén, C., Larsson, R., Leroux, V., and Dahlin, T. 2004. Quick clay in Sweden. Swedish Geotechnical Institute, Linkoping, Sweden. Report No.65.

Ratahallintokeskus 2005. Radan stabiliteetin laskenta, olemassa olevat penkereet. Ratahallintokeskuksen julkaisuja B15, Ratahallintokeskus, Helsinki. (In Finnish. In English: Guidelines for embankments stability calculation by the Finnish Transport Agency, publication B15).

Rosenqvist, I. T. 1953. Considerations on the sensitivity of Norwegian quick-clays. Géotechnique, 3(5): 195-200. 
Rosenqvist, I.T. 1966. Norwegian research into the properties of quick clay-a review. Engineering Geology, 1(6): 445-450.

Schofield, A.N., and Wroth, C.P. 1968. Critical state soil mechanics. McGraw-Hill, London, UK.

Selänpää, J. 2015. Personal communication.

Skempton, A.W. 1954. Discussion of the structure of inorganic soil. Journal of American Society of Civil Engineers, 80(478): 19-22.

Tanaka, H., Hirabayashi, H., Matsuoka, T., and Kaneko, H. 2012. Use of fall cone test as measurement of shear strength for soft clay materials. Soils and Foundations, 52(4): 590-599.

Terzaghi, K., Peck, R.B., and Mesri, G. 1996. Soil mechanics in engineering practice, 3rd Ed., Wiley, New York.

Westerberg, B., Müller, R., and Larsson, S. 2015. Evaluation of undrained shear strength of Swedish fine-grained sulphide soils. Engineering Geology, 188: 77-87.

Wroth, C.P., and Wood, D.M. 1978. The correlation of index properties with some basic engineering properties of soils. Canadian Geotechnical Journal, 15(2):137-145. doi:10.1139/t78-014. 


\section{Figure Captions}

Fig. 1: Plasticity chart.

Fig. 2: Water content $(w)$ vs liquid limit (LL) for F-CLAY/7/216 and S-CLAY/7/168.

Fig. 3: $s_{\mathrm{u}}(\mathrm{mob}) / \sigma^{\prime}{ }_{\mathrm{v}}$ against OCR for (a) raw data points and (b) data points corrected to $\sigma_{\mathrm{p}}$ from CRS oedometer test using $\sigma^{\prime}{ }_{\mathrm{pCRS}} / \sigma^{\prime}{ }_{\mathrm{pIL}}=1.27$

Fig. 4: OCR-( $\left.\mathrm{s}_{\mathrm{u}}(\mathrm{mob}) / \sigma^{\prime}{ }_{\mathrm{v}}\right)$ model proposed by Jamiolkowski et al. (1985).

Fig. 5: PI- $\left[\mathrm{s}_{\mathrm{u}}(\mathrm{mob}) / \sigma_{\mathrm{p}}\right]$ model proposed by Mesri $(1975,1989)$.

Fig. 6: OCR- $\left[\mathrm{s}_{\mathrm{u}}(\mathrm{mob}) / \sigma^{\prime}{ }_{\mathrm{v}}\right]-\mathrm{S}_{\mathrm{t}}$ model by Ching and Phoon (2012a) for (a) F-CLAY/10/216 and (b) S-CLAY/10/168.

Fig. 7: LL-( $\left.\mathrm{s}_{\mathrm{u}}{ }^{\mathrm{FV}} / \sigma_{\mathrm{p}}\right)$ model proposed by Hansbo (1957).

Fig. 8: PI- $\left(\mathrm{s}_{\mathrm{u}}{ }^{\mathrm{FV}} / \sigma_{\mathrm{p}}\right)$ models proposed by Larsson (1980) and Chandler (1988).

Fig. 9: LI- $\left(\mathrm{s}_{\mathrm{u}}{ }^{\mathrm{re}} / \mathrm{P}_{\mathrm{a}}\right)$ models.

Fig. 10: Comparison of strengths measured by FC, FV and LVT at undisturbed and remolded conditions (a) undisturbed condition, (b) remolded condition. (Tanaka et al. 2012)

Fig. 11: LI-S models.

Fig. 12: LI- $\left(\sigma^{\prime}{ }_{p} / \mathrm{P}_{\mathrm{a}}\right)-\mathrm{S}_{\mathrm{t}}$ model by Ching and Phoon (2012a) for (a) F-CLAY/10/216 and (b) SCLAY/10/168.

Fig. 13: Comparison between OCR $-\left(\mathrm{s}_{\mathrm{u}}{ }^{\mathrm{FV}} / \sigma^{\prime}{ }_{\mathrm{v}}\right)-\mathrm{LL}$ for Finnish clays and OCR- $\left[\mathrm{s}_{\mathrm{u}}{ }^{\mathrm{DSS}} / \sigma^{\prime}{ }_{\mathrm{v}}\right]-\mathrm{LL}$ model by Larsson et al. (2007) for Swedish clays.

Fig. 14: Comparison between OCR- $\left(\mathrm{s}_{\mathrm{u}}{ }^{\mathrm{FV}} / \sigma^{\prime}{ }_{\mathrm{v}}\right)-w$ for Finnish clays and OCR $-\left[\mathrm{S}_{\mathrm{u}}{ }^{\mathrm{DSS}} / \sigma^{\prime}{ }_{\mathrm{v}}\right]-w$ model by Karlsrud and Hernandez-Martinez (2013) for Norwegian clays.

Fig. 15: Comparison between measured (calibration and validation) data and OCR $-\left(\mathrm{s}_{\mathrm{u}}{ }^{\mathrm{FV}} / \sigma^{\prime}{ }_{\mathrm{v}}\right)-$ LL model for Finnish clays for various LL ranges. 


\section{List of symbols}

b Bias factor

COV Coefficient of variation

DSS Direct simple shear

F Multivariable function

FC Fall cone test

FV Field vane test

LI Liquidity index $[\mathrm{LI}=(\mathrm{w}-\mathrm{PL}) /(\mathrm{LL}-\mathrm{PL})]$

LL Liquid limit

LVT Laboratory vane test

OCR Over-consolidation ratio (OCR $\left.=\square{ }_{\mathrm{p}}^{\prime} / \square{ }_{\mathrm{v}}^{\prime}\right)$

$\mathrm{P}_{\mathrm{a}} \quad$ Atmospheric pressure $\left(\mathrm{P}_{\mathrm{a}}=101.3 \mathrm{kPa}\right)$

PI Plasticity index $(\mathrm{PI}=\mathrm{LL}-\mathrm{PL})$

PL Plastic limit

$\mathrm{S}_{\mathrm{t}} \quad$ Sensitivity $\left(\mathrm{S}_{\mathrm{t}}=\mathrm{s}_{\mathrm{u}} / \mathrm{S}_{\mathrm{u}}{ }^{\text {re }}\right)$

$\mathrm{s}_{\mathrm{u}} \quad$ Undrained shear strength

$\mathrm{S}_{\mathrm{u}}^{\mathrm{FV}} \quad$ Undrained shear strength measured from field vane test

$\mathrm{s}_{\mathrm{u}}(\mathrm{mob})$ Mobilized undrained shear strength $\left[\mathrm{s}_{\mathrm{u}}(\mathrm{mob})=\lambda \mathrm{s}_{\mathrm{u}}{ }^{\mathrm{FV}}\right]$

$\mathrm{s}_{\mathrm{u}}^{\mathrm{re}} \quad$ Remolded undrained shear strength

TXC Triaxial compression

TXE Triaxial extension

$\mathrm{Y}_{\mathrm{i}} \quad$ Secondary input parameter

w Natural water content

$\delta \quad \operatorname{COV}$ of $\varepsilon$

$\varepsilon \quad$ Variability term

$\lambda \quad$ Correction factor for $\mathrm{s}_{\mathrm{u}}^{\mathrm{FV}}$ based on plasticity

$\sigma \quad$ Standard deviation 
$\sigma^{\prime} \quad$ Effective vertical stress

$\sigma_{\mathrm{p}}^{\prime} \quad$ Vertical preconsolidation pressure

$\sigma_{\text {pCRS }}^{\prime}$ Vertical preconsolidation pressure from CRS test

$\sigma_{\text {pIL }}^{\prime}$ Vertical preconsolidation pressure from IL test 


\section{Appendix A: Multivariate clay databases}

\section{F-CLAY/7/216}

Table A.1. Basic information of the F-CLAY/7/216 database. $\sigma_{p}^{\prime}$ data points from IL oedometer test.

\begin{tabular}{|c|c|c|c|c|c|c|c|c|}
\hline Location & Depth (m) & $s_{u}^{F V}(\mathrm{kPa})$ & $\sigma_{v}^{\prime}(\mathrm{kPa})$ & $\sigma_{p}^{\prime}(\mathrm{kPa})$ & LL (\%) & PL (\%) & $w(\%)$ & $S_{t}$ \\
\hline \multirow[t]{3}{*}{ Espoo, Kaukalahti } & 3.2 & 13.0 & 30.2 & 43.0 & 70.0 & 25.0 & 85.0 & 11.0 \\
\hline & 4.6 & 7.0 & 38.6 & 60.0 & 60.0 & 25.0 & 75.0 & 11.0 \\
\hline & 5.2 & 7.5 & 42.2 & 45.0 & 45.0 & 20.0 & 50.0 & 10.0 \\
\hline \multirow[t]{4}{*}{ Espoo, Martinkylä } & 5.5 & 7.0 & 24.5 & 25.0 & 70.0 & 20.0 & 80.0 & 4.0 \\
\hline & 6.0 & 7.0 & 27.0 & 30.0 & 30.0 & 15.0 & 75.0 & 2.0 \\
\hline & 7.0 & 12.0 & 32.0 & 40.0 & 80.0 & 20.0 & 100.0 & 6.0 \\
\hline & 8.0 & 12.0 & 37.0 & 40.0 & 90.0 & 15.0 & 120.0 & 5.0 \\
\hline \multirow[t]{6}{*}{ Helsinki, Malmi } & 3.0 & 9.0 & 18.0 & 30.0 & 80.0 & 35.0 & 110.0 & 12.0 \\
\hline & 4.0 & 11.0 & 23.0 & 35.0 & 75.0 & 30.0 & 100.0 & 10.0 \\
\hline & 5.0 & 10.0 & 28.0 & 30.0 & 43.0 & 20.0 & 65.0 & 10.0 \\
\hline & 6.0 & 11.0 & 33.0 & 40.0 & 55.0 & 20.0 & 80.0 & 11.0 \\
\hline & 7.0 & 8.0 & 38.0 & 50.0 & 25.0 & 20.0 & 40.0 & 9.0 \\
\hline & 8.0 & 16.0 & 43.0 & 50.0 & 22.0 & 20.0 & 25.0 & 13.0 \\
\hline \multirow[t]{5}{*}{ Kouvola } & 1.5 & 42.0 & 24.2 & 150.0 & 45.0 & 20.0 & 40.0 & 6.5 \\
\hline & 3.0 & 15.0 & 33.0 & 40.0 & 80.0 & 25.0 & 100.0 & 11.0 \\
\hline & 5.0 & 21.0 & 43.0 & 50.0 & 110.0 & 25.0 & 130.0 & 8.0 \\
\hline & 6.0 & 23.0 & 48.0 & 55.0 & 110.0 & 25.0 & 120.0 & 8.0 \\
\hline & 7.0 & 25.0 & 53.0 & 60.0 & 80.0 & 25.0 & 110.0 & 7.0 \\
\hline \multirow[t]{15}{*}{ Kurkela* } & 2.2 & 19.1 & 35.4 & 105.4 & 69.0 & 32.3 & 75.0 & 40.0 \\
\hline & 2.7 & 20.0 & 37.8 & 107.8 & 66.3 & 31.6 & 79.0 & 39.5 \\
\hline & 3.2 & 28.2 & 40.3 & 110.3 & 60.8 & 30.2 & 70.0 & 39.0 \\
\hline & 3.7 & 25.0 & 42.7 & 112.4 & 55.2 & 28.8 & 62.0 & 38.5 \\
\hline & 4.2 & 22.3 & 45.2 & 115.2 & 49.7 & 27.4 & 56.7 & 37.0 \\
\hline & 4.7 & 23.7 & 47.6 & 117.6 & 48.8 & 27.2 & 60.0 & 35.0 \\
\hline & 5.2 & 31.3 & 50.1 & 120.1 & 48.5 & 27.1 & 65.3 & 24.1 \\
\hline & 6.2 & 28.4 & 55.0 & 127.3 & 48.0 & 27.0 & 52.1 & 24.2 \\
\hline & 7.2 & 27.8 & 59.9 & 140.0 & 51.8 & 28.0 & 53.5 & 24.0 \\
\hline & 8.2 & 29.9 & 64.8 & 152.3 & 55.8 & 28.9 & 55.7 & 24.0 \\
\hline & 9.2 & 34.9 & 69.7 & 160.0 & 68.8 & 32.2 & 65.0 & 13.5 \\
\hline & 10.2 & 34.1 & 74.6 & 163.0 & 82.4 & 35.6 & 77.4 & 10.0 \\
\hline & 11.2 & 35.1 & 79.5 & 170.0 & 94.9 & 38.7 & 82.0 & 10.5 \\
\hline & 12.2 & 23.3 & 84.4 & 182.3 & 107.3 & 41.8 & 87.7 & 10.5 \\
\hline & 13.2 & 21.1 & 89.3 & 185.0 & 111.8 & 42.9 & 83.9 & 10.0 \\
\hline \multirow[t]{3}{*}{ Loimaa } & 3.0 & 20.0 & 24.0 & 48.0 & 55.0 & 25.0 & 65.0 & 11.0 \\
\hline & 4.0 & 19.0 & 31.0 & 90.0 & 51.0 & 23.0 & 60.0 & 9.0 \\
\hline & 5.0 & 18.0 & 38.0 & 50.0 & 75.0 & 23.0 & 70.0 & 7.0 \\
\hline
\end{tabular}




\begin{tabular}{|c|c|c|c|c|c|c|c|c|}
\hline Location & Depth (m) & $s_{u}^{F V}(\mathrm{kPa})$ & $\sigma_{v}^{\prime}(\mathrm{kPa})$ & $\sigma_{p}^{\prime}(\mathrm{kPa})$ & LL (\%) & PL (\%) & $w(\%)$ & $S_{t}$ \\
\hline & 7.0 & 24.0 & 52.0 & 65.0 & 48.0 & 23.0 & 65.0 & 9.0 \\
\hline & 8.0 & 24.0 & 59.0 & 85.0 & 47.0 & 23.0 & 70.0 & 13.0 \\
\hline & 9.0 & 23.0 & 66.0 & 67.0 & 55.0 & 25.0 & 70.0 & 13.0 \\
\hline & 10.0 & 25.0 & 73.0 & 110.0 & 49.0 & 23.0 & 60.0 & 9.0 \\
\hline & 11.0 & 25.0 & 80.0 & 120.0 & 51.0 & 23.0 & 60.0 & 8.0 \\
\hline & 12.0 & 27.0 & 87.0 & 110.0 & 55.0 & 23.0 & 57.0 & 7.0 \\
\hline & 13.0 & 27.0 & 94.0 & 100.0 & 52.0 & 22.0 & 65.0 & 8.0 \\
\hline \multirow[t]{2}{*}{ Lokalahti } & 5.0 & 9.0 & 16.5 & 22.0 & 60.0 & 20.0 & 100.0 & 17.0 \\
\hline & 7.0 & 10.0 & 26.5 & 28.0 & 49.0 & 20.0 & 80.0 & 19.0 \\
\hline \multirow[t]{13}{*}{ Nurmijarvi } & 2.4 & 8.0 & 15.6 & 25.0 & 120.0 & 50.0 & 150.0 & 10.0 \\
\hline & 3.6 & 7.0 & 20.4 & 30.0 & 52.0 & 25.0 & 75.0 & 9.0 \\
\hline & 6.0 & 16.0 & 30.0 & 35.0 & 80.0 & 30.0 & 120.0 & 7.0 \\
\hline & 7.0 & 17.0 & 34.0 & 48.0 & 75.0 & 30.0 & 100.0 & 10.0 \\
\hline & 8.0 & 22.0 & 38.0 & 51.0 & 75.0 & 30.0 & 100.0 & 12.0 \\
\hline & 9.0 & 24.0 & 42.0 & 60.0 & 90.0 & 30.0 & 100.0 & 13.0 \\
\hline & 10.0 & 25.0 & 46.0 & 75.0 & 75.0 & 30.0 & 90.0 & 13.0 \\
\hline & 11.0 & 28.0 & 53.0 & 80.0 & 65.0 & 30.0 & 75.0 & 14.0 \\
\hline & 13.0 & 34.0 & 67.0 & 90.0 & 60.0 & 25.0 & 58.0 & 12.0 \\
\hline & 14.0 & 22.0 & 74.0 & 130.0 & 65.0 & 25.0 & 60.0 & 8.0 \\
\hline & 16.0 & 28.0 & 88.0 & 100.0 & 40.0 & 25.0 & 35.0 & 6.0 \\
\hline & 17.0 & 30.0 & 95.0 & 100.0 & 52.0 & 25.0 & 60.0 & 7.0 \\
\hline & 18.0 & 35.0 & 102.0 & 140.0 & 70.0 & 25.0 & 55.0 & 8.0 \\
\hline \multirow[t]{7}{*}{ Otaniemi } & 2.7 & 5.0 & 10.1 & 20.0 & 105.0 & 25.0 & 120.0 & 9.0 \\
\hline & 5.5 & 12.0 & 19.5 & 28.0 & 70.0 & 30.0 & 75.0 & 5.0 \\
\hline & 6.5 & 11.0 & 24.5 & 35.0 & 70.0 & 25.0 & 65.0 & 4.0 \\
\hline & 7.5 & 14.0 & 29.5 & 50.0 & 80.0 & 30.0 & 85.0 & 5.0 \\
\hline & 8.5 & 19.0 & 34.5 & 80.0 & 65.0 & 30.0 & 80.0 & 7.0 \\
\hline & 9.5 & 12.0 & 39.5 & 60.0 & 43.0 & 25.0 & 50.0 & 6.0 \\
\hline & 10.5 & 15.0 & 44.5 & 80.0 & 47.0 & 25.0 & 55.0 & 8.0 \\
\hline \multirow[t]{16}{*}{ Perniö (Location 1)* } & 2.2 & 9.30 & 28.9 & 74.3 & 79.0 & 32.0 & 75.0 & 14.0 \\
\hline & 2.7 & 10.20 & 31.4 & 62.6 & 74.0 & 32.0 & 78.5 & 18.6 \\
\hline & 2.6 & 12.20 & 31.0 & 64.7 & 75.0 & 32.0 & 80.8 & 19.1 \\
\hline & 2.7 & 13.60 & 31.6 & 61.5 & 82.0 & 32.0 & 97.6 & 22.9 \\
\hline & 2.1 & 19.10 & 28.5 & 73.8 & 76.0 & 32.0 & 88.0 & 25.2 \\
\hline & 5.1 & 12.80 & 43.5 & 61.5 & 65.0 & 32.0 & 80.1 & 30.7 \\
\hline & 3.1 & 9.30 & 33.5 & 51.5 & 65.0 & 32.0 & 83.0 & 32.0 \\
\hline & 2.2 & 18.60 & 29.1 & 73.9 & 46.0 & 32.0 & 61.7 & 32.7 \\
\hline & 5.7 & 11.60 & 46.4 & 64.4 & 58.0 & 32.0 & 80.9 & 33.7 \\
\hline & 3.6 & 9.90 & 36.0 & 54.0 & 63.0 & 32.0 & 86.0 & 35.0 \\
\hline & 4.2 & 12.80 & 39.1 & 57.1 & 64.0 & 32.0 & 90.0 & 35.5 \\
\hline & 5.2 & 15.40 & 44.1 & 62.1 & 64.0 & 32.0 & 70.9 & 35.6 \\
\hline & 6.1 & 13.30 & 48.5 & 66.5 & 38.0 & 32.0 & 47.9 & 36.7 \\
\hline & 4.7 & 14.80 & 41.6 & 59.6 & 55.0 & 32.0 & 88.2 & 37.4 \\
\hline & 3.2 & 11.30 & 33.9 & 51.9 & 60.0 & 32.0 & 82.3 & 39.1 \\
\hline & 3.7 & 6.40 & 36.4 & 54.4 & 51.0 & 32.0 & 77.5 & 39.4 \\
\hline
\end{tabular}




\begin{tabular}{|c|c|c|c|c|c|c|c|c|}
\hline Location & Depth (m) & $s_{u}^{F V}(\mathrm{kPa})$ & $\sigma_{v}^{\prime}(\mathrm{kPa})$ & $\sigma_{p}^{\prime}(\mathrm{kPa})$ & $\operatorname{LL}(\%)$ & PL (\%) & $w(\%)$ & $S_{t}$ \\
\hline & 4.6 & 10.70 & 41.0 & 59.0 & 76.0 & 32.0 & 96.6 & 41.3 \\
\hline & 4.7 & 11.60 & 41.4 & 59.4 & 51.0 & 32.0 & 72.6 & 45.7 \\
\hline & 4.1 & 10.40 & 38.5 & 56.5 & 50.0 & 32.0 & 69.6 & 45.7 \\
\hline & 3.7 & 16.00 & 36.6 & 54.6 & 50.0 & 32.0 & 74.4 & 46.3 \\
\hline & 5.2 & 9.90 & 43.9 & 61.9 & 59.0 & 32.0 & 84.1 & 46.5 \\
\hline & 3.2 & 12.50 & 34.1 & 52.1 & 45.0 & 32.0 & 70.6 & 49.4 \\
\hline & 5.7 & 16.80 & 46.6 & 64.6 & 54.0 & 32.0 & 80.1 & 51.1 \\
\hline & 4.2 & 11.30 & 38.9 & 56.9 & 51.0 & 32.0 & 72.0 & 51.3 \\
\hline & 5.6 & 11.30 & 46.0 & 64.0 & 50.0 & 32.0 & 75.9 & 57.7 \\
\hline \multirow[t]{20}{*}{ Perniö (Location 2)* } & 1.5 & 38.0 & 19.0 & 64.0 & 89.9 & 36.0 & 58.9 & 64.0 \\
\hline & 2.5 & 10.0 & 24.2 & 44.2 & 89.9 & 36.0 & 110.0 & 58.0 \\
\hline & 3.0 & 8.7 & 26.4 & 41.4 & 86.3 & 36.0 & 104.0 & 55.5 \\
\hline & 3.5 & 7.5 & 28.6 & 38.6 & 71.1 & 36.0 & 94.0 & 53.5 \\
\hline & 4.0 & 8.7 & 30.8 & 40.8 & 60.2 & 36.0 & 84.0 & 52.3 \\
\hline & 4.5 & 10.0 & 33.0 & 43.0 & 58.2 & 36.0 & 75.0 & 51.4 \\
\hline & 5.0 & 11.0 & 35.2 & 45.2 & 54.1 & 36.0 & 80.0 & 50.4 \\
\hline & 5.5 & 15.0 & 37.4 & 47.4 & 50.4 & 36.0 & 75.0 & 47.5 \\
\hline & 6.0 & 17.0 & 39.6 & 49.6 & 52.0 & 36.0 & 80.0 & 43.8 \\
\hline & 6.5 & 14.0 & 41.8 & 51.8 & 66.9 & 36.0 & 92.0 & 39.2 \\
\hline & 7.0 & 16.0 & 44.0 & 54.0 & 75.5 & 36.0 & 84.0 & 39.5 \\
\hline & 7.5 & 17.0 & 46.2 & 56.2 & 75.9 & 36.0 & 88.0 & 40.0 \\
\hline & 8.0 & 15.0 & 48.4 & 58.4 & 76.3 & 36.0 & 87.0 & 40.0 \\
\hline & 8.5 & 16.5 & 50.6 & 60.6 & 76.7 & 36.0 & 86.0 & 45.0 \\
\hline & 9.0 & 15.0 & 52.8 & 62.8 & 77.2 & 36.0 & 88.0 & 45.0 \\
\hline & 9.5 & 21.0 & 55.0 & 65.0 & 77.2 & 36.0 & 85.0 & 40.0 \\
\hline & 2.0 & 13.0 & 21.5 & 45.0 & 75.0 & 25.0 & 75.0 & 11.0 \\
\hline & 3.0 & 10.0 & 27.0 & 30.0 & 75.0 & 30.0 & 75.0 & 20.0 \\
\hline & 5.0 & 16.0 & 38.0 & 60.0 & 51.0 & 25.0 & 75.0 & 21.0 \\
\hline & 6.0 & 18.0 & 43.5 & 65.0 & 49.0 & 30.0 & 65.0 & 20.0 \\
\hline \multirow[t]{5}{*}{ Raisio, Autolava } & 0.8 & 49.0 & 19.8 & 125.0 & 50.0 & 20.0 & 40.0 & 3.0 \\
\hline & 1.5 & 13.0 & 18.5 & 39.0 & 70.0 & 20.0 & 70.0 & 10.0 \\
\hline & 2.5 & 10.0 & 24.5 & 50.0 & 70.0 & 23.0 & 90.0 & 9.0 \\
\hline & 3.0 & 12.0 & 27.0 & 38.0 & 75.0 & 25.0 & 90.0 & 8.0 \\
\hline & 4.0 & 14.0 & 32.0 & 40.0 & 100.0 & 27.0 & 130.0 & 10.0 \\
\hline \multirow[t]{9}{*}{ Raisio, Krookila } & 2.5 & 13.0 & 26.3 & 60.0 & 85.0 & 25.0 & 87.0 & 11.0 \\
\hline & 3.5 & 11.0 & 30.8 & 40.0 & 80.0 & 25.0 & 90.0 & 12.0 \\
\hline & 4.5 & 12.0 & 35.3 & 48.0 & 85.0 & 25.0 & 80.0 & 9.0 \\
\hline & 5.5 & 17.0 & 39.8 & 47.0 & 125.0 & 30.0 & 130.0 & 10.0 \\
\hline & 6.5 & 25.0 & 44.3 & 50.0 & 120.0 & 25.0 & 120.0 & 10.0 \\
\hline & 7.5 & 23.0 & 48.8 & 50.0 & 110.0 & 25.0 & 110.0 & 9.0 \\
\hline & 8.5 & 22.0 & 53.3 & 60.0 & 100.0 & 25.0 & 95.0 & 10.0 \\
\hline & 9.5 & 22.0 & 57.8 & 90.0 & 100.0 & 25.0 & 95.0 & 8.0 \\
\hline & 10.5 & 23.0 & 62.3 & 80.0 & 85.0 & 25.0 & 80.0 & 8.0 \\
\hline \multirow[t]{2}{*}{ Raisio, Ristimaki } & 0.5 & 10.0 & 7.5 & 30.0 & 70.0 & 30.0 & 70.0 & 12.0 \\
\hline & 1.5 & 10.0 & 12.5 & 35.0 & 75.0 & 40.0 & 85.0 & 9.0 \\
\hline
\end{tabular}




\begin{tabular}{|c|c|c|c|c|c|c|c|c|}
\hline Location & Depth (m) & $s_{u}^{F V}(\mathrm{kPa})$ & $\sigma_{v}^{\prime}(\mathrm{kPa})$ & $\sigma_{p}^{\prime}(\mathrm{kPa})$ & LL $(\%)$ & PL $(\%)$ & $w(\%)$ & $S_{t}$ \\
\hline & 2.5 & 10.0 & 17.5 & 35.0 & 80.0 & 45.0 & 95.0 & 12.0 \\
\hline & 3.5 & 17.0 & 22.5 & 50.0 & 65.0 & 25.0 & 100.0 & 10.0 \\
\hline & 5.5 & 15.0 & 32.5 & 43.0 & 70.0 & 35.0 & 80.0 & 11.0 \\
\hline & 8.0 & 18.0 & 45.0 & 50.0 & 55.0 & 30.0 & 75.0 & 9.0 \\
\hline \multirow[t]{4}{*}{ Raisio, Siirinpelto } & 3.5 & 7.0 & 29.5 & 50.0 & 48.0 & 20.0 & 85.0 & 10.0 \\
\hline & 4.5 & 8.0 & 34.5 & 52.0 & 49.0 & 20.0 & 80.0 & 10.0 \\
\hline & 6.0 & 9.5 & 42.0 & 90.0 & 35.0 & 20.0 & 37.0 & 10.0 \\
\hline & 7.5 & 10.0 & 49.5 & 90.0 & 30.0 & 20.0 & 52.0 & 11.0 \\
\hline \multirow[t]{7}{*}{ Saimaan kanava } & 3.0 & 30.0 & 31.0 & 120.0 & 80.0 & 27.0 & 60.0 & 8.0 \\
\hline & 4.0 & 30.0 & 37.0 & 80.0 & 100.0 & 30.0 & 110.0 & 7.5 \\
\hline & 5.0 & 20.0 & 43.0 & 80.0 & 55.0 & 25.0 & 65.0 & 7.0 \\
\hline & 6.0 & 20.0 & 49.0 & 85.0 & 32.0 & 22.0 & 70.0 & 10.0 \\
\hline & 7.0 & 18.0 & 55.0 & 90.0 & 35.0 & 25.0 & 50.0 & 9.0 \\
\hline & 8.0 & 25.0 & 61.0 & 80.0 & 55.0 & 25.0 & 65.0 & 7.0 \\
\hline & 9.0 & 30.0 & 67.0 & 110.0 & 60.0 & 25.0 & 75.0 & 6.0 \\
\hline \multirow[t]{3}{*}{ Salo, Salonkyla } & 10.0 & 18.0 & 50.0 & 50.0 & 105.0 & 25.0 & 100.0 & 10.0 \\
\hline & 16.0 & 28.0 & 80.0 & 100.0 & 90.0 & 25.0 & 85.0 & 16.0 \\
\hline & 20.0 & 28.0 & 100.0 & 160.0 & 90.0 & 25.0 & 75.0 & 10.0 \\
\hline \multirow[t]{10}{*}{ Sipoo } & 1.0 & 47.0 & 16.0 & 120.0 & 60.0 & 35.0 & 50.0 & 10.0 \\
\hline & 1.5 & 20.0 & 20.5 & 80.0 & 85.0 & 25.0 & 80.0 & 9.0 \\
\hline & 3.5 & 24.0 & 32.5 & 80.0 & 80.0 & 25.0 & 85.0 & 12.5 \\
\hline & 4.5 & 21.0 & 37.5 & 78.0 & 75.0 & 25.0 & 75.0 & 11.5 \\
\hline & 5.5 & 20.0 & 42.5 & 90.0 & 70.0 & 25.0 & 80.0 & 10.5 \\
\hline & 6.5 & 20.0 & 47.5 & 80.0 & 49.9 & 25.0 & 65.0 & 10.0 \\
\hline & 7.5 & 21.0 & 52.5 & 125.0 & 44.0 & 25.0 & 60.0 & 9.0 \\
\hline & 10.0 & 16.0 & 42.0 & 42.0 & 85.0 & 25.0 & 85.0 & 8.0 \\
\hline & 12.0 & 17.0 & 52.0 & 67.0 & 75.0 & 25.0 & 80.0 & 10.0 \\
\hline & 14.6 & 24.0 & 65.0 & 70.0 & 100.0 & 25.0 & 85.0 & 11.0 \\
\hline \multirow[t]{11}{*}{ Somero, Joenssu } & 1.0 & 45.0 & 17.0 & 100.0 & 85.0 & 30.0 & 60.0 & 7.0 \\
\hline & 2.0 & 23.0 & 25.0 & 60.0 & 100.0 & 25.0 & 90.0 & 15.0 \\
\hline & 4.0 & 20.0 & 35.0 & 55.0 & 100.0 & 25.0 & 110.0 & 13.0 \\
\hline & 6.0 & 28.0 & 45.0 & 75.0 & 80.0 & 25.0 & 110.0 & 14.0 \\
\hline & 8.0 & 23.0 & 55.0 & 85.0 & 80.0 & 30.0 & 110.0 & 15.0 \\
\hline & 10.0 & 27.0 & 65.0 & 95.0 & 70.0 & 25.0 & 80.0 & 13.0 \\
\hline & 12.0 & 28.0 & 79.0 & 98.0 & 60.0 & 23.0 & 75.0 & 16.0 \\
\hline & 14.0 & 33.0 & 93.0 & 100.0 & 52.0 & 23.0 & 70.0 & 10.0 \\
\hline & 18.0 & 40.0 & 121.0 & 180.0 & 60.0 & 23.0 & 60.0 & 13.0 \\
\hline & 20.0 & 43.0 & 135.0 & 175.0 & 50.0 & 23.0 & 60.0 & 8.0 \\
\hline & 24.0 & 51.0 & 163.0 & 220.0 & 60.0 & 25.0 & 50.0 & 7.0 \\
\hline \multirow[t]{4}{*}{ Somero, Kirkonkyla } & 4.0 & 35.0 & 39.0 & 130.0 & 75.0 & 27.0 & 70.0 & 14.0 \\
\hline & 5.0 & 33.0 & 45.0 & 115.0 & 80.0 & 25.0 & 75.0 & 17.0 \\
\hline & 6.0 & 31.0 & 51.0 & 75.0 & 70.0 & 25.0 & 70.0 & 16.0 \\
\hline & 7.0 & 31.0 & 57.0 & 110.0 & 75.0 & 24.0 & 75.0 & 13.0 \\
\hline
\end{tabular}




\begin{tabular}{|c|c|c|c|c|c|c|c|c|}
\hline Location & Depth (m) & $s_{u}^{F V}(\mathrm{kPa})$ & $\sigma_{v}^{\prime}(\mathrm{kPa})$ & $\sigma_{p}^{\prime}(\mathrm{kPa})$ & LL $(\%)$ & PL $(\%)$ & $w(\%)$ & $S_{t}$ \\
\hline & 8.0 & 33.0 & 64.0 & 110.0 & 55.0 & 23.0 & 65.0 & 12.0 \\
\hline & 11.0 & 42.0 & 85.0 & 150.0 & 60.0 & 24.0 & 55.0 & 8.0 \\
\hline & 12.0 & 45.0 & 92.0 & 230.0 & 46.0 & 23.0 & 55.0 & 7.0 \\
\hline \multirow[t]{10}{*}{ Somero, Pajulanjoki } & 4.0 & 19.0 & 21.0 & 70.0 & 80.0 & 27.0 & 110.0 & 12.0 \\
\hline & 5.0 & 17.0 & 25.0 & 79.0 & 75.0 & 27.0 & 100.0 & 13.0 \\
\hline & 6.0 & 23.0 & 29.0 & 80.0 & 75.0 & 27.0 & 100.0 & 22.0 \\
\hline & 7.0 & 23.0 & 33.0 & 90.0 & 75.0 & 27.0 & 100.0 & 18.0 \\
\hline & 8.0 & 25.0 & 37.0 & 62.0 & 80.0 & 25.0 & 85.0 & 18.0 \\
\hline & 9.0 & 27.0 & 42.0 & 105.0 & 75.0 & 25.0 & 80.0 & 12.0 \\
\hline & 10.0 & 28.0 & 47.0 & 110.0 & 75.0 & 27.0 & 85.0 & 17.0 \\
\hline & 11.0 & 30.0 & 52.0 & 120.0 & 70.0 & 25.0 & 80.0 & 20.0 \\
\hline & 12.0 & 31.0 & 57.0 & 135.0 & 70.0 & 25.0 & 80.0 & 10.0 \\
\hline & 13.0 & 32.0 & 62.0 & 100.0 & 65.0 & 25.0 & 75.0 & 21.0 \\
\hline \multirow[t]{13}{*}{ Tampere } & 1.5 & 75.0 & 33.0 & 180.0 & 70.0 & 27.0 & 70.0 & 9.0 \\
\hline & 2.5 & 37.0 & 40.0 & 190.0 & 52.0 & 27.0 & 40.0 & 6.0 \\
\hline & 3.0 & 24.0 & 43.5 & 80.0 & 55.0 & 27.0 & 40.0 & 9.0 \\
\hline & 3.5 & 18.0 & 47.0 & 60.0 & 60.0 & 25.0 & 70.0 & 17.0 \\
\hline & 4.0 & 16.0 & 50.5 & 55.0 & 47.0 & 27.0 & 62.0 & 14.0 \\
\hline & 4.5 & 17.0 & 54.0 & 70.0 & 40.0 & 25.0 & 60.0 & 20.0 \\
\hline & 5.0 & 13.0 & 57.5 & 75.0 & 35.0 & 28.0 & 45.0 & 11.0 \\
\hline & 5.5 & 14.0 & 61.0 & 77.0 & 32.0 & 25.0 & 42.0 & 10.0 \\
\hline & 6.0 & 22.0 & 64.5 & 80.0 & 35.0 & 27.0 & 50.0 & 8.0 \\
\hline & 6.5 & 21.0 & 68.0 & 68.0 & 51.0 & 25.0 & 55.0 & 16.0 \\
\hline & 7.0 & 35.0 & 71.5 & 130.0 & 35.0 & 25.0 & 60.0 & 14.0 \\
\hline & 7.5 & 42.0 & 75.0 & 115.0 & 31.0 & 26.0 & 50.0 & 9.0 \\
\hline & 8.0 & 37.0 & 78.5 & 220.0 & 37.0 & 32.0 & 40.0 & 11.0 \\
\hline \multirow[t]{9}{*}{ Vihti } & 3.0 & 20.0 & 23.0 & 55.0 & 35.0 & 15.0 & 35.0 & 10.0 \\
\hline & 4.0 & 23.0 & 30.0 & 85.0 & 75.0 & 50.0 & 80.0 & 16.0 \\
\hline & 6.0 & 21.0 & 44.0 & 85.0 & 60.0 & 30.0 & 65.0 & 7.0 \\
\hline & 9.0 & 18.0 & 65.0 & 70.0 & 25.0 & 10.0 & 30.0 & 11.0 \\
\hline & 10.0 & 26.0 & 72.0 & 95.0 & 40.0 & 20.0 & 45.0 & 7.0 \\
\hline & 11.0 & 29.0 & 79.0 & 97.0 & 55.0 & 30.0 & 57.0 & 6.0 \\
\hline & 12.0 & 32.0 & 86.0 & 120.0 & 48.0 & 25.0 & 52.0 & 9.0 \\
\hline & 13.0 & 34.0 & 93.0 & 100.0 & 52.0 & 25.0 & 55.0 & 10.0 \\
\hline & 14.0 & 37.0 & 100.0 & 115.0 & 51.0 & 25.0 & 55.0 & 10.0 \\
\hline \multirow[t]{10}{*}{ Viiala } & 3.0 & 22.0 & 23.8 & 45.0 & 65.0 & 25.0 & 75.0 & 8.5 \\
\hline & 4.0 & 22.0 & 29.3 & 40.0 & 48.0 & 25.0 & 60.0 & 9.0 \\
\hline & 4.5 & 20.0 & 32.0 & 75.0 & 75.0 & 25.0 & 80.0 & 8.0 \\
\hline & 6.0 & 25.0 & 40.3 & 90.0 & 52.0 & 25.0 & 70.0 & 8.5 \\
\hline & 6.5 & 22.0 & 43.0 & 100.0 & 85.0 & 30.0 & 95.0 & 11.0 \\
\hline & 7.0 & 35.0 & 45.8 & 95.0 & 100.0 & 35.0 & 100.0 & 14.0 \\
\hline & 8.0 & 32.0 & 51.3 & 120.0 & 85.0 & 35.0 & 90.0 & 14.0 \\
\hline & 8.5 & 42.0 & 54.0 & 110.0 & 80.0 & 30.0 & 90.0 & 11.0 \\
\hline & 9.0 & 43.0 & 56.8 & 125.0 & 77.0 & 35.0 & 80.0 & 16.6 \\
\hline & 9.5 & 55.0 & 59.5 & 130.0 & 95.0 & 25.0 & 80.0 & 15.0 \\
\hline
\end{tabular}




\begin{tabular}{lllllllll}
\hline Location & Depth $(\mathrm{m})$ & $S_{u}{ }^{F V}(\mathrm{kPa})$ & $\sigma_{v}^{\prime}(\mathrm{kPa})$ & $\sigma_{p}^{\prime}(\mathrm{kPa})$ & $\operatorname{LL}(\%)$ & PL $(\%)$ & $w(\%)$ & $S_{t}$ \\
\hline & 15.0 & 43.0 & 90.5 & 95.0 & 80.0 & 30.0 & 65.0 & 6.0 \\
& 14.0 & 32.0 & 83.5 & 83.5 & 75.0 & 30.0 & 60.0 & 6.0 \\
\hline
\end{tabular}

${ }^{*} \sigma_{p}^{\prime}$ data points from CRS oedometer test.

\section{S-CLAY/7/168 database}

Table A.1. Basic information of the S-CLAY/7/168 database. $\sigma_{p}^{\prime}$ data points from CRS oedometer test.

\begin{tabular}{|c|c|c|c|c|c|c|c|c|}
\hline Location & Depth (m) & $s_{u}^{F V}(\mathrm{kPa})$ & $\sigma_{v}^{\prime}(\mathrm{kPa})$ & $\sigma_{p}^{\prime}(\mathrm{kPa})$ & LL (\%) & PL (\%) & $w(\%)$ & $S_{t}$ \\
\hline \multirow[t]{16}{*}{ Drammen (Norway) } & 4.0 & 8.3 & 41.2 & 57.4 & 39.3 & 9.7 & 30.7 & 3.0 \\
\hline & 5.2 & 11.8 & 50.4 & 78.7 & 58.7 & 10.3 & 65.5 & 3.0 \\
\hline & 6.2 & 11.7 & 57.8 & 89.6 & 65.6 & 18.8 & 65.6 & 3.0 \\
\hline & 7.1 & 12.3 & 64.7 & 98.5 & 75.2 & 20.6 & 56.2 & 3.0 \\
\hline & 7.5 & 13.0 & 67.1 & 100.0 & 88.5 & 18.7 & 65.3 & 3.0 \\
\hline & 7.5 & 22.8 & 68.0 & 95.2 & 88.0 & 18.0 & 65.0 & 6.0 \\
\hline & 7.8 & 25.2 & 70.0 & 105.0 & 60.0 & 29.0 & 52.0 & 8.0 \\
\hline & 8.5 & 20.6 & 74.5 & 114.4 & 75.8 & 15.4 & 61.7 & 3.0 \\
\hline & 8.5 & 12.3 & 74.5 & 114.4 & 75.8 & 15.4 & 61.7 & 3.0 \\
\hline & 9.0 & 13.7 & 78.7 & 124.3 & 78.2 & 19.1 & 58.2 & 3.0 \\
\hline & 9.3 & 11.2 & 80.0 & 104.0 & 33.0 & 23.0 & 32.0 & 8.0 \\
\hline & 9.4 & 20.9 & 81.5 & 113.4 & 92.2 & 20.4 & 64.1 & 3.0 \\
\hline & 11.9 & 10.0 & 102.6 & 108.0 & 40.2 & 8.8 & 27.6 & 7.0 \\
\hline & 13.0 & 20.8 & 112.5 & 135.0 & 25.0 & 3.0 & 26.0 & 6.0 \\
\hline & 13.0 & 14.0 & 112.5 & 129.3 & 25.0 & 3.0 & 25.7 & 7.0 \\
\hline & 17.4 & 19.0 & 152.6 & 182.3 & 23.3 & 2.7 & 17.3 & 7.0 \\
\hline Ellingsrud (Norway) & 10.5 & 7.8 & 60.0 & 60.0 & 24.0 & 20.0 & 36.0 & 42.5 \\
\hline $\begin{array}{l}\text { Fredrikstad } \\
\text { (Norway) }\end{array}$ & 6.5 & 10.8 & 43.0 & 47.3 & 34.0 & 21.0 & 40.5 & 20.0 \\
\hline Haga (Norway) & 2.8 & 41.6 & 52.0 & 315.6 & 41.1 & 26.3 & 37.9 & \\
\hline
\end{tabular}




\begin{tabular}{|c|c|c|c|c|c|c|c|c|}
\hline Location & Depth (m) & $s_{u}^{F V}(\mathrm{kPa})$ & $\sigma_{v}^{\prime}(\mathrm{kPa})$ & $\sigma_{p}^{\prime}(\mathrm{kPa})$ & $\operatorname{LL}(\%)$ & PL (\%) & $w(\%)$ & $S_{t}$ \\
\hline \multirow{18}{*}{ Onsøy (Norway) } & 2.8 & 40.4 & 53.0 & 282.5 & 40.6 & 27.5 & 38.8 & \\
\hline & 3.9 & 40.3 & 72.0 & 274.3 & 40.8 & 26.1 & 36.9 & \\
\hline & 4.9 & 45.0 & 92.0 & 296.2 & 62.5 & 28.2 & 54.2 & \\
\hline & 5.2 & 48.7 & 97.0 & 257.1 & 68.0 & 29.6 & 60.7 & \\
\hline & 6.2 & 39.3 & 115.0 & 310.5 & 40.4 & 25.4 & 36.5 & \\
\hline & 6.5 & 39.3 & 121.0 & 150.0 & 39.0 & 25.4 & 34.4 & \\
\hline & 1.9 & 10.8 & 12.2 & 61.1 & 50.2 & 32.1 & 65.1 & 3.0 \\
\hline & 2.1 & 12.7 & 13.9 & 58.4 & 65.2 & 32.1 & 67.1 & 3.0 \\
\hline & 3.5 & 11.8 & 22.4 & 48.2 & 59.9 & 29.4 & 57.6 & 3.0 \\
\hline & 5.2 & 12.1 & 32.6 & 45.1 & 56.8 & 33.9 & 58.5 & 3.0 \\
\hline & 5.5 & 12.0 & 34.3 & 46.1 & 56.4 & 34.0 & 58.9 & 3.0 \\
\hline & 7.6 & 12.9 & 47.5 & 54.3 & 66.3 & 34.8 & 62.3 & 3.0 \\
\hline & 7.9 & 13.5 & 48.9 & 56.3 & 66.2 & 34.9 & 65.8 & 3.0 \\
\hline & 10.8 & 17.6 & 66.2 & 85.2 & 74.4 & 38.3 & 67.5 & 7.0 \\
\hline & 11.0 & 19.5 & 67.5 & 86.9 & 72.9 & 36.8 & 69.4 & 7.0 \\
\hline & 13.4 & 22.2 & 82.2 & 106.3 & 71.4 & 35.6 & 66.7 & 7.0 \\
\hline & 13.6 & 22.0 & 83.5 & 107.0 & 71.5 & 35.6 & 68.9 & 7.0 \\
\hline & 16.3 & 27.4 & 99.8 & 100.2 & 72.7 & 37.9 & 64.5 & 7.0 \\
\hline \multirow{2}{*}{$\begin{array}{l}\text { Studenterlunden } \\
\text { (Norway) }\end{array}$} & 15.0 & 16.5 & 87.0 & 108.8 & 37.0 & 20.0 & 33.0 & 5.0 \\
\hline & 15.0 & 17.0 & 87.0 & 87.0 & 44.0 & 25.0 & 37.4 & 4.0 \\
\hline Sundland (Norway) & 6.5 & 15.1 & 43.0 & 55.9 & 58.0 & 30.0 & 59.0 & 11.0 \\
\hline \multirow{5}{*}{$\begin{array}{l}\text { Unknown location } 1 \\
\text { (Norway) }\end{array}$} & 3.1 & 14.8 & 21.4 & 49.1 & 56.1 & 29.2 & 59.2 & \\
\hline & 5.0 & 14.6 & 31.3 & 56.2 & 58.8 & 30.2 & 61.2 & \\
\hline & 7.0 & 13.1 & 43.4 & 64.8 & 63.6 & 31.6 & 68.3 & \\
\hline & 9.2 & 17.6 & 54.8 & 96.8 & 71.3 & 27.9 & 68.7 & \\
\hline & 10.0 & 17.9 & 61.2 & 83.3 & 68.6 & 27.9 & 68.9 & \\
\hline \multirow{4}{*}{$\begin{array}{l}\text { Unknown location } 2 \\
\text { (Norway) }\end{array}$} & 4.5 & 16.6 & 34.6 & 142.5 & 22.8 & 18.9 & 40.3 & \\
\hline & 6.0 & 17.9 & 42.7 & 119.0 & 29.0 & 17.2 & 44.3 & \\
\hline & 7.5 & 14.6 & 52.3 & 123.5 & 25.8 & 19.8 & 41.1 & \\
\hline & 8.0 & 11.4 & 54.6 & 130.1 & 24.8 & 20.7 & 41.3 & \\
\hline Vaterland (Norway) & 7.5 & 24.4 & 52.0 & 52.0 & 47.0 & 27.0 & 40.0 & 5.0 \\
\hline \multirow[t]{8}{*}{ Bäckebol (Sweden) } & 9.1 & 18.2 & 55.4 & 81.8 & 87.1 & 32.1 & 74.7 & 15.0 \\
\hline & 11.1 & 26.6 & 66.6 & 75.1 & 85.6 & 37.3 & 94.9 & 24.0 \\
\hline & 13.1 & 32.1 & 78.7 & 84.1 & 86.1 & 39.9 & 89.2 & \\
\hline & 14.1 & 33.2 & 84.7 & 226.6 & 89.7 & 38.4 & 93.3 & \\
\hline & 15.1 & 34.3 & 91.6 & 177.0 & 89.2 & 38.4 & 92.8 & \\
\hline & 4.0 & 17.7 & 26.7 & 36.1 & 85.8 & 25.3 & 78.4 & 11.0 \\
\hline & 6.0 & 16.3 & 36.4 & 44.5 & 84.7 & 31.1 & 103.1 & 32.0 \\
\hline & 7.0 & 16.5 & 41.5 & 51.6 & 83.0 & 35.1 & 88.1 & 28.0 \\
\hline \multirow[t]{3}{*}{ Göta Alv (Sweden) } & 2.6 & 12.7 & 20.5 & 45.6 & 76.5 & 33.2 & 85.3 & \\
\hline & 3.0 & 13.4 & 23.1 & 42.7 & 75.8 & 33.9 & 84.4 & \\
\hline & 3.5 & 13.1 & 26.1 & 41.8 & 75.2 & 34.2 & 83.4 & \\
\hline
\end{tabular}




\begin{tabular}{|c|c|c|c|c|c|c|c|c|}
\hline Location & Depth (m) & $s_{u}^{F V}(\mathrm{kPa})$ & $\sigma_{v}^{\prime}(\mathrm{kPa})$ & $\sigma_{p}^{\prime}(\mathrm{kPa})$ & $\operatorname{LL}(\%)$ & PL (\%) & $w(\%)$ & $S_{t}$ \\
\hline & 3.9 & 13.1 & 28.2 & 53.0 & 72.7 & 34.6 & 82.4 & \\
\hline & 4.5 & 12.8 & 32.0 & 47.1 & 70.3 & 35.2 & 83.0 & \\
\hline & 5.0 & 12.7 & 34.4 & 53.6 & 78.8 & 35.9 & 92.2 & \\
\hline & 5.5 & 12.5 & 37.3 & 60.1 & 82.1 & 35.9 & 98.1 & \\
\hline & 5.9 & 12.5 & 39.4 & 69.0 & 75.8 & 33.2 & 93.8 & \\
\hline & 6.9 & 12.6 & 46.2 & 63.4 & 69.6 & 32.6 & 83.4 & \\
\hline & 7.9 & 13.3 & 51.8 & 65.4 & 65.7 & 31.3 & 79.4 & \\
\hline & 8.9 & 14.7 & 56.9 & 63.4 & 78.1 & 35.5 & 83.0 & \\
\hline \multirow[t]{3}{*}{ Järva Krog (Sweden) } & 5.0 & 18.6 & 48.8 & 72.0 & 88.1 & 37.7 & 93.2 & 26.0 \\
\hline & 7.0 & 21.1 & 61.7 & 69.5 & 51.4 & 24.4 & 57.5 & 20.0 \\
\hline & 9.0 & 25.8 & 74.4 & 79.5 & 50.4 & 23.9 & 62.6 & 23.0 \\
\hline \multirow[t]{3}{*}{ Kalix (Sweden) } & 2.0 & 13.5 & 15.0 & 40.1 & 201.8 & 73.9 & 180.1 & 17.0 \\
\hline & 3.0 & 14.8 & 16.5 & 31.8 & 191.3 & 70.4 & 176.0 & 15.0 \\
\hline & 5.0 & 15.8 & 23.2 & 37.8 & 157.8 & 61.0 & 136.1 & 10.0 \\
\hline \multicolumn{9}{|l|}{ Lilla Mellösa } \\
\hline \multirow{15}{*}{ (Sweden) } & 2.8 & 8.4 & 18.4 & 21.1 & 129.7 & 47.0 & 122.6 & \\
\hline & 3.6 & 8.6 & 21.8 & 25.3 & 124.2 & 43.7 & 114.9 & \\
\hline & 4.2 & 9.4 & 24.7 & 28.5 & 119.3 & 41.0 & 111.1 & \\
\hline & 5.0 & 10.3 & 28.3 & 32.6 & 110.0 & 38.2 & 108.3 & \\
\hline & 5.7 & 10.8 & 31.9 & 35.9 & 105.1 & 36.0 & 100.7 & \\
\hline & 6.4 & 11.2 & 35.2 & 40.2 & 100.7 & 31.7 & 97.4 & \\
\hline & 7.1 & 12.1 & 39.2 & 45.1 & 93.0 & 30.0 & 95.2 & \\
\hline & 7.9 & 13.2 & 43.4 & 49.9 & 84.8 & 27.3 & 83.1 & \\
\hline & 8.5 & 14.2 & 47.0 & 54.3 & 82.1 & 26.2 & 82.6 & \\
\hline & 9.0 & 17.0 & 50.0 & 65.0 & 76.0 & 25.0 & 69.9 & 17.5 \\
\hline & 9.1 & 15.3 & 50.5 & 58.4 & 78.8 & 25.1 & 78.2 & \\
\hline & 9.9 & 17.4 & 55.3 & 64.4 & 73.8 & 22.3 & 72.2 & \\
\hline & 10.7 & 18.4 & 61.2 & 71.5 & 71.1 & 23.4 & 71.1 & \\
\hline & 11.5 & 18.6 & 67.5 & 79.1 & 73.3 & 22.3 & 74.4 & \\
\hline & 12.4 & 18.6 & 74.8 & 86.7 & 73.3 & 22.9 & 83.1 & \\
\hline \multirow[t]{11}{*}{ Munkedal (Sweden) } & 3.2 & 25.0 & 37.7 & 126.6 & 65.1 & 31.3 & 98.9 & \\
\hline & 4.1 & 22.7 & 45.4 & 105.0 & 64.0 & 31.0 & 97.0 & \\
\hline & 6.1 & 31.6 & 63.5 & 102.9 & 61.6 & 30.4 & 92.7 & \\
\hline & 7.2 & 22.1 & 73.3 & 122.8 & 60.3 & 30.1 & 90.4 & \\
\hline & 8.1 & 22.7 & 82.2 & 135.5 & 59.2 & 29.8 & 88.5 & \\
\hline & 9.2 & 29.2 & 91.9 & 132.9 & 57.9 & 29.5 & 86.3 & \\
\hline & 10.1 & 30.9 & 100.3 & 143.5 & 56.7 & 29.2 & 84.2 & \\
\hline & 12.2 & 28.7 & 120.7 & 149.8 & 54.1 & 28.5 & 79.7 & \\
\hline & 16.2 & 33.5 & 160.4 & 184.5 & 49.3 & 27.3 & 71.2 & \\
\hline & 17.1 & 34.4 & 169.7 & 215.4 & 48.1 & 27.0 & 69.2 & \\
\hline & 21.2 & 31.5 & 212.9 & 240.8 & 43.1 & 25.8 & 60.4 & \\
\hline $\begin{array}{l}\text { Nörrkaping } \\
\text { (Sweden) }\end{array}$ & 2.1 & 10.9 & 27.5 & 42.8 & 82.0 & 35.5 & 85.0 & \\
\hline
\end{tabular}




\begin{tabular}{|c|c|c|c|c|c|c|c|c|}
\hline Location & Depth (m) & $s_{u}^{F V}(\mathrm{kPa})$ & $\sigma_{v}^{\prime}(\mathrm{kPa})$ & $\sigma_{p}^{\prime}(\mathrm{kPa})$ & $\operatorname{LL}(\%)$ & PL (\%) & $w(\%)$ & $S_{t}$ \\
\hline & 2.9 & 10.0 & 31.2 & 42.8 & 83.0 & 35.8 & 120.0 & \\
\hline & 3.4 & 10.3 & 33.9 & 43.8 & 79.0 & 34.8 & 115.0 & \\
\hline & 4.1 & 10.6 & 37.5 & 45.8 & 75.0 & 33.8 & 110.0 & \\
\hline & 4.7 & 11.2 & 40.2 & 48.5 & 60.0 & 30.0 & 85.0 & \\
\hline & 5.3 & 12.0 & 43.1 & 50.8 & 65.0 & 31.3 & 77.0 & \\
\hline & 5.9 & 13.1 & 45.8 & 54.4 & 70.0 & 32.5 & 70.0 & \\
\hline & 6.6 & 14.3 & 49.5 & 59.1 & 71.0 & 32.8 & 82.0 & \\
\hline & 7.3 & 15.6 & 52.4 & 64.7 & 72.0 & 33.0 & 95.0 & \\
\hline & 7.8 & 16.1 & 55.1 & 69.4 & 71.0 & 32.8 & 90.0 & \\
\hline & 8.6 & 16.5 & 59.1 & 78.3 & 70.0 & 32.5 & 85.0 & \\
\hline & 9.4 & 16.7 & 64.1 & 89.6 & 60.0 & 30.0 & 65.0 & \\
\hline & 10.3 & 16.9 & 69.0 & 101.6 & 70.0 & 32.5 & 72.0 & \\
\hline & 11.1 & 16.9 & 74.7 & 113.5 & 35.0 & 23.8 & 40.0 & \\
\hline & 12.0 & 17.0 & 80.3 & 125.8 & 40.0 & 25.0 & 40.0 & \\
\hline & 12.9 & 17.5 & 86.0 & 136.1 & 40.0 & 25.0 & 40.0 & \\
\hline \multirow[t]{6}{*}{ Skå-Edeby (Sweden) } & 10.0 & 15.6 & 60.0 & 84.0 & 51.0 & 23.0 & 63.0 & 20.0 \\
\hline & 2.0 & 11.1 & 12.5 & 24.1 & 126.1 & 58.5 & 122.5 & 8.0 \\
\hline & 4.0 & 6.9 & 21.0 & 24.9 & 66.4 & 30.2 & 95.9 & 18.0 \\
\hline & 6.0 & 10.5 & 31.5 & 38.1 & 51.3 & 24.1 & 71.8 & 14.0 \\
\hline & 8.0 & 13.8 & 44.7 & 40.1 & 55.5 & 26.6 & 73.0 & 23.0 \\
\hline & 9.9 & 15.0 & 59.1 & 59.5 & 50.7 & 24.1 & 64.6 & 21.0 \\
\hline \multirow[t]{7}{*}{ Stora an (Sweden) } & 1.5 & 10.2 & 10.4 & 43.8 & 113.8 & 40.0 & 107.8 & \\
\hline & 2.0 & 8.9 & 11.3 & 26.0 & 115.3 & 40.7 & 109.3 & \\
\hline & 2.3 & 8.2 & 11.9 & 24.0 & 125.0 & 54.2 & 122.8 & \\
\hline & 3.1 & 7.2 & 14.0 & 18.7 & 118.3 & 42.2 & 117.5 & \\
\hline & 3.8 & 7.1 & 16.4 & 20.2 & 123.5 & 37.7 & 113.8 & \\
\hline & 4.6 & 9.0 & 19.6 & 28.9 & 104.1 & 46.0 & 107.1 & \\
\hline & 5.3 & 11.3 & 22.8 & 31.7 & 104.9 & 41.5 & 103.4 & \\
\hline \multirow{16}{*}{$\begin{array}{l}\text { Svartiolandet } \\
\text { (Sweden) }\end{array}$} & 2.0 & 8.8 & 14.0 & 36.0 & 92.5 & 32.4 & 91.3 & \\
\hline & 2.5 & 8.5 & 16.2 & 33.1 & 81.2 & 27.6 & 87.7 & \\
\hline & 3.0 & 8.4 & 18.4 & 31.6 & 76.4 & 24.6 & 80.6 & \\
\hline & 3.7 & 8.3 & 22.1 & 31.6 & 70.5 & 26.4 & 78.8 & \\
\hline & 4.3 & 8.2 & 25.0 & 32.4 & 68.7 & 26.4 & 78.8 & \\
\hline & 4.9 & 8.5 & 28.3 & 34.9 & 67.5 & 27.0 & 78.8 & \\
\hline & 5.5 & 9.3 & 32.0 & 37.9 & 58.0 & 24.0 & 74.6 & \\
\hline & 6.0 & 9.7 & 36.0 & 41.2 & 53.2 & 20.5 & 65.7 & \\
\hline & 6.4 & 10.3 & 37.9 & 43.4 & 51.4 & 20.5 & 65.1 & \\
\hline & 6.8 & 11.0 & 40.1 & 46.3 & 49.6 & 19.3 & 63.9 & \\
\hline & 7.3 & 11.9 & 43.4 & 51.1 & 49.6 & 19.3 & 63.9 & \\
\hline & 7.9 & 13.0 & 46.3 & 55.5 & 49.6 & 21.0 & 62.1 & \\
\hline & 8.5 & 13.7 & 50.4 & 60.7 & 49.6 & 21.0 & 60.9 & \\
\hline & 9.0 & 14.6 & 54.4 & 65.4 & 49.0 & 19.3 & 59.7 & \\
\hline & 9.6 & 15.5 & 58.1 & 71.3 & 49.0 & 19.9 & 58.0 & \\
\hline & 10.3 & 16.8 & 62.5 & 76.8 & 51.4 & 19.3 & 57.4 & \\
\hline Tuve (Sweden) & 2.1 & 5.9 & 6.9 & 16.7 & 110.0 & 40.0 & 121.0 & \\
\hline
\end{tabular}




\begin{tabular}{lllllllll}
\hline Location & Depth $(\mathrm{m})$ & $S_{u}^{F V}(\mathrm{kPa})$ & $\sigma_{v}^{\prime}(\mathrm{kPa})$ & $\sigma_{p}^{\prime}(\mathrm{kPa})$ & LL $(\%)$ & PL $(\%)$ & $w(\%)$ & $S_{t}$ \\
\hline & 3.1 & 6.7 & 9.2 & 15.2 & 105.0 & 40.0 & 115.5 & \\
& 4.0 & 7.7 & 12.0 & 22.1 & 100.0 & 40.0 & 110.0 & \\
& 5.0 & 8.7 & 14.7 & 25.5 & 100.0 & 40.0 & 110.0 & \\
& 6.0 & 9.5 & 17.4 & 27.5 & 95.0 & 40.0 & 104.5 & \\
& 7.0 & 10.4 & 20.5 & 47.1 & 75.0 & 30.0 & 82.5 & \\
& 7.9 & 13.2 & 23.5 & 45.1 & 83.0 & 30.0 & 91.3 & \\
& 8.9 & 15.8 & 26.9 & 55.9 & 95.0 & 30.0 & 104.5 & \\
& 10.0 & 19.2 & 30.4 & 54.9 & 87.0 & 30.0 & 95.7 & \\
& 11.0 & 19.9 & 33.8 & 61.3 & 86.0 & 30.0 & 94.6 & \\
& 11.5 & 20.4 & 35.5 & 63.2 & 85.0 & 30.0 & 93.5 & \\
& 12.1 & 21.0 & 38.2 & 66.2 & 85.0 & 30.0 & 93.5 & \\
& 12.6 & 21.4 & 39.5 & 68.1 & 84.0 & 30.0 & 92.4 & \\
& 13.2 & 22.2 & 41.6 & 70.6 & 83.0 & 30.0 & 91.3 & \\
& & & & & & & & \\
& 2.0 & 5.6 & 11.3 & 29.6 & 47.9 & 18.5 & 57.5 & 14.0 \\
& 4.0 & 6.9 & 20.2 & 49.4 & 49.2 & 21.7 & 97.8 & 18.0 \\
& 5.0 & 7.2 & 25.7 & 50.2 & 40.3 & 14.7 & 60.1 & 22.0 \\
& 6.0 & 9.0 & 31.9 & 62.3 & 49.9 & 21.7 & 59.5 & 27.0 \\
& 6.9 & 11.7 & 38.1 & 55.6 & 47.3 & 21.1 & 55.0 & 26.0 \\
& 8.0 & 11.2 & 44.7 & 91.8 & 47.3 & 21.7 & 51.8 & 26.0 \\
10.0 & 16.1 & 58.4 & 100.8 & 44.7 & 19.2 & 53.1 & 17.0 \\
& & & & & & & &
\end{tabular}




\section{Tables}

Table 1 . Summary of multivariate clay databases.

\begin{tabular}{|c|c|c|c|c|c|c|c|}
\hline \multirow{2}{*}{ Database } & \multirow{2}{*}{ Reference } & \multirow{2}{*}{$\begin{array}{l}\text { Parameters of } \\
\text { interest }\end{array}$} & \multirow{2}{*}{$\begin{array}{l}\text { \# data } \\
\text { points }\end{array}$} & \multirow{2}{*}{$\begin{array}{l}\text { \# sites/ } \\
\text { studies }\end{array}$} & \multicolumn{3}{|c|}{ Range of properties } \\
\hline & & & & & OCR & PI & $\mathrm{S}_{\mathrm{t}}$ \\
\hline CLAY/5/345 & $\begin{array}{l}\text { Ching and } \\
\text { Phoon } \\
\text { (2012a) }\end{array}$ & $\begin{array}{c}\text { LI, } \mathrm{s}_{\mathrm{u}}, \mathrm{s}_{\mathrm{u}}^{\mathrm{re}}, \sigma_{\mathrm{p}}^{\prime}, \\
\sigma_{\mathrm{v}}^{\prime}\end{array}$ & 345 & $\begin{array}{l}37 \\
\text { sites }\end{array}$ & $1 \sim 4$ & & $\begin{array}{l}\text { Sensitive to } \\
\text { quick clays }\end{array}$ \\
\hline CLAY/7/6310 & $\begin{array}{l}\text { Ching and } \\
\text { Phoon } \\
(2013)\end{array}$ & $\begin{array}{c}\mathrm{CIUC}, \mathrm{CK}_{0} \mathrm{UC}, \\
\mathrm{CK}_{0} \mathrm{UE}, \mathrm{DSS}, \\
\mathrm{FV}, \mathrm{UU}, \mathrm{UC}\end{array}$ & 6310 & $\begin{array}{c}164 \\
\text { studies }\end{array}$ & $1 \sim 10$ & $\begin{array}{l}\text { Low to } \\
\text { very high } \\
\text { plasticity }\end{array}$ & $\begin{array}{l}\text { Insensitive } \\
\text { to quick } \\
\text { clays }\end{array}$ \\
\hline CLAY/6/535 & $\begin{array}{l}\text { Ching et } \\
\text { al. (2014) }\end{array}$ & $\begin{array}{c}\mathrm{s}_{\mathrm{u}} / \sigma_{\mathrm{v}}^{\prime}, \mathrm{OCR}, \\
\left(\mathrm{q}_{\mathrm{t}}-\sigma_{\mathrm{v}}\right) / \sigma_{\mathrm{v}}^{\prime} \\
\left(\mathrm{q}_{\mathrm{t}}-\mathrm{u}_{2}\right) / \sigma_{\mathrm{v}}^{\prime} \\
\left(\mathrm{u}_{2}-\mathrm{u}_{0}\right) / \sigma_{\mathrm{v}}^{\prime}, \mathrm{B}_{\mathrm{q}} \\
\mathrm{LL}, \mathrm{PI}, \mathrm{LI},\end{array}$ & 535 & $\begin{array}{c}40 \\
\text { sites }\end{array}$ & $1 \sim 6$ & $\begin{array}{l}\text { Low to } \\
\text { very high } \\
\text { plasticity }\end{array}$ & $\begin{array}{l}\text { Insensitive } \\
\text { to quick } \\
\text { clays }\end{array}$ \\
\hline CLAY/10/7490 & $\begin{array}{l}\text { Ching \& } \\
\text { Phoon } \\
(2014 a)\end{array}$ & $\begin{array}{c}\sigma_{\mathrm{v}}^{\prime} / \mathrm{P}_{\mathrm{a}}, \sigma_{\mathrm{p}}^{\prime} / \mathrm{P}_{\mathrm{a}} \\
\mathrm{s}_{\mathrm{u}} / \sigma_{\mathrm{v}}^{\prime}, \mathrm{S}_{\mathrm{t}} \\
\left(\mathrm{q}_{\mathrm{t}}-\sigma_{\mathrm{v}}\right) / \sigma_{\mathrm{v}}^{\prime} \\
\left(\mathrm{q}_{\mathrm{t}}-\mathrm{u}_{2}\right) / \sigma_{\mathrm{v}}^{\prime}, \mathrm{B}_{\mathrm{q}}\end{array}$ & 7490 & $\begin{array}{c}251 \\
\text { studies }\end{array}$ & $1 \sim 10$ & $\begin{array}{l}\text { Low to } \\
\text { very high } \\
\text { plasticity }\end{array}$ & $\begin{array}{l}\text { Insensitive } \\
\text { to quick } \\
\text { clays }\end{array}$ \\
\hline
\end{tabular}

Note: $\mathrm{LL}=$ liquid limit; $\mathrm{PI}=$ plasticity index; $\mathrm{LI}=$ liquidity index; $\sigma_{\mathrm{v}}^{\prime}=$ vertical effective stress; $\sigma_{\mathrm{p}}^{\prime}=$ preconsolidation stress; $s_{u}=$ undrained shear strength; $s_{u}{ }^{r e}=$ remoulded $s_{u} ;$ CIUC $=s_{u}$ from isotropically consolidated undrained compression test; $\mathrm{CK}_{0} \mathrm{UC}=\mathrm{s}_{\mathrm{u}}$ from $\mathrm{K}_{0}$-consolidated undrained compression test; $\mathrm{CK}_{0} \mathrm{UE}=\mathrm{s}_{\mathrm{u}}$ from $\mathrm{K}_{0}$-consolidated undrained extension test; $\mathrm{DSS}=\mathrm{s}_{\mathrm{u}}$ from direct simple shear test; $\mathrm{FV}=$ $\mathrm{s}_{\mathrm{u}}$ from field vane; $\mathrm{UU}=\mathrm{s}_{\mathrm{u}}$ from unconsolidated undrained compression test; $\mathrm{UC}=\mathrm{s}_{\mathrm{u}}$ from unconfined compression test; $S_{t}=$ sensitivity; OCR = overconsolidation ratio, $\left(\mathrm{q}_{\mathrm{t}}-\sigma_{\mathrm{v}}\right) / \sigma_{\mathrm{v}}^{\prime}=$ normalized cone tip resistance; $\left(\mathrm{q}_{\mathrm{t}}-\mathrm{u}_{2}\right) / \sigma_{\mathrm{v}}^{\prime}=$ effective cone tip resistance; $\mathrm{u}_{0}=$ hydrostatic pore pressure; $\left(\mathrm{u}_{2} \mathrm{u}_{0}\right) / \sigma_{\mathrm{v}}^{\prime}=$ normalized excess pore pressure; $\mathrm{B}_{\mathrm{q}}=$ pore pressure ratio $=\left(\mathrm{u}_{2}-\mathrm{u}_{0}\right) /\left(\mathrm{q}_{\mathrm{t}}-\sigma_{\mathrm{v}}\right)$; and $\mathrm{P}_{\mathrm{a}}=$ atmospheric pressure $=101.3 \mathrm{kPa}$. 
Table 2: Basic statistics of the 7 basic parameters in F-CLAY/7/216.

\begin{tabular}{cccccc}
\hline Variable & $\mathrm{n}$ & Mean & COV & Min & Max \\
\hline $\mathbf{s}_{\mathbf{u}}{ }^{\mathbf{F V}}(\mathbf{k P a})$ & 216 & 21.443 & 0.501 & 5 & 75 \\
$\boldsymbol{\sigma}_{\mathbf{v}} / \mathbf{P}_{\mathbf{a}}$ & 216 & 0.464 & 0.485 & 0.074 & 1.609 \\
$\boldsymbol{\sigma}_{\mathbf{p}} \mathbf{P}_{\mathbf{a}}$ & 216 & 0.948 & 0.515 & 0.251 & 2.884 \\
$\mathbf{L L}$ & 216 & 66.284 & 0.298 & 22.0 & 125.0 \\
$\mathbf{P L}$ & 216 & 27.740 & 0.204 & 10.0 & 50.0 \\
$\mathbf{w}$ & 216 & 76.340 & 0.268 & 25.0 & 150.0 \\
$\mathbf{S}_{\mathbf{t}}$ & 216 & 17.447 & 0.789 & 2.0 & 64.0 \\
\hline
\end{tabular}

Table 3: Basic statistics of the 7 basic parameters in S-CLAY/7/168.

\begin{tabular}{cccccc}
\hline Variable & $\mathrm{n}$ & Mean & COV & Min & Max \\
\hline $\mathbf{s}_{\mathbf{u}}^{\mathbf{F V}}(\mathbf{k P a})$ & 168 & 16.346 & 0.505 & 5.62 & 48.75 \\
$\boldsymbol{\sigma}_{\mathbf{v}}^{\prime} / \mathbf{P}_{\mathbf{a}}$ & 168 & 0.503 & 0.632 & 0.068 & 2.101 \\
$\boldsymbol{\sigma}_{\mathbf{p}}^{\prime} / \mathbf{P}_{\mathbf{a}}$ & 168 & 0.786 & 0.726 & 0.150 & 3.116 \\
$\mathbf{L L}$ & 168 & 71.055 & 0.396 & 22.77 & 201.81 \\
$\mathbf{P L}$ & 168 & 29.448 & 0.344 & 2.73 & 73.92 \\
$\mathbf{w}$ & 168 & 76.631 & 0.347 & 17.27 & 180.11 \\
$\mathbf{S}_{\mathbf{t}}$ & 59 & 12.068 & 0.779 & 3.0 & 42.5 \\
\hline
\end{tabular}

Table 4: Basic statistics of 10 dimensionless soil parameters in F-CLAY/10/216, derived from the 7 basic parameters in F-CLAY/7/216.

\begin{tabular}{cccccc}
\hline Variable & $\mathrm{n}$ & Mean & COV & Min & Max \\
\hline $\mathbf{s}_{\mathbf{u}(\mathbf{m o b})} / \boldsymbol{\sigma}_{\mathbf{v}}^{\prime}$ & 216 & 0.458 & 0.715 & 0.167 & 2.754 \\
$\mathbf{S}_{\mathbf{u}(\mathbf{m o b})} / \boldsymbol{\sigma}_{\mathbf{p}}^{\prime}$ & 216 & 0.209 & 0.281 & 0.081 & 0.469 \\
$\mathbf{s}_{\mathbf{u}} \mathbf{F V} / \sigma_{\mathbf{v}}^{\prime}$ & 216 & 0.513 & 0.712 & 0.176 & 2.938 \\
$\mathbf{s}_{\mathbf{u}} \mathbf{F V} / \sigma_{\mathbf{p}}^{\prime}$ & 216 & 0.234 & 0.293 & 0.083 & 0.594 \\
$\mathbf{O C R}$ & 216 & 2.170 & 0.467 & 1.18 & 7.50 \\
$\mathbf{L L}$ & 216 & 66.284 & 0.298 & 22.0 & 125.0 \\
$\mathbf{P I}$ & 216 & 38.545 & 0.482 & 2.0 & 95.0 \\
$\mathbf{w}$ & 216 & 76.340 & 0.268 & 25.0 & 150.0 \\
$\mathbf{L I}$ & 216 & 1.443 & 0.459 & 0.425 & 4.800 \\
$\mathbf{S}_{\mathbf{t}}$ & 216 & 17.447 & 0.789 & 2.0 & 64.0 \\
\hline
\end{tabular}


Table 5: Basic statistics of 10 dimensionless soil parameters in S-CLAY/10/168, derived from the 7 basic parameters in S-CLAY/7/168.

\begin{tabular}{cccccc}
\hline Variable & $\mathrm{n}$ & Mean & COV & Min & Max \\
\hline $\mathbf{s}_{\mathbf{u}(\mathbf{m o b})} / \boldsymbol{\sigma}_{\mathbf{v}}^{\prime}$ & 168 & 0.329 & 0.417 & 0.098 & 0.885 \\
$\mathbf{s}_{\mathbf{u}(\mathbf{m o b})} / \boldsymbol{\sigma}_{\mathbf{p}}^{\prime}$ & 168 & 0.210 & 0.269 & 0.088 & 0.470 \\
$\mathbf{s}_{\mathbf{u}}^{\mathbf{F V}} / \boldsymbol{\sigma}_{\mathbf{v}}^{\prime}$ & 168 & 0.386 & 0.469 & 0.098 & 0.974 \\
$\mathbf{s}_{\mathbf{u}}^{\mathbf{F V}} / \boldsymbol{\sigma}_{\mathbf{p}}^{\prime}$ & 168 & 0.244 & 0.311 & 0.088 & 0.490 \\
$\mathbf{O C R}$ & 168 & 1.664 & 0.476 & 1.00 & 6.07 \\
$\mathbf{L L}$ & 168 & 71.06 & 0.396 & 22.77 & 201.81 \\
$\mathbf{P I}$ & 168 & 41.61 & 0.496 & 3.91 & 127.89 \\
$\mathbf{w}$ & 168 & 76.63 & 0.347 & 17.27 & 180.11 \\
$\mathbf{L I}$ & 168 & 1.267 & 0.507 & 0.60 & 5.50 \\
$\mathbf{S}_{\mathbf{t}}$ & 59 & 12.068 & 0.779 & 3.00 & 42.50 \\
\hline
\end{tabular}


Table 6. Transformation models in literature and their calibration results for F-CLAY/10/216.

\begin{tabular}{|c|c|c|c|c|c|c|c|c|}
\hline \multirow[b]{2}{*}{ Type } & \multirow[b]{2}{*}{ Relationship } & \multirow[b]{2}{*}{ Literature } & \multirow[b]{2}{*}{$\mathrm{n}$} & \multirow[b]{2}{*}{ Transformation model } & \multicolumn{2}{|c|}{$\begin{array}{l}\text { Comparison to } \\
\text { F- } \\
\text { CLAY/10/216 } \\
\text { database }\end{array}$} & \multicolumn{2}{|c|}{$\begin{array}{l}\text { Calibration } \\
\text { results }\end{array}$} \\
\hline & & & & & Figure & $\begin{array}{l}\text { Fit to } \\
\text { the } \\
\text { trend? }\end{array}$ & $\begin{array}{l}\text { Bias } \\
\text { factor, } \\
b\end{array}$ & $\begin{array}{l}\mathrm{COV} \\
\text { of } \\
\varepsilon=\delta\end{array}$ \\
\hline \multirow[t]{4}{*}{ A } & $\mathrm{LI}-\left(\mathrm{s}_{\mathrm{u}}{ }^{\mathrm{re}} / \mathrm{P}_{\mathrm{a}}\right)$ & $\begin{array}{l}\text { Wroth and Wood } \\
\text { (1978) } \\
\text { Locat and }\end{array}$ & 216 & $\mathrm{~s}_{\mathrm{u}}^{\mathrm{re}} / \mathrm{P}_{\mathrm{a}}=1.7 \exp (-4.6 \mathrm{LI})$ & 9 & No & - & - \\
\hline & & Demers (1988) & 216 & $\mathrm{~s}_{\mathrm{u}}^{\mathrm{re}} / \mathrm{P}_{\mathrm{a}}=0.0144 \mathrm{LI}^{-2.44}$ & 9 & Yes & 4.05 & 3.02 \\
\hline & $\mathrm{LI}-\left(\mathrm{S}_{\mathrm{t}}\right)$ & Bjerrum (1954) & 216 & $\mathrm{~S}_{\mathrm{t}}=10^{0.8 \mathrm{LI}}$ & 11 & Yes & 1.56 & 1.40 \\
\hline & & (2012a) & 216 & $\mathrm{~S}_{\mathrm{t}}=20.726 \mathrm{LI}^{1.910}$ & 11 & No & 0.57 & 1.94 \\
\hline \multirow[t]{2}{*}{ B } & $\begin{array}{l}\mathrm{LI}-\left(\sigma_{\mathrm{p}} / \mathrm{P}_{\mathrm{a}}\right)-\mathrm{S}_{\mathrm{t}} \\
\left(\text { for } \mathrm{S}_{\mathrm{t}}<15\right)\end{array}$ & $\begin{array}{l}\text { Ching and Phoon } \\
\text { (2012a) }\end{array}$ & 216 & $\begin{array}{l}\sigma_{p}^{\prime} / P_{a}=0.235 \mathrm{LI}^{-} \\
{ }_{1.319} \mathrm{~S}_{\mathrm{t}}^{0.536}\end{array}$ & $12 \mathrm{a}$ & Yes & 2.02 & 0.94 \\
\hline & $\begin{array}{l}\mathrm{LI}-\left(\sigma_{\mathrm{p}}^{\prime} / \mathrm{P}_{\mathrm{a}}\right)-\mathrm{S}_{\mathrm{t}} \\
\left(\text { for } \mathrm{S}_{\mathrm{t}}>15\right)\end{array}$ & $\begin{array}{l}\text { Ching and Phoon } \\
\text { (2012a) }\end{array}$ & 216 & $\begin{array}{l}\sigma_{p}^{\prime} / P_{a}=0.235 \mathrm{LI}^{-} \\
{ }_{1.319} \mathrm{~S}_{\mathrm{t}}^{0.536}\end{array}$ & $12 \mathrm{a}$ & Yes & 0.95 & 0.47 \\
\hline \multirow[t]{3}{*}{$\mathrm{C}$} & $\operatorname{PI}-\left(\mathrm{s}_{\mathrm{u}}(\mathrm{mob}) / \sigma_{\mathrm{p}}{ }^{\prime}\right)$ & $\begin{array}{l}\text { Mesri }(1975, \\
1989)\end{array}$ & 216 & $\mathrm{~s}_{\mathrm{u}}(\mathrm{mob}) / \sigma_{\mathrm{p}}^{\prime}=0.22$ & 5 & Yes & 0.95 & 0.28 \\
\hline & & $\begin{array}{l}\text { Jamiolkowski et } \\
\text { al. (1985) }\end{array}$ & 216 & $\begin{array}{l}\mathrm{s}_{\mathrm{u}}(\mathrm{mob}) / \sigma_{\mathrm{v}}^{\prime}= \\
0.23 \mathrm{OCR}^{0.8}\end{array}$ & 4 & Yes & 1.06 & 0.30 \\
\hline & $\begin{array}{l}\text { OCR- } \\
\left(\mathrm{s}_{\mathrm{u}}(\mathrm{mob}) / \sigma_{\mathrm{v}}{ }^{\prime}\right)-\mathrm{S}_{\mathrm{t}}\end{array}$ & $\begin{array}{l}\text { Ching and Phoon } \\
(2012 a)\end{array}$ & 216 & $\begin{array}{l}\mathrm{S}_{\mathrm{u}}(\mathrm{mob}) / \sigma_{\mathrm{v}}^{\prime}= \\
0.2290 \mathrm{OR}^{0.823} \mathrm{~S}_{\mathrm{t}}^{0.121}\end{array}$ & $6 a$ & Yes & 0.77 & 0.32 \\
\hline \multirow[t]{3}{*}{$\mathrm{D}$} & LL- $\left(\mathrm{s}_{\mathrm{u}}{ }^{\mathrm{FV}} / \sigma_{\mathrm{p}}{ }^{\prime}\right)$ & Hansbo (1957) & 216 & $\mathrm{~s}_{\mathrm{u}}^{\mathrm{FV}} / \sigma_{\mathrm{p}}^{\prime}=0.45 \mathrm{LL}$ & 7 & Yes & 0.84 & 0.38 \\
\hline & PI- $\left(\mathrm{s}_{\mathrm{u}}^{\mathrm{FV}} / \sigma_{\mathrm{p}}{ }^{\prime}\right)$ & Larsson (1980) & 216 & $\begin{array}{l}0.08+0.0055 \mathrm{PI} \\
\mathrm{S}_{\mathrm{u}} / \sigma_{\mathrm{n}}^{\prime}=\end{array}$ & 8 & Yes & 0.89 & 0.43 \\
\hline & & Chandler (1988) & 216 & $0.11+0.0037 \mathrm{PI}$ & 8 & Yes & 0.97 & 0.35 \\
\hline
\end{tabular}


Table 7. Transformation models in literature and their calibration results for S-CLAY/10/168.

\begin{tabular}{|c|c|c|c|c|c|c|c|c|}
\hline \multirow[b]{2}{*}{ Type } & \multirow[b]{2}{*}{ Relationship } & \multirow[b]{2}{*}{ Literature } & \multirow[b]{2}{*}{$\mathrm{n}$} & \multirow[b]{2}{*}{ Transformation model } & \multicolumn{2}{|c|}{$\begin{array}{l}\text { Comparison to } \\
\text { S- } \\
\text { CLAY/10/168 } \\
\text { database }\end{array}$} & \multicolumn{2}{|c|}{$\begin{array}{l}\text { Calibration } \\
\text { results }\end{array}$} \\
\hline & & & & & Figure & $\begin{array}{l}\text { Fit to } \\
\text { the } \\
\text { trend? }\end{array}$ & $\begin{array}{l}\text { Bias } \\
\text { factor, } \\
b\end{array}$ & $\begin{array}{l}\text { COV } \\
\text { of } \\
\varepsilon=\delta\end{array}$ \\
\hline \multirow[t]{4}{*}{ A } & $\mathrm{LI}-\left(\mathrm{s}_{\mathrm{u}}{ }^{\mathrm{re}} / \mathrm{P}_{\mathrm{a}}\right)$ & $\begin{array}{l}\text { Wroth and } \\
\text { Wood (1978) } \\
\text { Locat and }\end{array}$ & 59 & $\begin{array}{l}\mathrm{s}_{\mathrm{u}}^{\mathrm{re}} / \mathrm{P}_{\mathrm{a}}=1.7 \exp (- \\
4.6 \mathrm{LI})\end{array}$ & 9 & No & - & - \\
\hline & & Demers (1988) & 59 & $\mathrm{~s}_{\mathrm{u}}^{\mathrm{re}} / \mathrm{P}_{\mathrm{a}}=0.0144 \mathrm{LI}^{-2.44}$ & 9 & Yes & 1.60 & 0.96 \\
\hline & LI- $\left(\mathrm{S}_{\mathrm{t}}\right)$ & $\begin{array}{l}\text { Bjerrum (1954) } \\
\text { Ching and }\end{array}$ & 59 & $\mathrm{~S}_{\mathrm{t}}=10^{0.8 \mathrm{LI}}$ & 11 & Yes & 1.48 & 0.65 \\
\hline & & Phoon (2012a) & 59 & $\mathrm{~S}_{\mathrm{t}}=20.726 \mathrm{LI}^{1.910}$ & 11 & No & 0.49 & 0.61 \\
\hline \multirow[t]{2}{*}{ B } & $\begin{array}{l}\mathrm{LI}-\left(\sigma^{\prime}{ }_{\mathrm{p}} / \mathrm{P}_{\mathrm{a}}\right)-\mathrm{S}_{\mathrm{t}} \\
\left(\text { for } \mathrm{S}_{\mathrm{t}}<15\right)\end{array}$ & $\begin{array}{l}\text { Ching and } \\
\text { Phoon (2012a) }\end{array}$ & 59 & $\begin{array}{l}\sigma_{p}^{\prime} / \mathrm{P}_{\mathrm{a}}=0.235 \mathrm{LI}^{-} \\
{ }^{3.319} \mathrm{~S}_{\mathrm{t}}^{0.536}\end{array}$ & $12 \mathrm{~b}$ & Yes & 1.23 & 0.51 \\
\hline & $\begin{array}{l}\mathrm{LI}-\left(\sigma_{\mathrm{p}} / \mathrm{P}_{\mathrm{a}}\right)-\mathrm{S}_{\mathrm{t}} \\
\left(\text { for } \mathrm{S}_{\mathrm{t}}>15\right)\end{array}$ & $\begin{array}{l}\text { Ching and } \\
\text { Phoon (2012a) }\end{array}$ & 59 & $\begin{array}{l}\sigma^{\prime} / \mathrm{P}_{\mathrm{a}}=0.235 \mathrm{LI}^{-} \\
{ }^{1.319} \mathrm{~S}_{\mathrm{t}}^{0.536}\end{array}$ & $12 \mathrm{~b}$ & Yes & 0.84 & 0.54 \\
\hline \multirow[t]{3}{*}{$\mathrm{C}$} & PI- $\left(s_{u}(m o b) / \sigma_{p}^{\prime}\right)$ & $\begin{array}{l}\text { Mesri (1975, } \\
\text { 1989) }\end{array}$ & 168 & $\mathrm{~s}_{\mathrm{u}}(\mathrm{mob}) / \sigma_{\mathrm{p}}^{\prime}=0.22$ & 5 & Yes & 0.96 & 0.27 \\
\hline & $\begin{array}{l}\text { OCR- } \\
\left(\mathrm{s}_{\mathrm{u}}(\mathrm{mob}) / \sigma^{\prime}{ }_{v}\right)\end{array}$ & $\begin{array}{l}\text { Jamiolkowski et } \\
\text { al. (1985) }\end{array}$ & 168 & $\begin{array}{l}\mathrm{s}_{\mathrm{u}}(\mathrm{mob}) / \sigma_{\mathrm{v}}^{\prime}= \\
0.23 \mathrm{OCR}^{0.8}\end{array}$ & 4 & Yes & 0.97 & 0.25 \\
\hline & $\begin{array}{l}\text { OCR- } \\
\left(\mathrm{s}_{\mathrm{u}}(\mathrm{mob}) / \sigma_{\mathrm{v}}\right)-\mathrm{S}_{\mathrm{t}}\end{array}$ & $\begin{array}{l}\text { Ching and } \\
\text { Phoon (2012a) }\end{array}$ & 168 & $\begin{array}{l}\mathrm{s}_{\mathrm{u}}(\mathrm{mob}) / \sigma_{\mathrm{v}}^{\prime}= \\
0.229 \mathrm{OCR}^{0.823} \mathrm{~S}_{\mathrm{t}}^{0.121}\end{array}$ & $6 \mathrm{~b}$ & Yes & 0.71 & 0.36 \\
\hline \multirow[t]{3}{*}{$\mathrm{D}$} & LL- $\left(s_{u}^{F V} / \sigma_{p}^{\prime}\right)$ & Hansbo (1957) & 168 & $\mathrm{~s}_{\mathrm{u}}^{\mathrm{FV}} / \sigma_{\mathrm{p}}^{\prime}=0.45 \mathrm{LL}$ & 7 & Yes & 0.82 & 0.34 \\
\hline & $\operatorname{PI}-\left(\mathrm{s}_{\mathrm{u}}{ }^{\mathrm{FV}} / \sigma_{\mathrm{p}}{ }^{\prime}\right)$ & Larsson (1980) & 168 & $\begin{array}{l}\mathrm{s}_{\mathrm{u}} / \mathrm{op}_{\mathrm{p}}- \\
0.08+0.0055 \mathrm{PI} \\
\mathrm{s}_{\mathrm{u}} \mathrm{FV} / \sigma_{\mathrm{p}}^{\prime}=\end{array}$ & 8 & Yes & 0.85 & 0.37 \\
\hline & & Chandler (1988) & 168 & $0.11+0.0037 \mathrm{PI}$ & 8 & Yes & 0.96 & 0.31 \\
\hline
\end{tabular}


Table 8. Basic statistics of the data points after removal of outliers (database F-CLAY/10/173).

\begin{tabular}{cccccc}
\hline Variable & $\mathrm{n}$ & Mean & COV & Min & Max \\
\hline $\mathbf{s}_{\mathbf{u}(\mathbf{m o b})} / \boldsymbol{\sigma}_{\mathbf{v}}^{\prime}$ & 173 & 0.399 & 0.284 & 0.213 & 0.690 \\
$\mathbf{S}_{\mathbf{u}(\mathbf{m o b})} / \boldsymbol{\sigma}_{\mathbf{p}}^{\prime}$ & 173 & 0.213 & 0.183 & 0.148 & 0.338 \\
$\mathbf{s}_{\mathbf{u}} \mathbf{F V} / \boldsymbol{\sigma}_{\mathbf{v}}^{\prime}$ & 173 & 0.447 & 0.306 & 0.226 & 0.920 \\
$\mathbf{s}_{\mathbf{u}}^{\mathbf{F V}} / \boldsymbol{\sigma}_{\mathbf{p}}^{\prime}$ & 173 & 0.239 & 0.203 & 0.148 & 0.394 \\
$\mathbf{O C R}$ & 173 & 1.91 & 0.31 & 1.18 & 3.69 \\
$\mathbf{L L}$ & 173 & 66.4 & 0.29 & 22 & 125.0 \\
$\mathbf{P I}$ & 173 & 38 & 0.47 & 2 & 95.0 \\
$\boldsymbol{w}$ & 173 & 78.3 & 0.25 & 25.00 & 150.0 \\
$\mathbf{L I}$ & 173 & 1.48 & 0.43 & 0.46 & 4.80 \\
$\mathbf{S}_{\mathbf{t}}$ & 173 & 18.80 & 0.76 & 2.00 & 58.0 \\
\hline
\end{tabular}

Table 9. Linear regression coefficients for multivariable function $F$.

\begin{tabular}{|c|c|c|c|c|c|}
\hline Transformation model & $\begin{array}{l}\text { Secondary input } \\
\text { parameter }\left(\mathrm{Y}_{\mathrm{i}}\right)\end{array}$ & $\alpha$ & $\beta$ & $\gamma$ & $r^{2}$ \\
\hline \multirow[t]{5}{*}{ OCR $-s_{u}(m o b) / \sigma_{v}^{\prime}-Y_{i}$} & $\mathrm{Y}_{1}(\mathrm{PI})$ & 0.242 & 0.763 & -0.013 & 0.67 \\
\hline & $\mathrm{Y}_{2}(\mathrm{LL})$ & 0.245 & 0.760 & -0.005 & 0.67 \\
\hline & $\mathrm{Y}_{3}(w)$ & 0.246 & 0.760 & 0.027 & 0.67 \\
\hline & $\mathrm{Y}_{4}(\mathrm{LI})$ & 0.241 & 0.770 & 0.045 & 0.67 \\
\hline & $\mathrm{Y}_{5}\left(\mathrm{~S}_{\mathrm{t}}\right)$ & 0.242 & 0.762 & 0.006 & 0.67 \\
\hline \multirow[t]{5}{*}{ OCR $-s_{u}^{F V} / \sigma_{v}^{\prime}-Y_{i}$} & $\mathrm{Y}_{1}(\mathrm{PI})$ & 0.328 & 0.756 & 0.165 & 0.68 \\
\hline & $\mathrm{Y}_{2}(\mathrm{LL})$ & 0.319 & 0.757 & 0.333 & 0.70 \\
\hline & $\mathrm{Y}_{3}(w)$ & 0.296 & 0.788 & 0.337 & 0.69 \\
\hline & $\mathrm{Y}_{4}(\mathrm{LI})$ & 0.281 & 0.770 & -0.088 & 0.63 \\
\hline & $\mathrm{Y}_{5}\left(\mathrm{~S}_{\mathrm{t}}\right)$ & 0.280 & 0.786 & -0.013 & 0.62 \\
\hline
\end{tabular}


Table 10. Transformation models for Finnish clays and their calibration results for S-CLAY/10/168.

\begin{tabular}{|c|c|c|c|c|}
\hline \multirow[b]{2}{*}{ Relationship } & \multirow[b]{2}{*}{$\mathrm{n}$} & \multirow[b]{2}{*}{ Transformation model } & \multicolumn{2}{|c|}{ Calibration results } \\
\hline & & & Bias factor, $b$ & $\begin{array}{l}\text { COV of } \\
\varepsilon=\delta\end{array}$ \\
\hline OCR- $\left(\mathrm{s}_{\mathrm{u}}(\mathrm{mob}) / \sigma^{\prime}{ }_{\mathrm{v}}\right)-\mathrm{PI}$ & 168 & $\mathrm{~s}_{\mathrm{u}}(\mathrm{mob}) / \sigma_{\mathrm{v}}^{\prime}=0.242 \mathrm{OCR}^{0.763} \mathrm{PI}^{-0.013}$ & 0.94 & 0.26 \\
\hline $\begin{array}{l}\text { OCR- }\left(s_{u}(m o b) / \sigma_{v}{ }_{v}\right)- \\
\text { LL }\end{array}$ & 168 & $\begin{array}{l}\mathrm{s}_{\mathrm{u}}(\mathrm{mob}) / \sigma_{\mathrm{v}}^{\prime}=0.245 \mathrm{OCR}^{0.760} \mathrm{LL}^{-} \\
0.005\end{array}$ & 0.94 & 0.25 \\
\hline OCR $-\left(\mathrm{s}_{\mathrm{u}}(\mathrm{mob}) / \sigma_{\mathrm{v}}^{\prime}\right)-w$ & 168 & $\mathrm{~s}_{\mathrm{u}}(\mathrm{mob}) / \sigma_{\mathrm{v}}^{\prime}=0.246 \mathrm{OCR}^{0.760} w^{0.027}$ & 0.94 & 0.25 \\
\hline OCR-( $\left(\mathrm{u}_{\mathrm{u}}(\mathrm{mob}) / \sigma_{\mathrm{v}}{ }_{\mathrm{v}}\right)-\mathrm{LI}$ & 168 & $\mathrm{~s}_{\mathrm{u}}(\mathrm{mob}) / \sigma_{\mathrm{v}}^{\prime}=0.241 \mathrm{OCR}^{0.770} \mathrm{LI}^{0.045}$ & 0.95 & 0.26 \\
\hline OCR $-\left(\mathrm{s}_{\mathrm{u}}(\mathrm{mob}) / \sigma_{\mathrm{v}}{ }_{\mathrm{v}}\right)-\mathrm{S}_{\mathrm{t}}$ & 59 & $\mathrm{~s}_{\mathrm{u}}(\mathrm{mob}) / \sigma_{\mathrm{v}}^{\prime}=0.242 \mathrm{OCR} \mathrm{R}^{0.762} \mathrm{~S}_{\mathrm{t}}^{0.006}$ & 0.90 & 0.34 \\
\hline OCR- $\left.\left(\mathrm{s}_{\mathrm{u}}^{\mathrm{FV}} / \sigma_{\mathrm{v}}\right)^{\prime}\right)-\mathrm{PI}$ & 168 & $\mathrm{~s}_{\mathrm{u}}^{\mathrm{FV}} / \sigma_{\mathrm{v}}^{\prime}=0.328 \mathrm{OCR}^{0.756} \mathrm{PI}^{0.165}$ & 0.95 & 0.29 \\
\hline OCR $-\left(\mathrm{s}_{\mathrm{u}}{ }^{\mathrm{FV}} / \sigma_{\mathrm{v}}{ }_{\mathrm{v}}\right)-\mathrm{LL}$ & 168 & $\mathrm{~s}_{\mathrm{u}}^{\mathrm{FV}} / \sigma_{\mathrm{v}}^{\prime}=0.319 O \mathrm{OR}^{0.757} \mathrm{LL}^{0.333}$ & 0.94 & 0.26 \\
\hline OCR $-\left(\mathrm{s}_{\mathrm{u}}^{\mathrm{FV}} / \sigma_{\mathrm{v}}^{\prime}\right)-w$ & 168 & $\mathrm{~s}_{\mathrm{u}}^{\mathrm{FV}} / \sigma_{\mathrm{v}}^{\prime}=0.296 \mathrm{OCR}^{0.788} w^{0.337}$ & 0.97 & 0.27 \\
\hline OCR- $\left(\mathrm{s}_{\mathrm{u}}^{\mathrm{FV}} / \sigma_{\mathrm{v}}^{\prime}\right)-\mathrm{LI}$ & 168 & $\mathrm{~s}_{\mathrm{u}}^{\mathrm{FV}} / \sigma_{\mathrm{v}}^{\prime}=0.281 \mathrm{OCR}^{0.770} \mathrm{LI}^{-0.088}$ & 0.95 & 0.33 \\
\hline OCR- $\left(\mathrm{s}_{\mathrm{u}}^{\mathrm{FV}} / \sigma_{\mathrm{v}}{ }_{\mathrm{v}}\right)-\mathrm{S}_{\mathrm{t}}$ & 59 & $\mathrm{~s}_{\mathrm{u}}^{\mathrm{FV}} / \sigma_{\mathrm{v}}^{\prime}=0.2800 \mathrm{CR}^{0.786} \mathrm{~S}_{\mathrm{t}}^{-0.013}$ & 0.91 & 0.44 \\
\hline
\end{tabular}




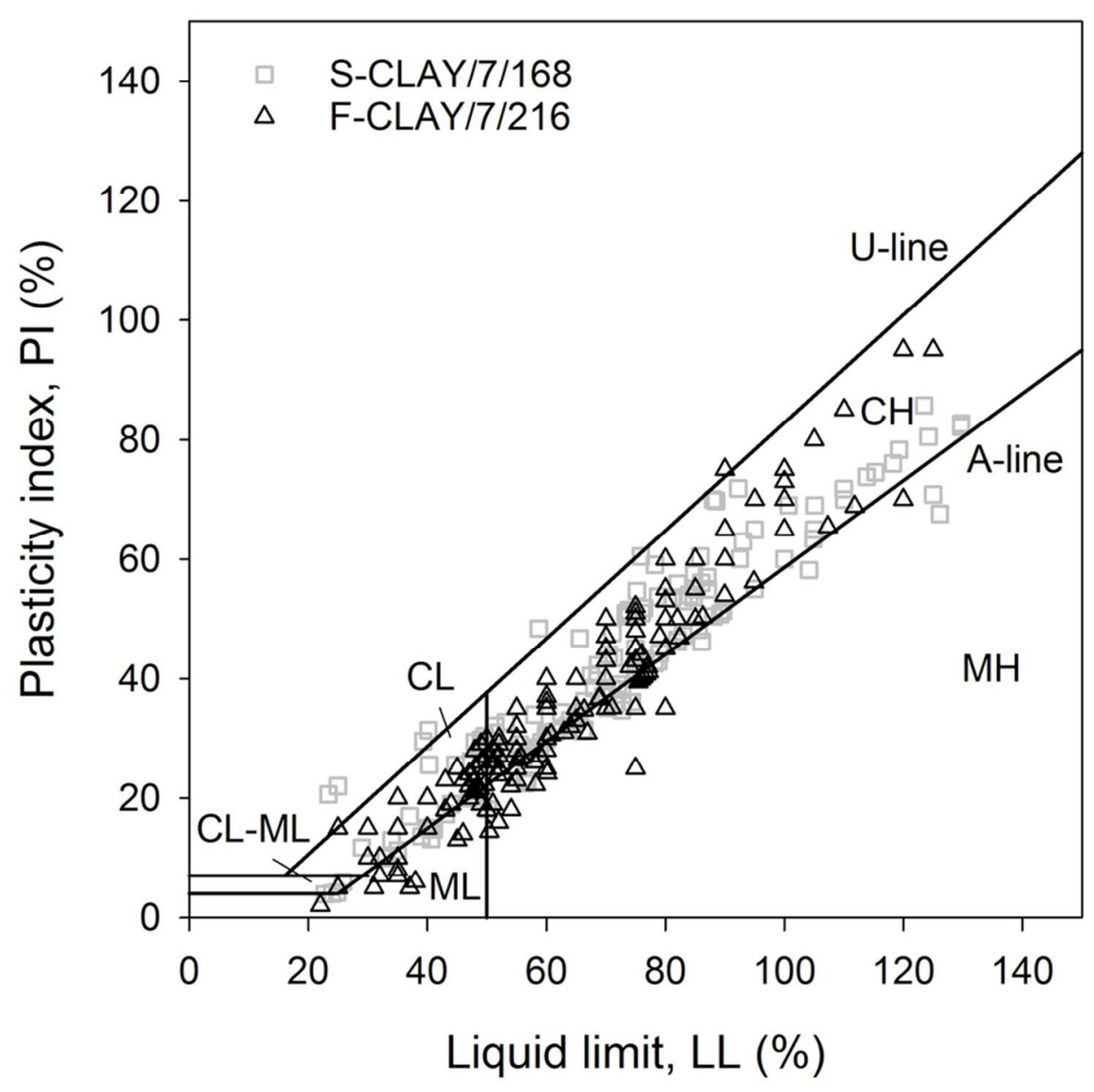

Fig. 1: Plasticity chart. $85 \times 85 \mathrm{~mm}$ (300 x 300 DPI) 


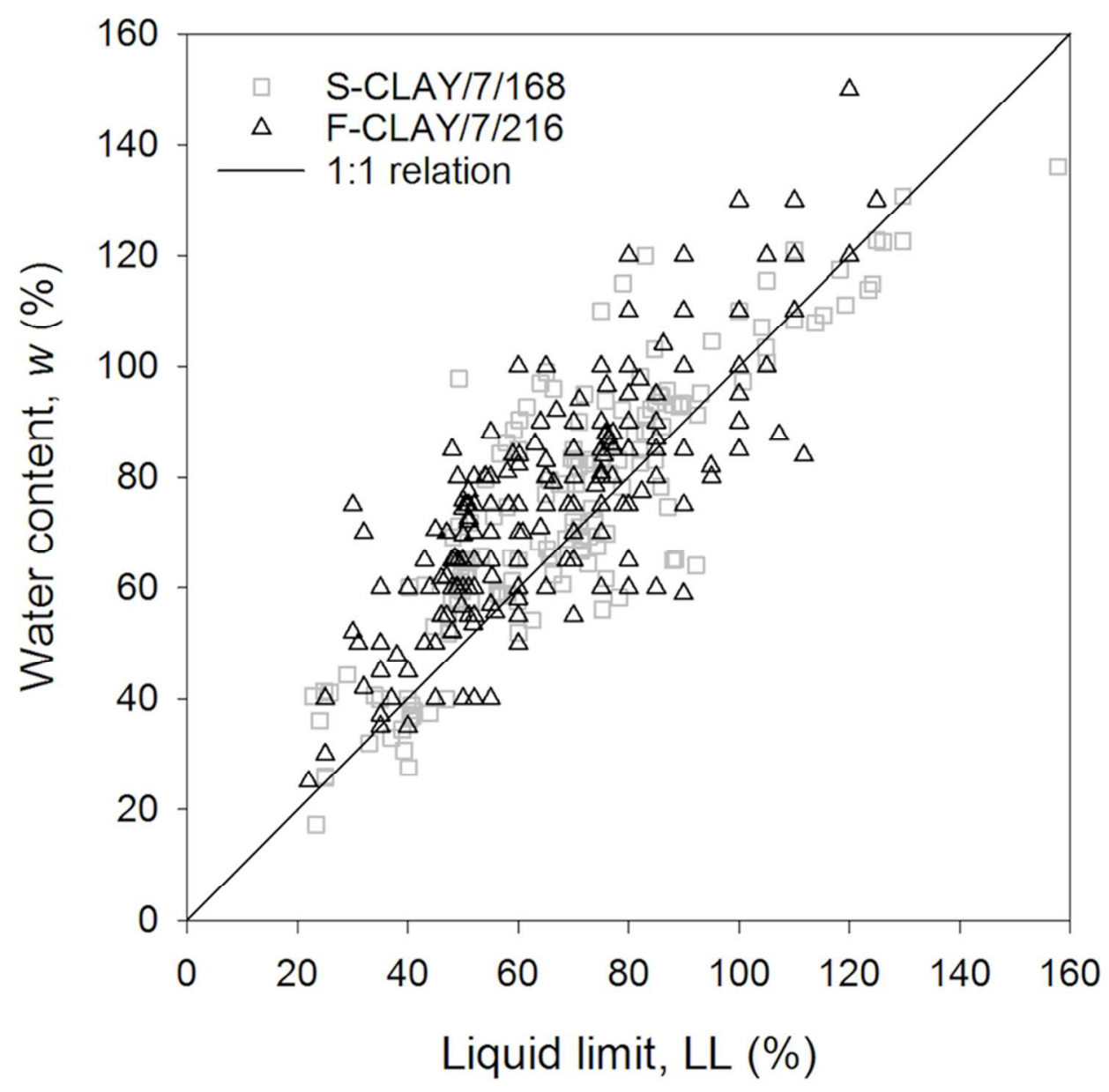

Fig. 2: Water content $(w)$ vs liquid limit (LL) for F-CLAY/7/216 and S-CLAY/7/168. $83 \times 81 \mathrm{~mm}(300 \times 300$ DPI) 

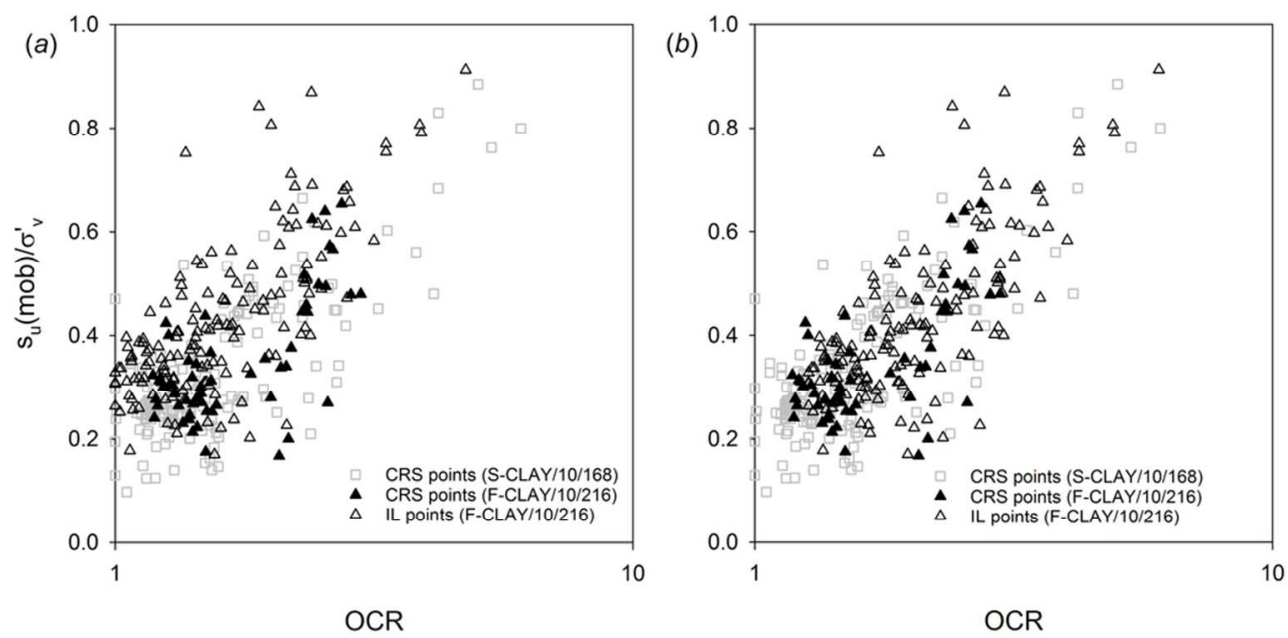

Fig. 3: $\mathrm{s}_{\mathrm{u}}(\mathrm{mob}) / \sigma^{\prime}$ vagainst OCR for (a) raw data points and (b) data points corrected to $\sigma_{p}^{\prime}$ from CRS oedometer test using $\sigma_{\mathrm{pCRS}}^{\prime} / \sigma_{\mathrm{pIL}}^{\prime}=1.27$. $89 \times 44 \mathrm{~mm}(300 \times 300 \mathrm{DPI})$ 


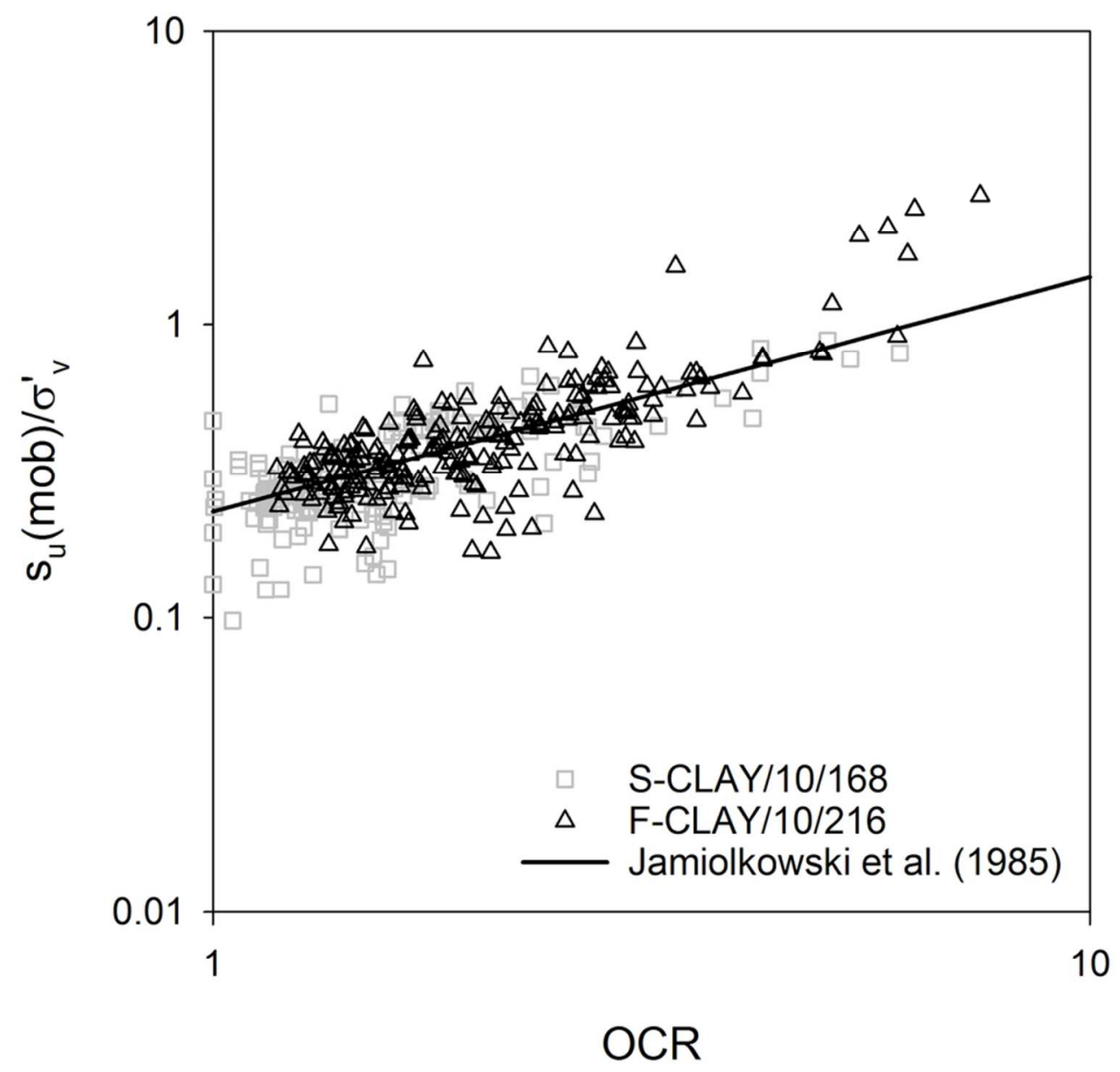

Fig. 4: OCR- $\left[\mathrm{s}_{\mathrm{u}}(\mathrm{mob}) / \sigma_{\mathrm{v}}^{\prime}\right]$ model proposed by Jamiolkowski et al. (1985). $82 \times 79 \mathrm{~mm}(300 \times 300 \mathrm{DPI})$ 


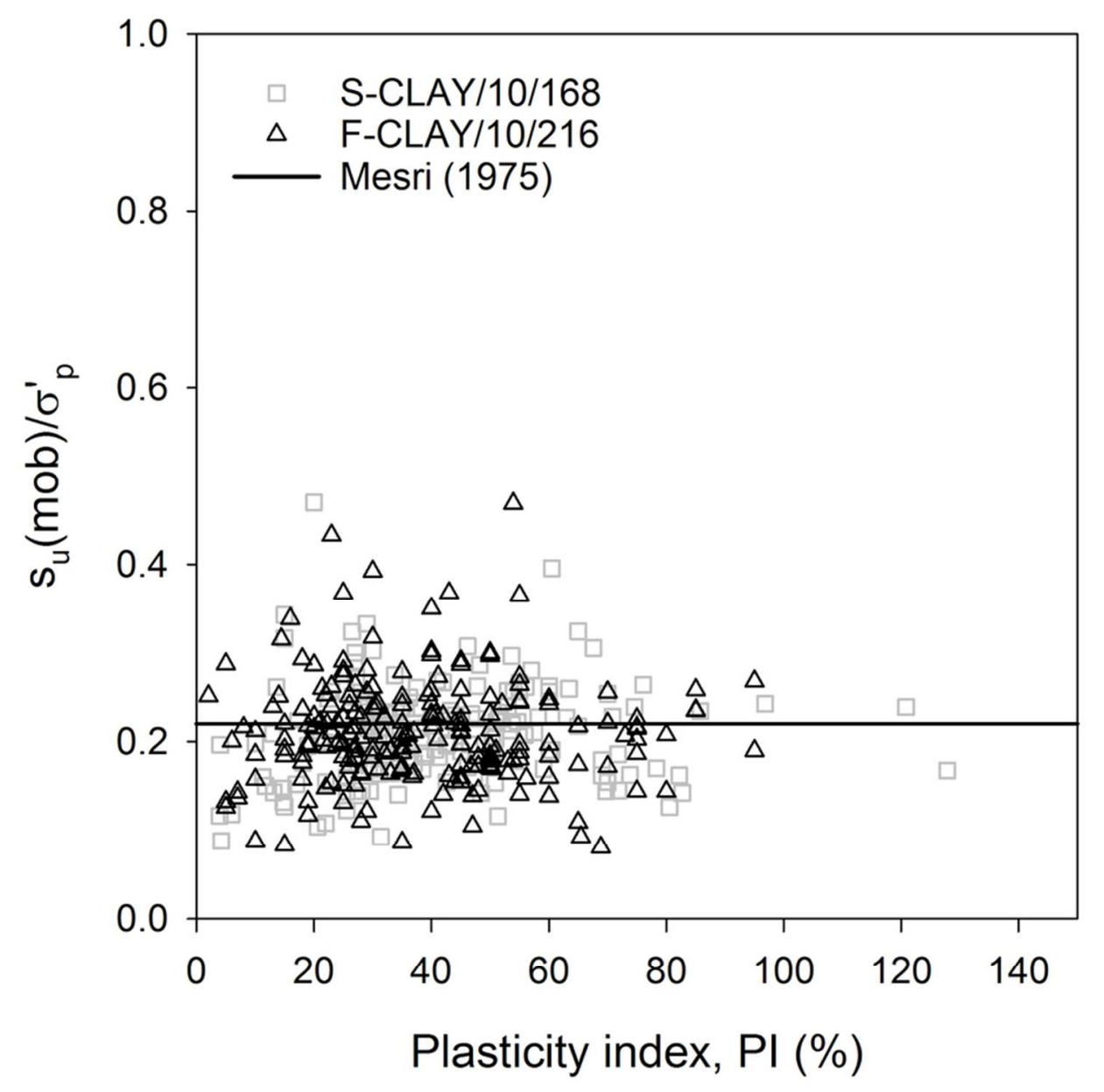

Fig. 5: PI- $\left[\mathrm{s}_{\mathrm{u}}(\mathrm{mob}) / \sigma_{\mathrm{p}}^{\prime}\right]$ model proposed by Mesri $(1975 ; 1989)$. $82 \times 79 \mathrm{~mm}(300 \times 300$ DPI $)$ 

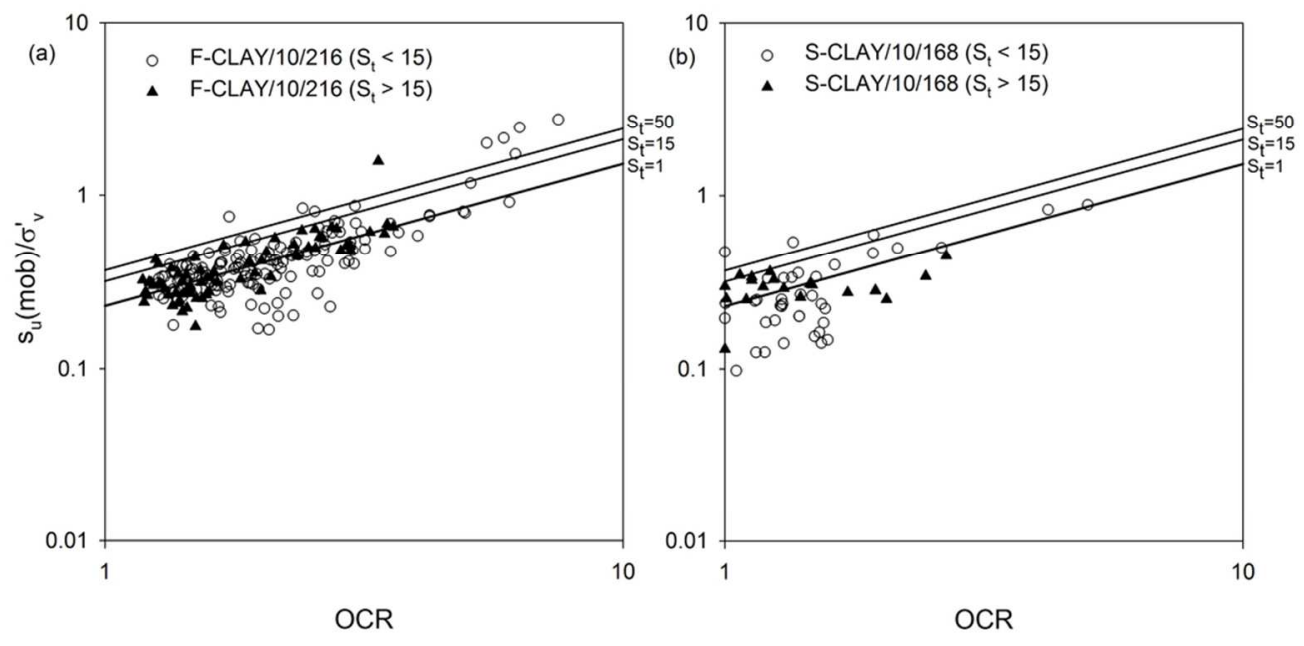

Fig. 6: OCR- $\left[\mathrm{S}_{\mathrm{u}}(\mathrm{mob}) / \sigma^{\prime} \mathrm{v}\right]-\mathrm{S}_{\mathrm{t}}$ model by Ching and Phoon (2012a) for a) F-CLAY/10/216 and b) SCLAY/10/168. $89 \times 44 \mathrm{~mm}(300 \times 300 \mathrm{DPI})$ 


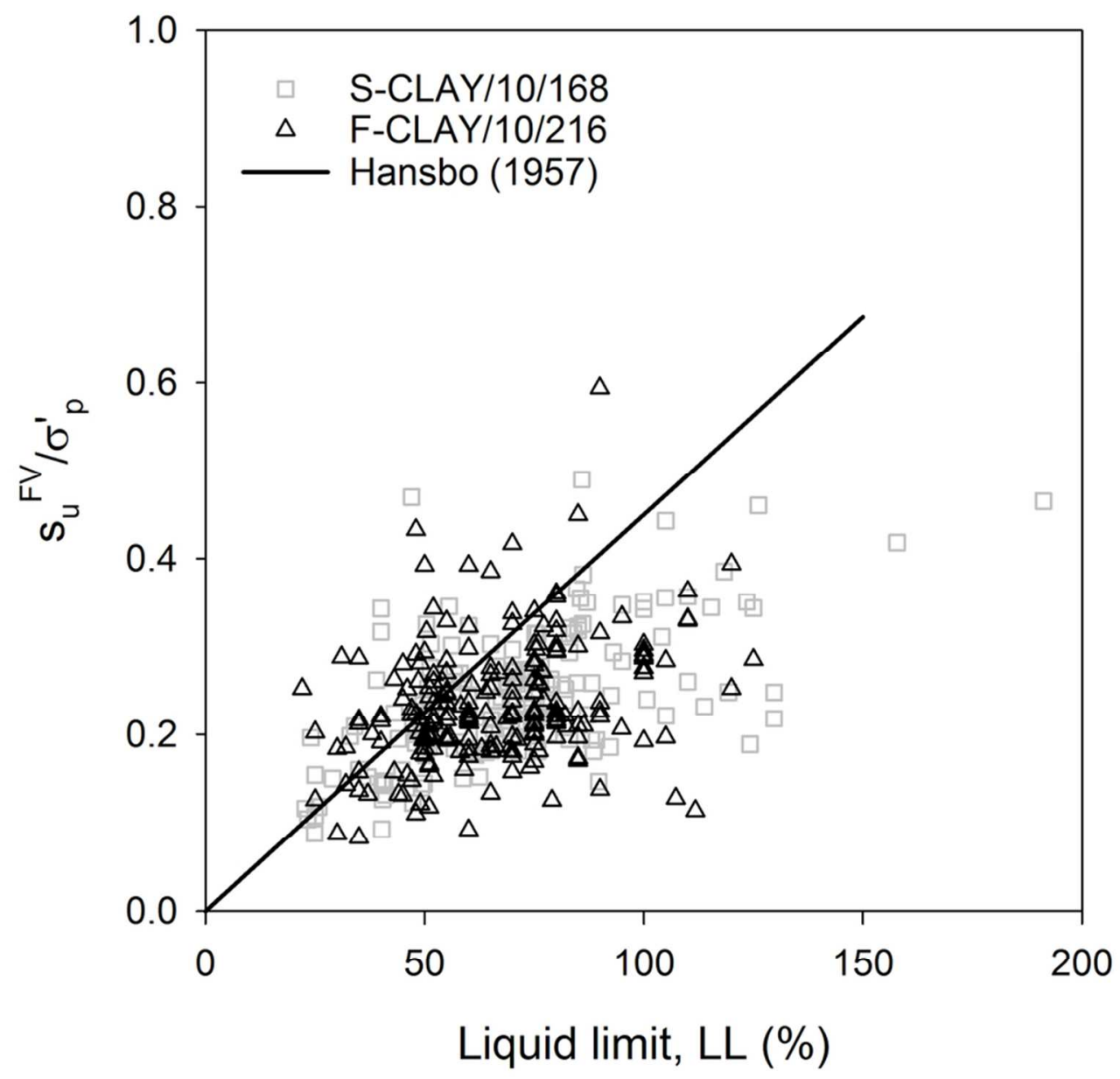

Fig. 7: LL-( $\left.\mathrm{S}_{\mathrm{u}} \mathrm{FV} / \sigma_{\mathrm{p}}^{\prime}\right)$ model proposed by Hansbo (1957). $82 \times 78 \mathrm{~mm}$ (300 x 300 DPI) 


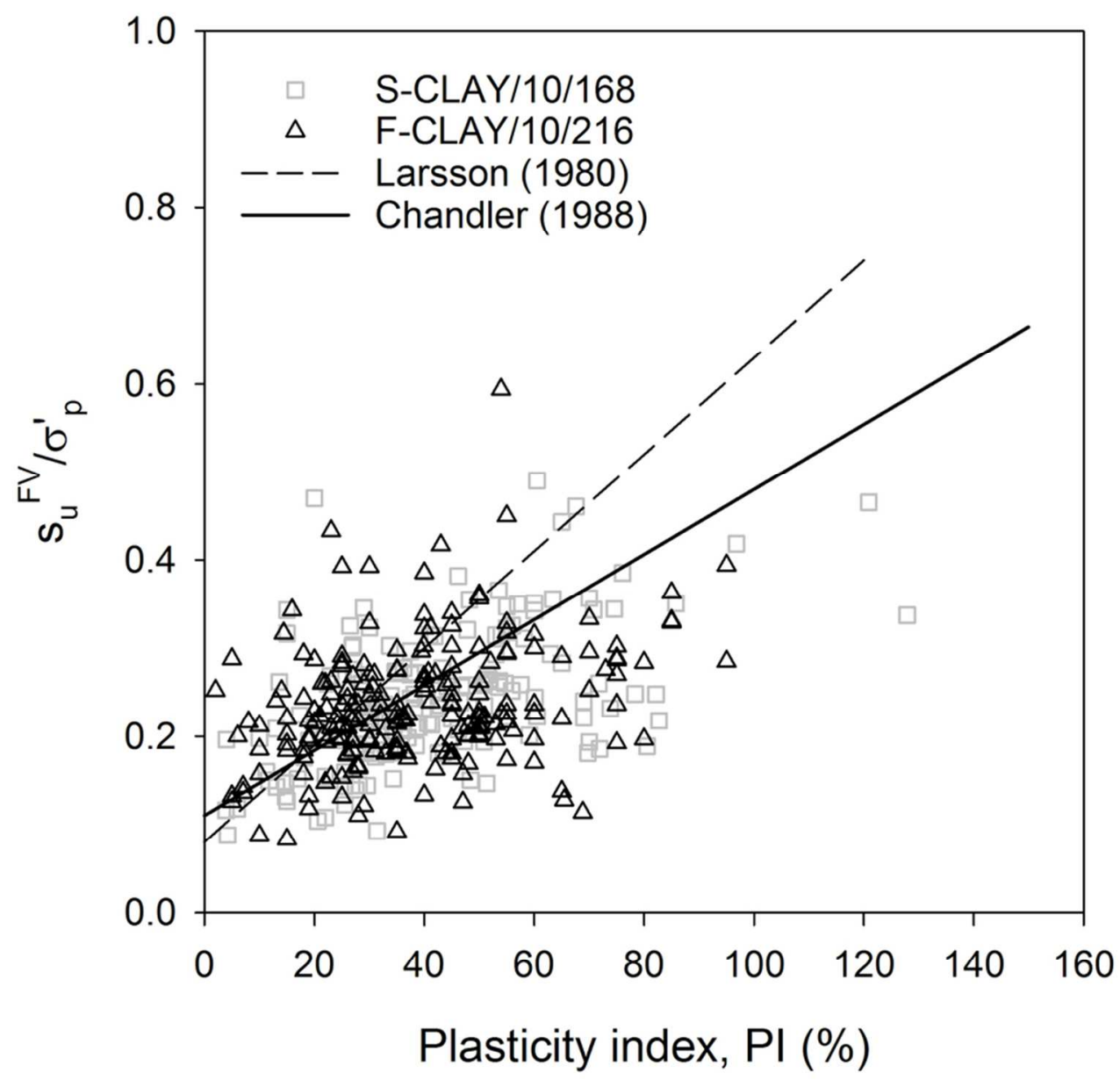

Fig. 8: PI-( $\left.\mathrm{s}_{\mathrm{u}} \mathrm{FV} / \sigma_{\mathrm{p}}^{\prime}\right)$ models proposed by Larsson (1980) and Chandler (1988). $82 \times 78 \mathrm{~mm}(300 \times 300$ DPI $)$ 


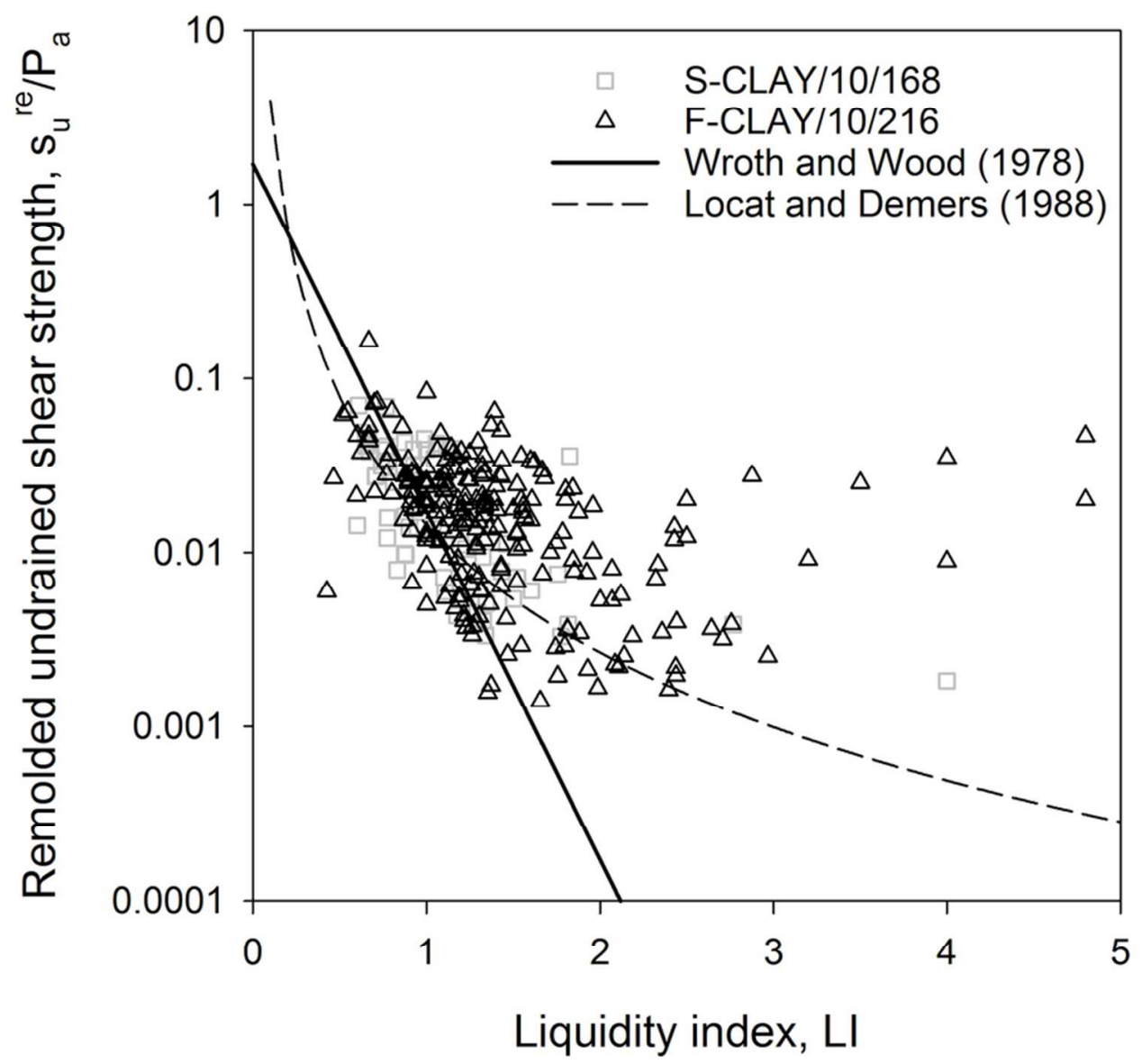

Fig. 9: $\mathrm{LI}-\left(\mathrm{S}_{\mathrm{u}}^{\mathrm{re}} / \mathrm{P}_{\mathrm{a}}\right)$ models.

$78 \times 72 \mathrm{~mm}(300 \times 300$ DPI $)$ 

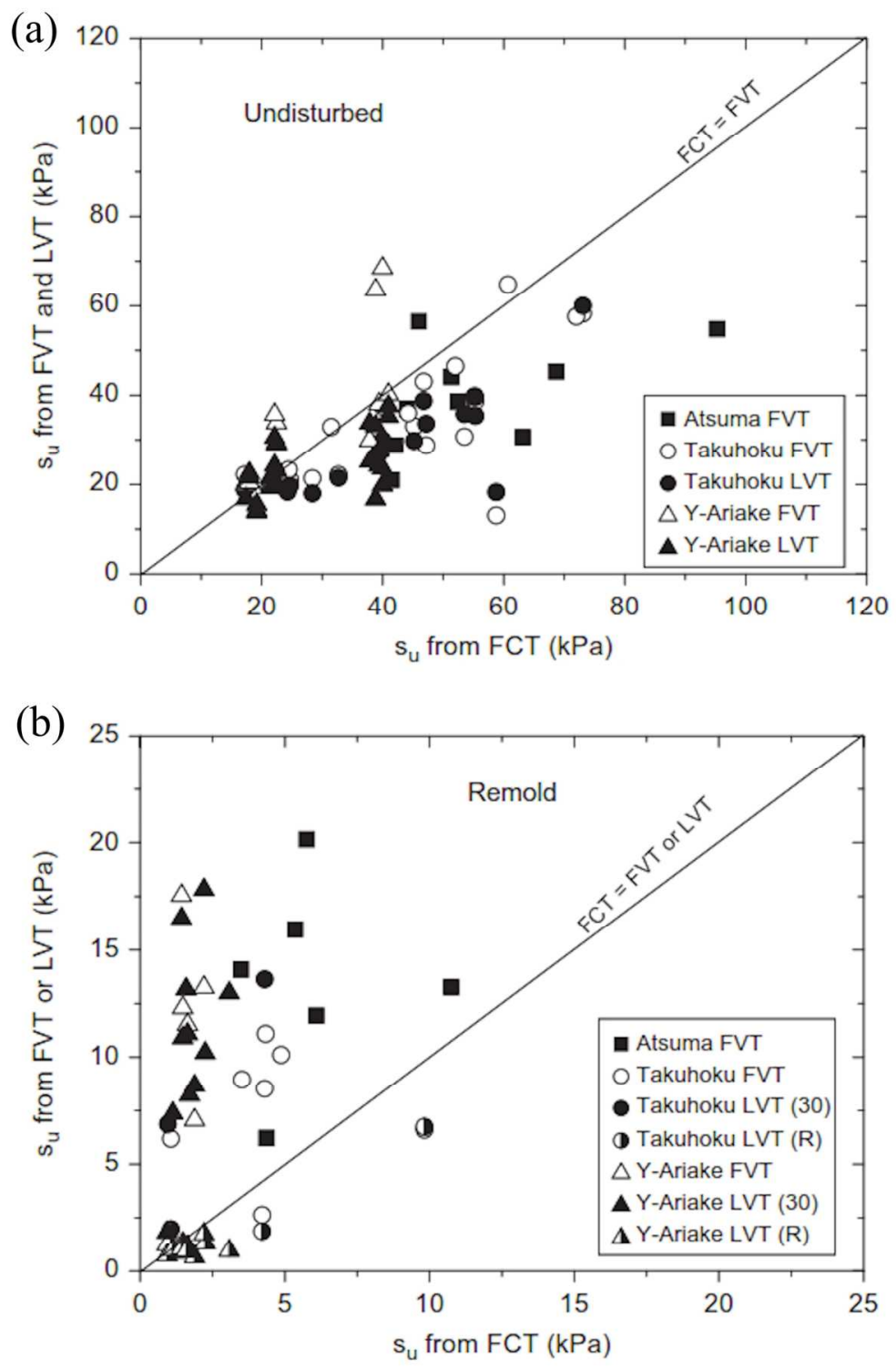

Fig. 10: Comparison of strengths measured by FC, FV and LVT at undisturbed and remolded conditions (a) undisturbed condition, (b) remolded condition. (Tanaka et al. 2012) $128 \times 190 \mathrm{~mm}(300 \times 300 \mathrm{DPI})$ 


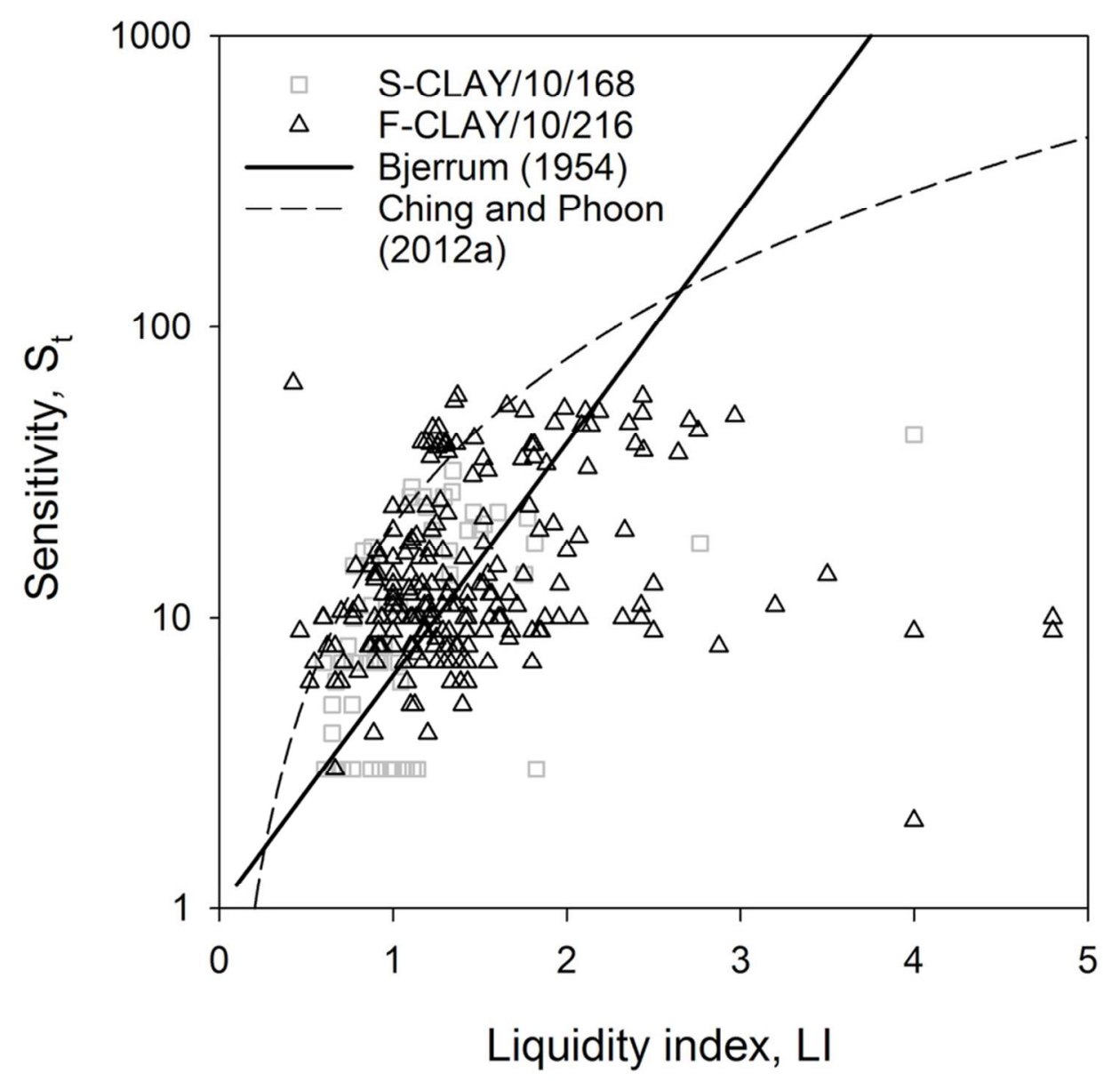

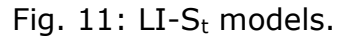
$83 \times 81 \mathrm{~mm}(300 \times 300$ DPI $)$ 

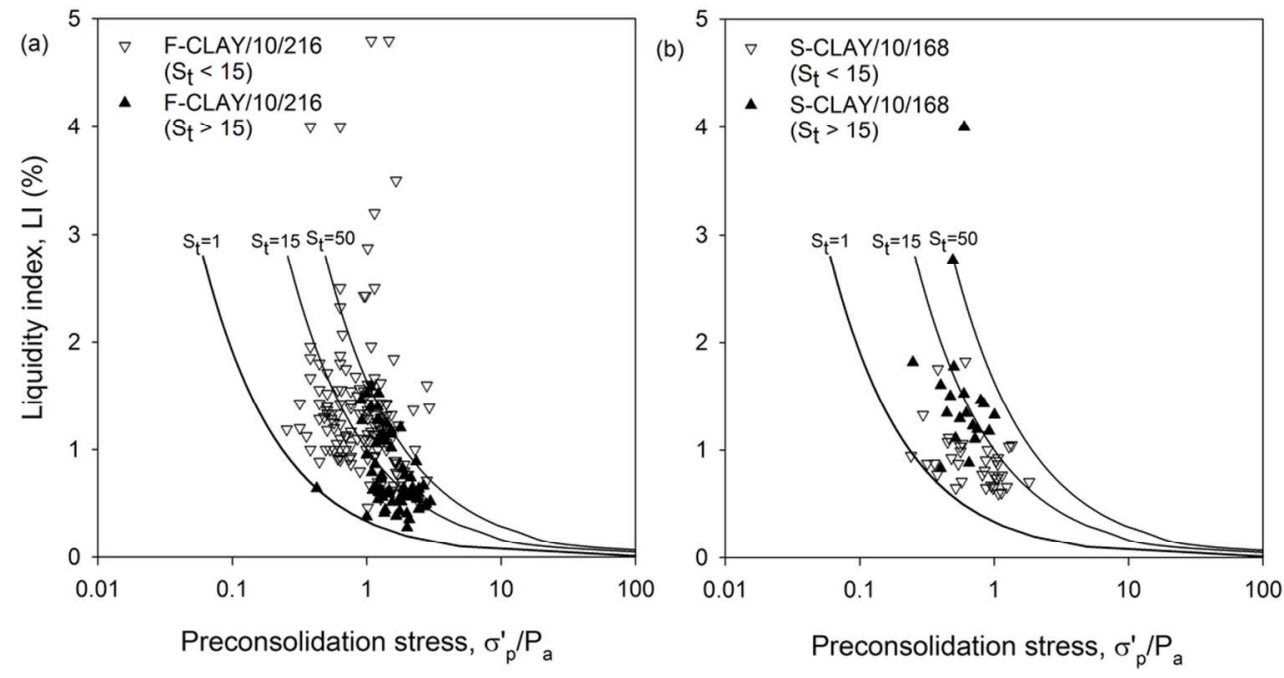

Fig. 12: LI- $\left(\sigma_{\mathrm{p}}^{\prime} / \mathrm{P}_{\mathrm{a}}\right)-\mathrm{S}_{\mathrm{t}}$ model by Ching and Phoon (2012a) for (a) F-CLAY/10/216 and (b) S-CLAY/10/168. $97 \times 51 \mathrm{~mm}(300 \times 300 \mathrm{DPI})$ 

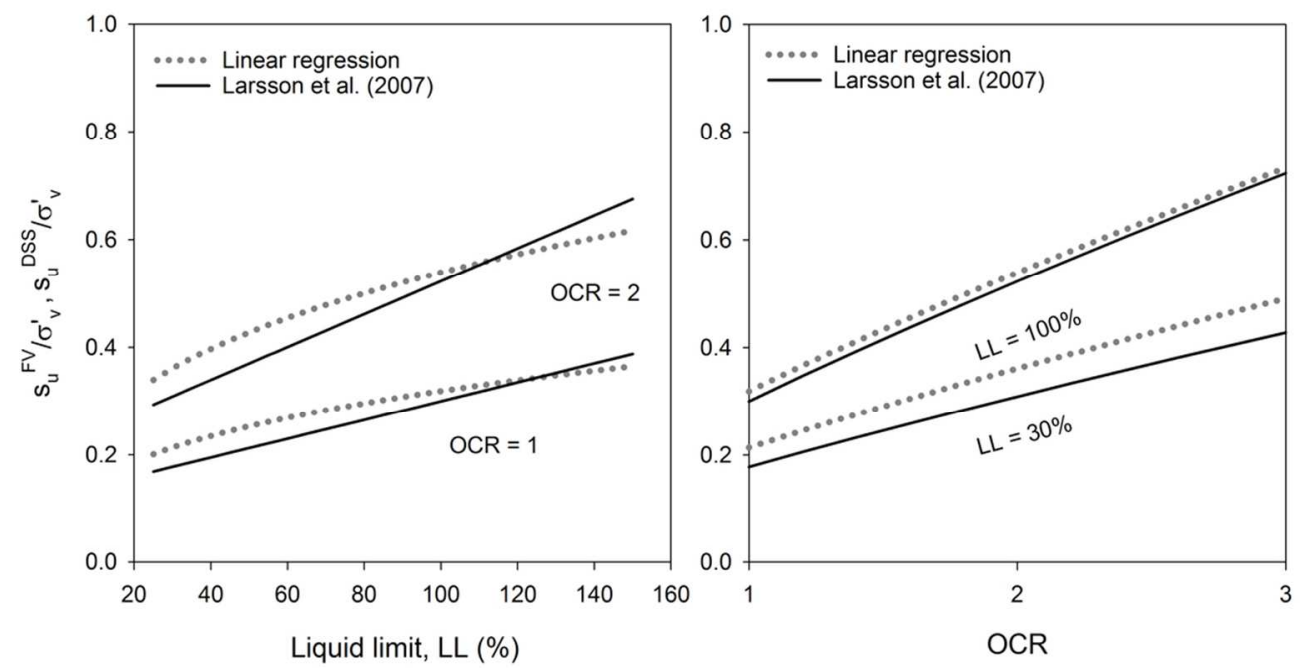

Fig. 13: Comparison between OCR- $\left(\mathrm{S}_{\mathrm{u}}^{\mathrm{FV}} / \sigma_{\mathrm{v}}^{\prime}\right)$-LL for Finnish clays and OCR- $\left[\mathrm{s}_{\mathrm{u}}{ }^{\mathrm{DSS}} / \sigma_{\mathrm{v}}^{\prime}\right]-\mathrm{LL}$ model by Larsson et al. (2007) for Swedish clays. $95 \times 50 \mathrm{~mm}(300 \times 300 \mathrm{DPI})$ 

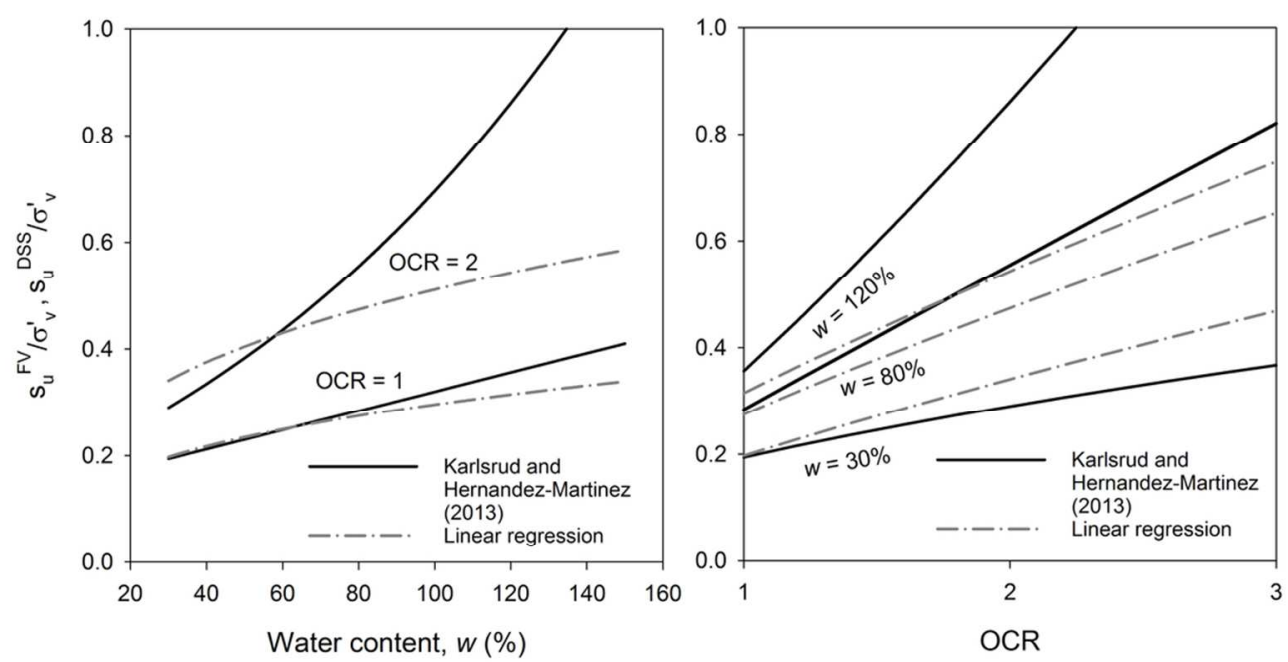

Fig. 14: Comparison between OCR- $\left(\mathrm{s}_{\mathrm{u}}{ }^{\mathrm{FV}} / \sigma_{\mathrm{v}}^{\prime}\right)-w$ for Finnish clays and OCR- $\left[\mathrm{s}_{\mathrm{u}}{ }^{\mathrm{DSS}} / \sigma_{\mathrm{v}}^{\prime}\right]-w$ model by Karlsrud and Hernandez-Martinez (2013) for Norwegian clays.

$93 \times 47 \mathrm{~mm}(300 \times 300 \mathrm{DPI})$ 

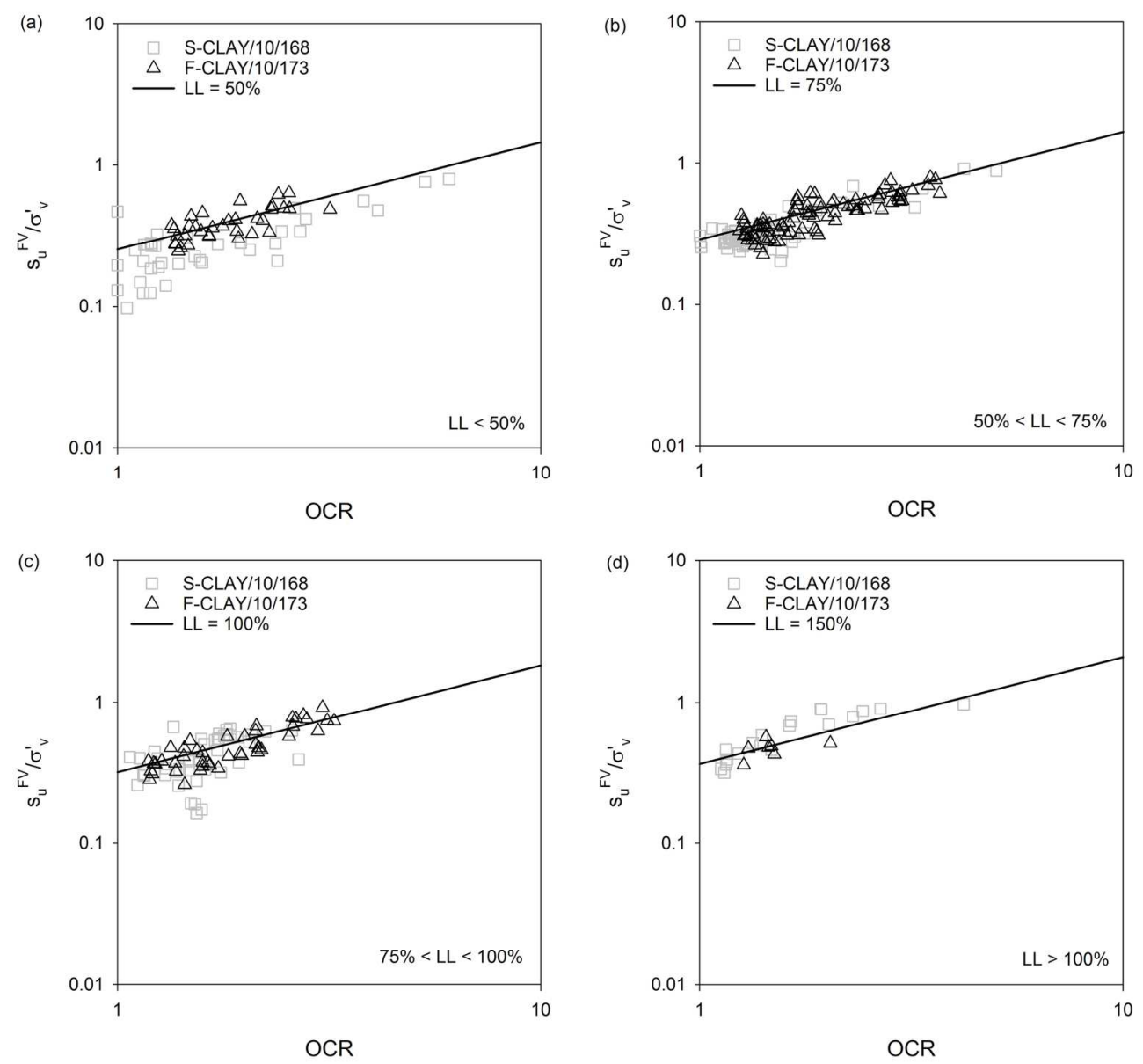

Fig. 15: Comparison between measured (calibration and validation) data and OCR- $\left(\mathrm{S}_{\mathrm{u}}^{\mathrm{FV}} / \sigma_{\mathrm{v}}^{\prime}\right)-\mathrm{LL}$ model for Finnish clays for various LL ranges. $168 \times 156 \mathrm{~mm}(300 \times 300 \mathrm{DPI})$ 